\title{
OFF THE BEATEN TRACK: A POSTMODERN FEMINIST ANALYSIS OF RURAL MIDWIFERY AND RURAL MEDIA HEALTH DISCOURSES
}

This represents the full title of the thesis

by

Jean Ann Patterson

A thesis submitted to the Victoria University of Wellington

In the fulfillment of the

Requirements for the degree of

Master of Arts

in

Midwifery

Victoria University of Wellington

2002 



\section{ACKNOWLEDGEMENTS}

My sincere thanks, to all those, too numerous to mention who have wished me well, on this research journey.

A salute to all the academic staff at Victoria, who over the years have encouraged and challenged me. Special thanks, to Joy Bickley, my supervisor; who possesses, the rare talent, of seeing through an idea to its possibility, and often, its artifice. Thank you for your enthusiasm, encouragement and humour. I remain in your debt for your thorough reading and astute comments. Also to Deb Davis my critical wombat friend, for her gift of listening and wise counsel in times of despair. I also wish to acknowledge the support of Otago Polytechnic for the financial assistance toward the costs of the data collection.

My profound thanks to my friends and colleagues, the rural midwives who participated in this study. Thank you for agreeing to participate and for trusting me with your stories, which have added the life and soul to this work.

And most of all Jack, thank you for your patience, for puzzling over drafts and keeping the home fires burning during this obsessional exercise. 



\section{OFF THE BEATEN TRACK: A POSTMODERN FEMINIST \\ ANALYSIS OF RURAL MIDWIFERY AND RURAL MEDIA \\ HEALTH DISCOURSES}

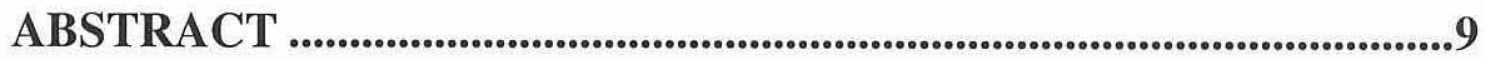

CHAPTER ONE: INTRODUCTION ..................................................11

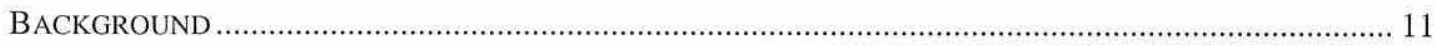

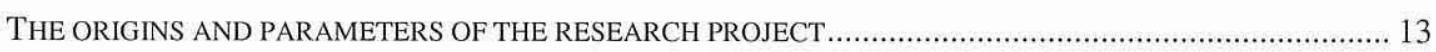

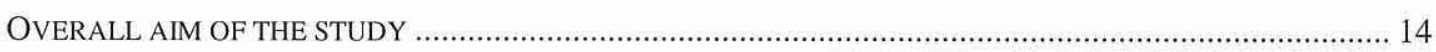

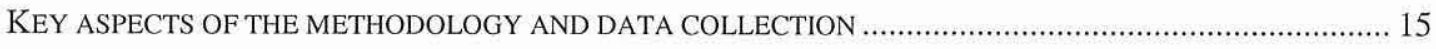

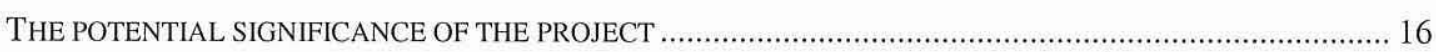

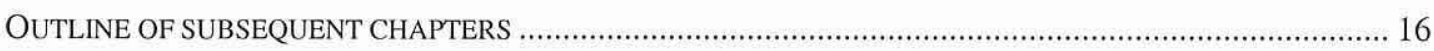

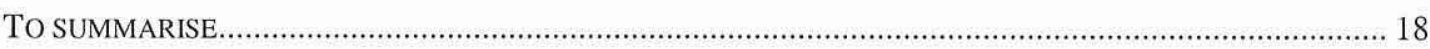

\section{CHAPTER TWO: BACKGROUND AND CONTEXTUAL ISSUES19}

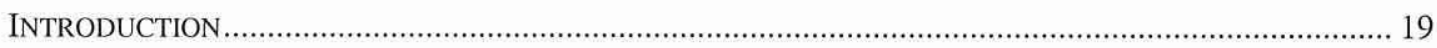

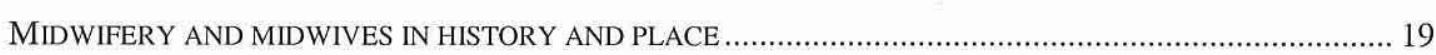

Putting myself in the picture …….................................................................................... 19

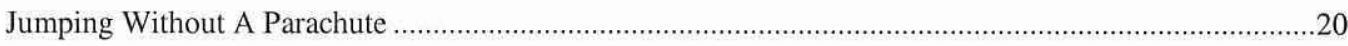

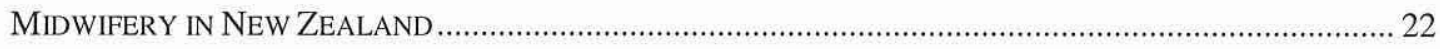

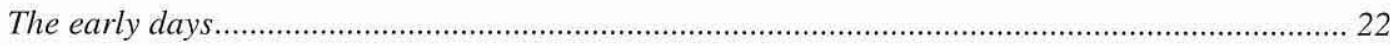

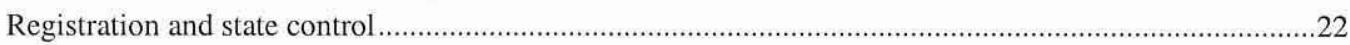

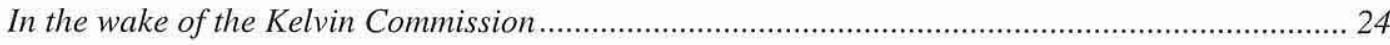

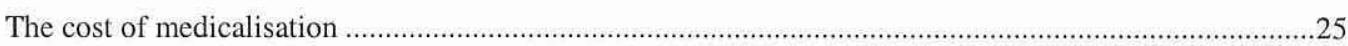

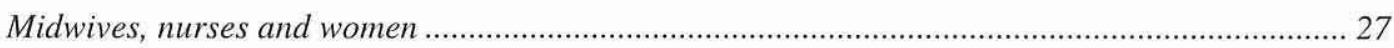

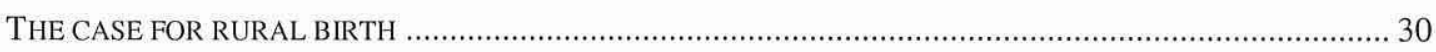

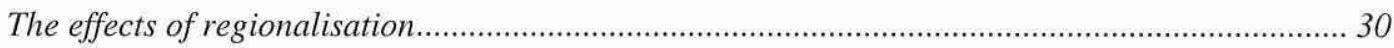

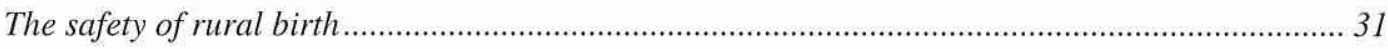

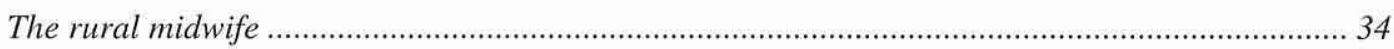




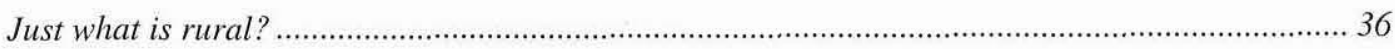

BIRTH IN SMALL AND RURAL UNITS IN OTHER WESTERNIZED COUNTRIES ....................................... 37

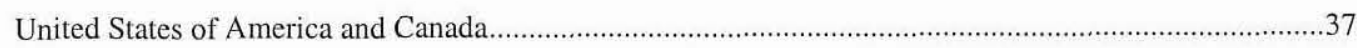

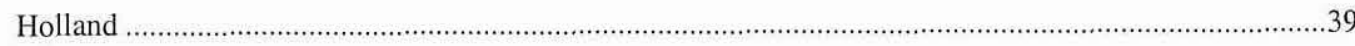

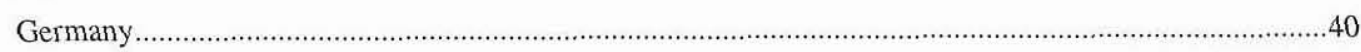

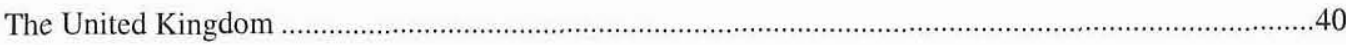

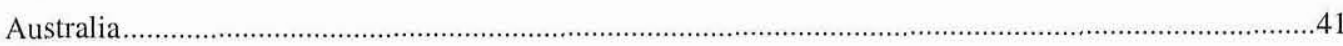

Home birth in rural areas......................................................................................................... 43

THE HISTORICAL AND POLITICAL DEVELOPMENT OF RURAL MIDWIFERY IN SUMMARY ........................ 44

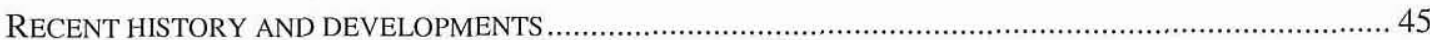

The changing demographic profile of rural South Otago............................................................... 46

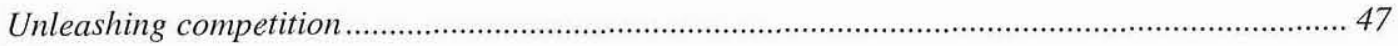

From competition to integration in rural areas...................................................................... 50

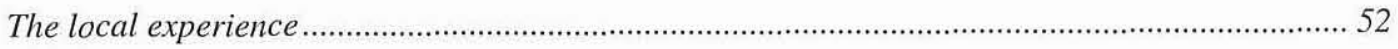

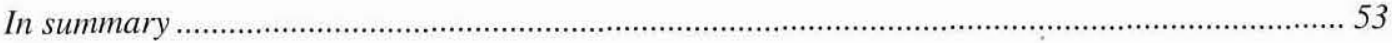

\section{CHAPTER THREE: IN SEARCH OF A THEORETICAL}

FRAMEWORK FOR THIS STUDY ..............................................55

INTRODUCTION: GETTING STARTED ON THE POSTMODERN MERRY-GO-ROUND ................................... 55

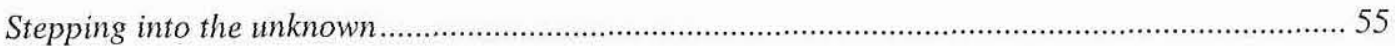

POST STRUCTURALISM AND THE END OF THE MODERNIST DREAM ….............................................. 56

POSTMODERN NOTIONS OF REPRESENTATION, POWER AND HISTORY .................................................. 57

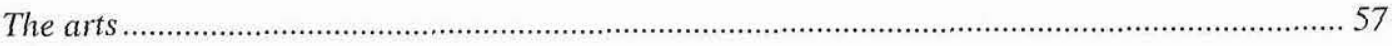

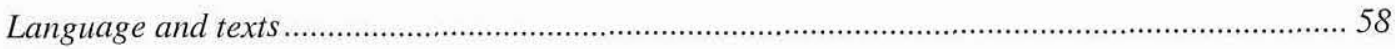

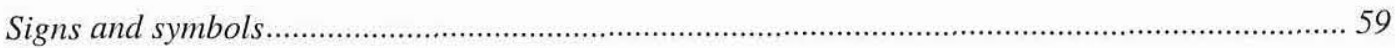

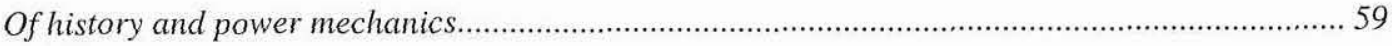

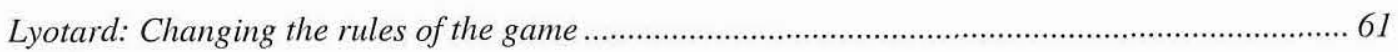

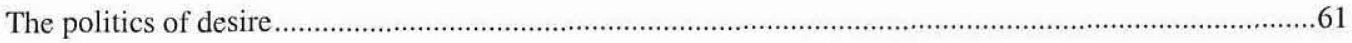

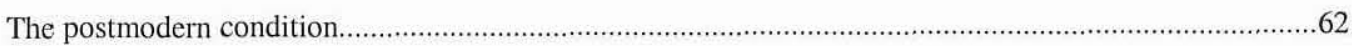

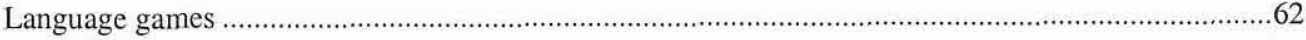

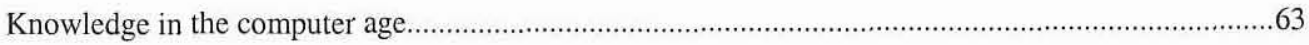

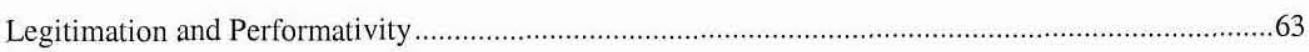

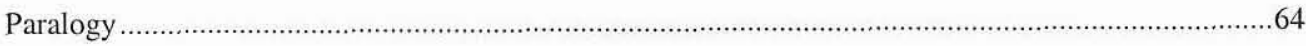

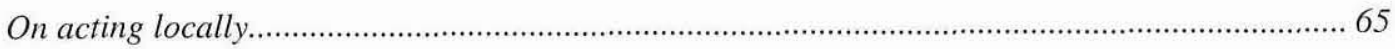

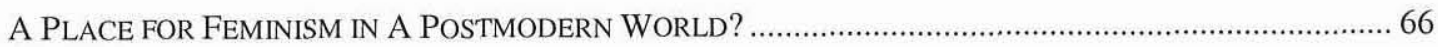

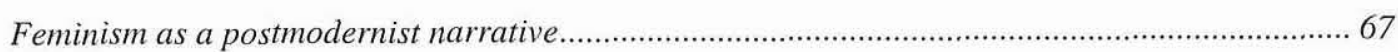




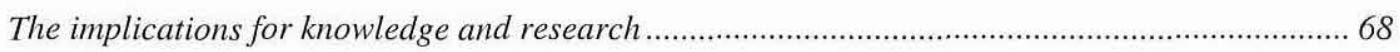

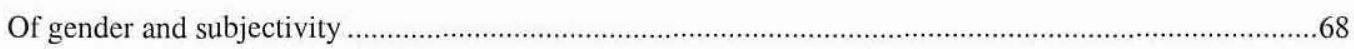

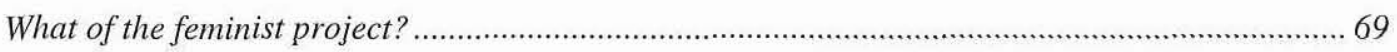

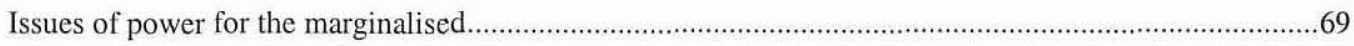

The feminist imperative to act................................................................................................................ 70

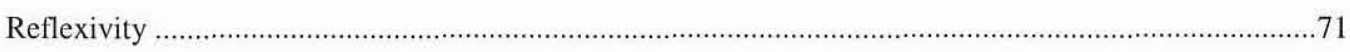

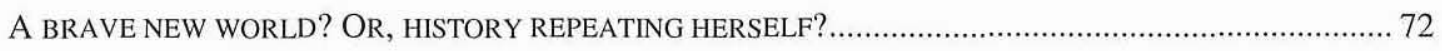

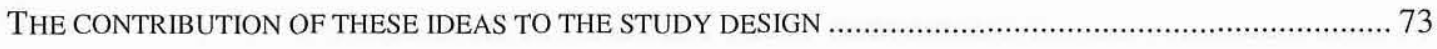

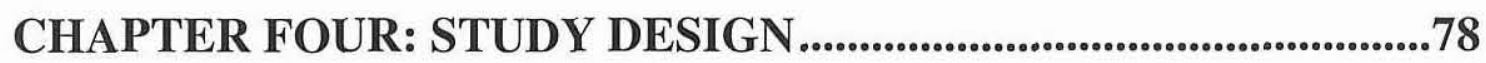

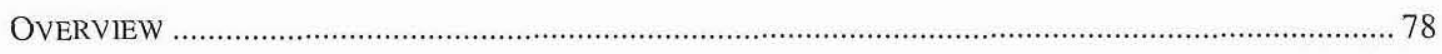

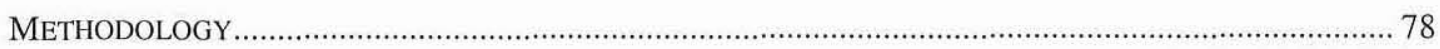

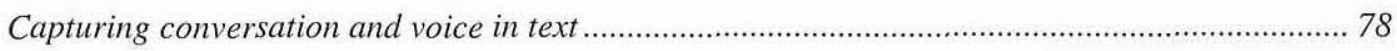

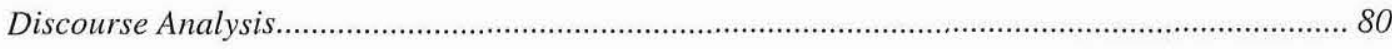

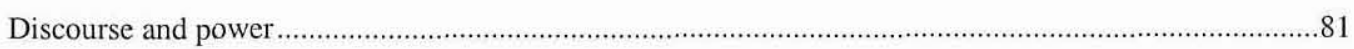

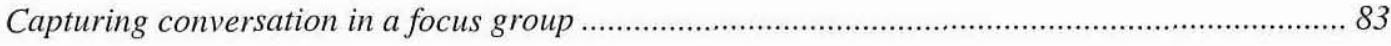

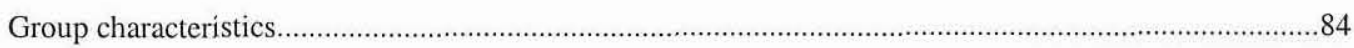

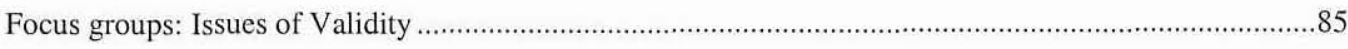

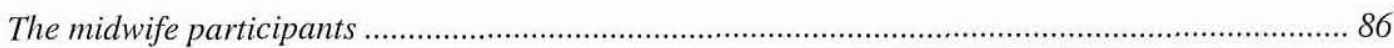

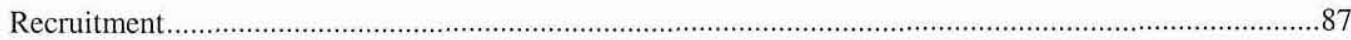

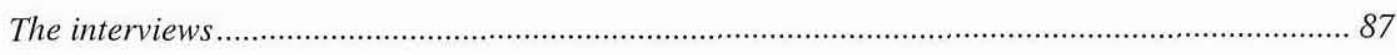

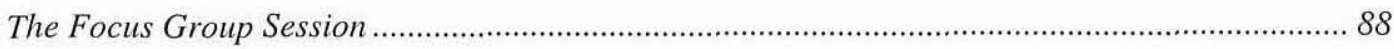

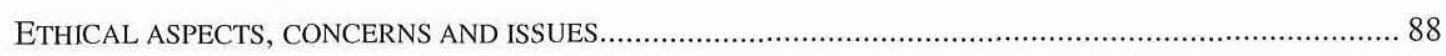

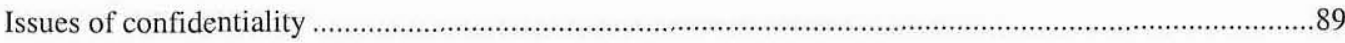

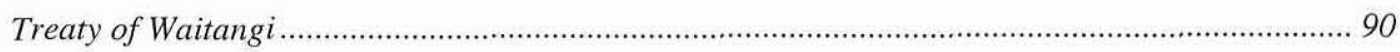

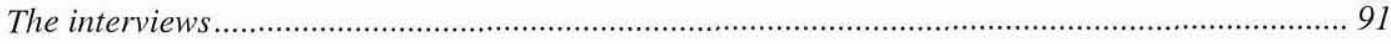

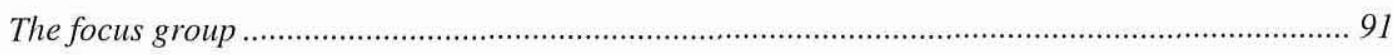

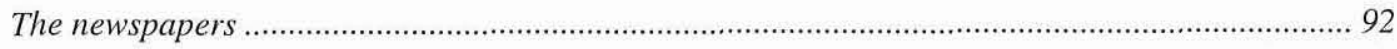

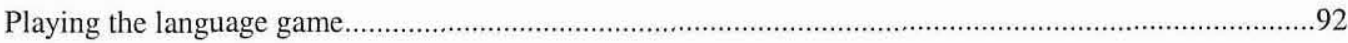

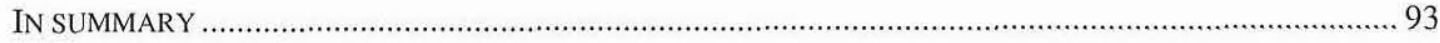

CHAPTER FIVE: THE LOCAL NEWS .........................................95

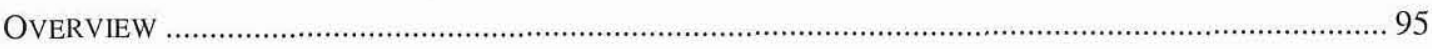

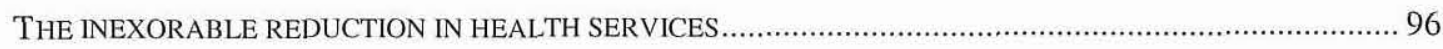

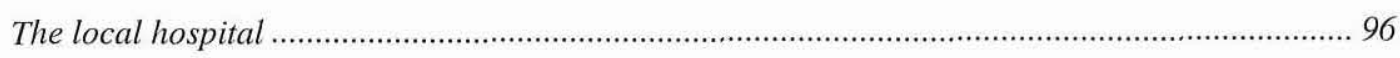

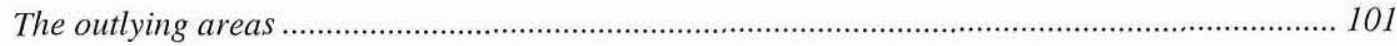


The fluctuating fortunes of the protest groups.....

CHANGES TO THE LOCAL MATERNITY SERVICES AND THE EMERGENCE OF THE 'MIDWIFE'.

GAME PLAYING

A Lyotardian analysis of the Clutha Leader and midwifery discourses.....

Pragmatics and efficiency

Moving margins

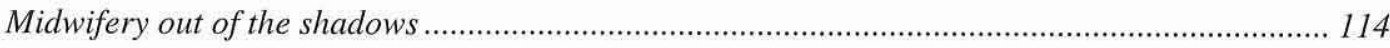

SUMMARISING THE LOCAL NEWS AND THE LANGUAGE GAMES ......................................................... 115

\section{CHAPTER SIX: TALKING WITH MIDWIVES .........................117}

OVERVIEW 117

WORKING IN RURAL PRACTICE AND THE CHALLENGES OF THE DECADE 118

Arriving in rural practice. 118

Leaving the familiar: Learning curves and closing the gaps. 119

Helping each other to grow 120

A RURAL MIDWIFERY DISCOURSE? 122

Mapping the rural midwifery discourse/s 122

Seeing is believing: The discourse of normal birth 122

The birth of homebirth

A discourse of rural/urban difference.

The trials of transfer

A discourse of community embeddedness: The weight on your shoulders...... 130

In summary: Discourses of harmony, contradiction and conflict 131

\section{CHAPTER SEVEN: A FOCUS ON RURAL MIDWIFERY}

\section{PRACTICE}

OVERVIEW

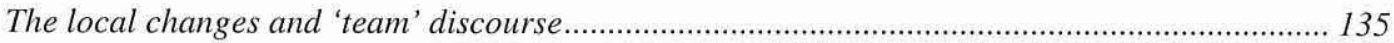

Fearing a return to the past ........................................................................................................... 136

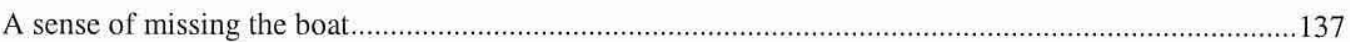

Advertising and promotion: Borrowing from the discourse of competition.................................. 137

Introducing new graduates to the rural midwifery discourse ...................................................... 139

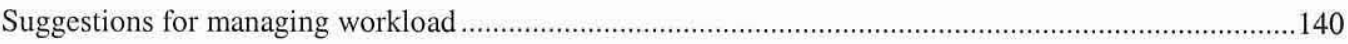

Educational preparation for rural practice ............................................................................................. 141

Rural meets urban: The discourse of difference ...................................................................... 143 


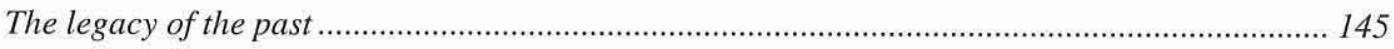

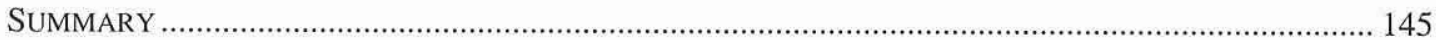

CHAPTER 8: A GAME PLAN FOR THE FUTURE ......................148

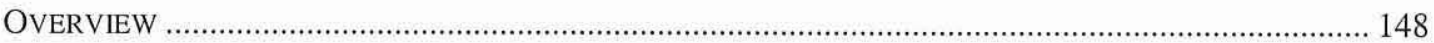

POSITIONING IN THE NEW ENVIRONMENT: RUMBLINGS AND PROMISES .............................................. 149

WORKING FROM THE MARGINS: A PLACE OF STRUGGLE AND STRENGTH ............................................ 151

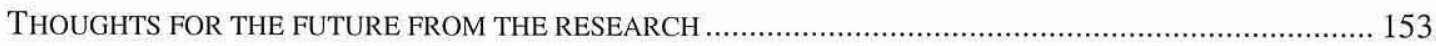

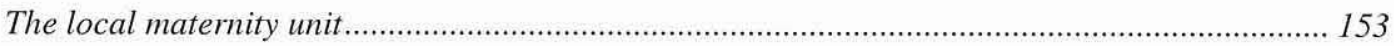

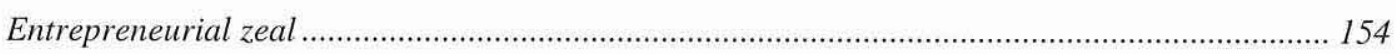

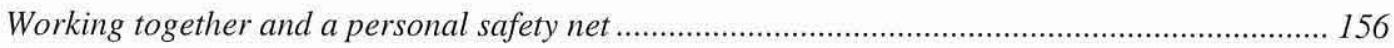

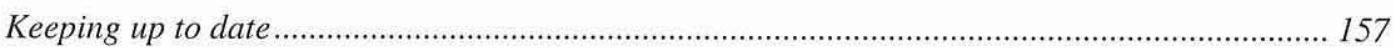

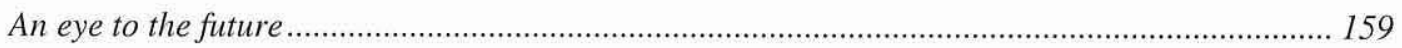

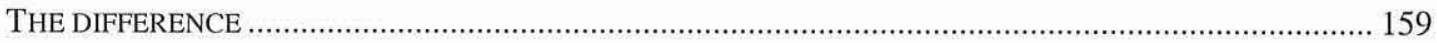

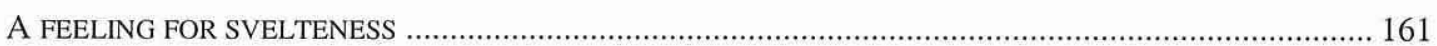

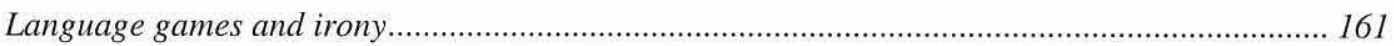

CHAPTER NINE: FINAL REFLECTIONS ....................................165

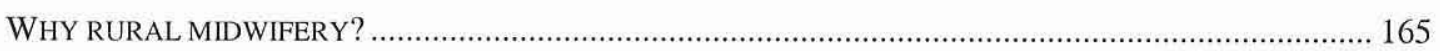

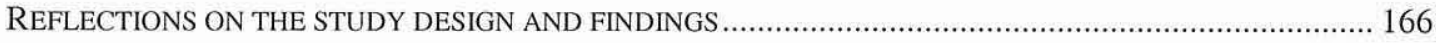

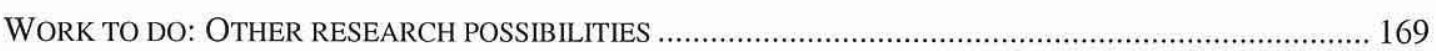

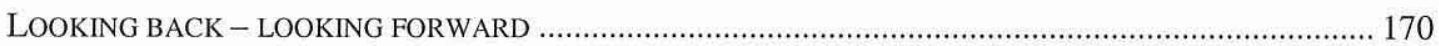

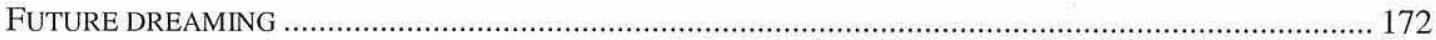

REFERENCES ................................................................................174

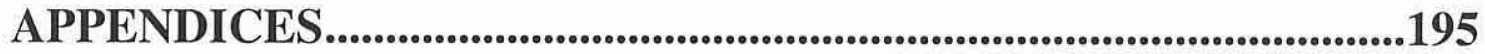

APPENDIX A Research proposal to Ethics Committee 
APPENDIX E

Letter to participants following interviews ......................................................................... 207

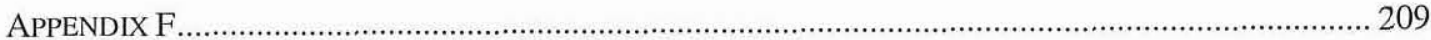

Letter confirming focus group venue ........................................................................................... 209

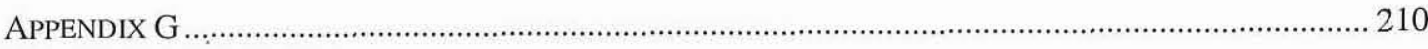

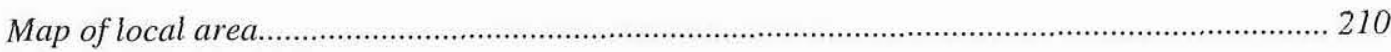




\begin{abstract}
Change was a constant companion for New Zealand midwives during the 1990's. The Nurses Amendment Act 1990, that restored midwifery autonomy was only one of a constellation of changes that saw significant restructuring of the health services in small communities. The purpose of this study was to look at the issues for a group of midwives in rural South Otago who took the opportunity to work independently and offer local women a choice of maternity care during this time.
\end{abstract}

In this study, five rural midwives were interviewed and met subsequently in a focus group. The transcripts were analyzed using discourse analysis informed by a postmodern/feminist theoretical framework. In addition the local newspapers covering the years 1990-1999 were read with a particular focus on the reports of health changes. These texts were also subjected to a discourse analysis using Lyotard's (1997) notion of language games, and bell hook's (1990) ideas around strategic positioning for the marginalised.

To practise autonomously, the midwives in this study perform an intricate dance, balancing the contradictions of competing discourses. Their positioning and place of difference is tensioned primarily by a deep sense of community commitment and entanglement, and also by a feeling of physical and perceptual distance from their urban midwifery colleagues. This is underpinned by a staunch belief in women's ability to birth safely in their local area.

The findings of this study suggest that the continuation of a comprehensive rural midwifery service is challenged by changes in the arrangement and funding of rural health, plus the increasing use of medical and technological intervention in childbirth. For rural midwifery to survive, this study shows that 
midwives need to remain flexible and alert while continuing to align themselves with women who are their primary source of support and inspiration. At the same time, they need to forge strategic linkages and alliances, both local and national that will allow them to move and reposition in order to continue their work and provide a realistic childbirth choice for rural women. 


\section{CHAPTER ONE: INTRODUCTION}

For the best part of thirty years I have been a rural midwife. This is my story and it is also the story of my friends and colleagues who traversed the changes in midwifery and the health services, during the 1990's in rural South Otago in New Zealand. In this chapter I preview the background, origins, aim and scope of this study, concluding with a review of the subsequent chapters.

\section{Background}

The background to this study is presented as a series of layers rather than a strict chronological record. These include a brief history of midwifery in New Zealand, the changes in rural demographics and a look at the concerns around safe birth in rural areas. I explore the issues that challenge small and rural midwifery services in other westernized nations; plus review the 1990's, looking at the specific legislative and social changes that impacted on New Zealand as a whole, and rural areas in particular.

My aim is to provide a multifaceted view of the events that contributed to the major changes in both legislation and practice and to the context in which this study is conducted. I have also included snippets from my research journal. The entries track my ideas, which were shaped by the reading, writing, and listening, to reveal how my expanded perceptions influenced the course of this research project.

I begin with a flashback to the significant events of midwifery history in New Zealand, leading up to 1990. From this juncture I track the evolution of the independent midwife from 1990 to 2000. This construction grew out of our midwifery history and rekindled aspirations for a social wellness model of care. The discourses surrounding this change included realignment with women as 
partners in the birth process, and an emphasis on continuity of care, with negotiation, and shared responsibility for the process and the outcome.

It was in this window of history, opened by the Nurses Amendment Act, 1990, that the title of midwife was re-instituted and linked with a definition and scope of practice, claiming expertise in the knowledge and management of normal birth. Subsequently, two pilot direct entry schools of midwifery were established in Dunedin and Auckland with the support of Helen Clark, in her role as the Minister of Health (Papps \& Olssen, 1997).

These changes initially brought a sense of euphoria and excitement, tinged with fear, as midwives contemplated the enlarged role. Midwives were variously prepared for the changes and for most it was a time to evaluate practice skills and close their knowledge gaps. It was also a time of forging realignment with their general practitioner (GP) colleagues, making contact with women's groups, and selling the idea to health managers and the public.

The nature and particular issues of rural midwifery practice are pertinent to this thesis and therefore are explored through the pages of midwifery journals. These include changes in the role, and the politicization of midwives in other westernized countries. However the range and variety of what is regarded as 'rural' makes a study of this area problematic. For instance, while Balclutha is one hour's drive south of Dunedin, it is not always easy to discern from the literature where other small units are situated in relation to secondary services, or exactly what assistance is available locally. And while distance from back up services adds an extra challenge for midwives in rural areas, it appears that midwives in small units within urban areas share some challenges in common with their rural colleagues. Because of these similarities I have looked at both 
rural areas and small 'low technology' units that have a midwifery practice philosophy.

The contextual layering is continued with a look at economic and demographic shifts in rural areas of New Zealand. Included are the changes in health services, which heralded the entry of competition, and population-based funding. These twin elements exacted a heavy toll on the sparsely populated areas in the south of the South Island.

\section{The origins and parameters of the research project}

I was personally aware of both the joys and demands of rural practice, but for this project, I was keen to talk with my friends and colleagues with whom I had shared part or all of the decade under study. I was curious as to whether their perceptions and memories of shared events were different from mine. Were they also curious about how the changes had come about? And what particular challenges do they see for independent rural midwives in the future?

Before embarking on my research I needed to think through some of the ethical issues that such a process could present. My plan was to interview former colleagues individually then to follow this with a focus group session. This involved gaining ethical approval for the proposed project from the Victoria University of Wellington's Human Ethics Committee. A detailed plan for my research was submitted including the proposed methodology, plus specific questions regarding the purpose, perceived benefits, and reportage of conclusions. Clearly, there was the possibility that my friends might feel obligated to participate, coerced even. Equally however, they might welcome the opportunity to reminisce and explore current issues.

Similarly if I was to make sense of the stories and ideas, I needed to ask some serious philosophical questions of myself. Feminist theory I felt could 
contribute to the analysis of my data, but it seemed that the very complexity of the period under study demanded more than a critique of gendered power positions. My reading took me on a fascinating expedition through the stimulating and confusing postmodern research commentary as it related to art, text and conversation. It was a personal challenge to put under scrutiny my tightly held beliefs about how the world worked. My research diary kept during this time reveals that there were doors I resisted opening for fear that what sustained me, would unravel in the process. Equally challenging was the need to look beyond the words of my friends and colleagues in search of underlying motivations and ideological positioning. But intriguing as postmodern ideas are, I needed to stay in touch with feminist ideas, which gave me a place to stand and a cause to fight. It was useful to see how feminists wrestled with the notions of postmodernism in an attempt to work with the irony that such a marriage presents. So while postmodernism's critique of humanistic aspiration appears to threaten the ethical foundation of feminism (Fahey, 1997), the deconstruction tools of postmodernism can help explicate the origins and mechanisms of the oppression that feminists seek to overcome.

\section{Overall aim of the study}

My aim therefore in this study was to review the history of the 1990 , decade looking for the emergence of the midwife since the change in the Act, while at the same time reviewing the impact of the health reforms within the South Otago area. While embedded in this was the desire for some sense of emancipation and a more desirable future, I needed to look firstly at the nature of midwifery construction and its' positioning in relation to other groups and discourses, both historical and extant. My hope was that such an understanding would give greater confidence when planning for the future. 


\section{Key aspects of the methodology and data collection}

During the course of this project I read the local newspapers that covered the period from 1990 to the end of 1999. The Clutha Leader is published three times a week and is a primary source of information for the local community. During this time the newspaper provided a forum for the local personalities to air their points of view on the changes to local health services, and for the disaffected to express their opposition. The local midwives also used the newspaper to advertise and promote changes to their service. These changes in maternity options were threaded through the more contentious topics that exercised the minds and emotions of the local people over this period. Most clearly, the local newspaper records the reduction of services, which transformed a busy hospital strongly, linked to services in Dunedin, to a Trust owned and managed by the community.

With these ideas swirling in my head I set off to talk with my former colleagues. Their generosity and enthusiasm for the work was humbling and their reflections on the joys and frustrations of rural practice flow through their transcripts. Their recollections of the period and the current issues that challenged them were explored in the individual interviews and further developed in the focus group with all the participating midwives present.

For us all, the events of the decade, collapsed in time and it was difficult to recall the order in which things had happened. Each midwife tells a different story. Their ages vary; they have different backgrounds, educational preparation, and experience in midwifery practice. What did emerge were some shared experiences and discourse positions that I have named a rural midwifery discourse. 


\section{The potential significance of the project}

To date in New Zealand little research has been done in the area of rural midwifery practice and its contribution to maternity care and outcomes overall. Therefore exploring the work reality issues and views of rural midwives may raise awareness of this area of practice for other midwives, and health professionals. An increased understanding would be useful too for those who determine funding and policies around rural maternity services, and assist those charged with the management responsibility for rural services. Similarly for women contemplating the option of rural birth, these findings may contribute to their understanding of the broader issues that impact on their choice of birthplace.

\section{Outline of subsequent chapters}

In Chapter Two I begin with my own experience and go on to review New Zealand midwifery and maternity care history from the early days of colonization. Birth in rural areas is discussed with particular emphasis on the impact of regionalisation policies for maternity care. I review the midwifery and other journals with a view to comparing some of the practice issues that are experienced by midwives working in rural areas in other westernized countries. This is followed by a summary of the significant policy changes and their subsequent impact on the South Otago rural community.

Chapter Three represents, my search for a theoretical framework within which to explore the historical and contextual information and the data gathered in this project. It involves the exploration of the postmodern and postmodern/ feminist commentary.

The study design is explained in Chapter Four. This begins firstly with the challenges of capturing conversation in text; both in individual interview and 
focus group format. I then go on to look at the usefulness of discourse analysis as a method of exposing the underlying discourses.

In Chapter Five, my analysis of the newspaper content is grouped around two major areas which include the continued restructuring of services with the responses of the community action groups, and the reconstruction and emergence of the midwife. Lyotard's (1997) notion of language games is used to expose the fluctuating strategies employed, as local groups and individuals sought to influence, or tried to avoid being marginalised by, the dominant language games.

Chapter Six traces the interviews with the five midwife participants as they record their interest and experience in rural midwifery practice. Emerging from this data is their sense of difference articulated as a distinct rural midwifery discourse.

The focus group session is captured in Chapter Seven where the participating midwives express the preoccupations and concerns about issues current and past. Future strategies are also discussed and tempered within the dynamic of the focus group process.

Chapter Eight explores the complex positioning that emerged in the data from all three data sources. The strategies emerging from the data are discussed taking into account the rural midwifery discourse and its potential to influence practice and rural maternity facilities in the future.

Finally in Chapter Nine I reflect on the study and its potential as a starting point for further research in the area of rural maternity and midwifery services. The complex positioning that I explore in this thesis is partly a personal search for 
some understanding of my own experiences, but also a quest for some insights into what sustains or threatens the continuance of autonomous midwifery practice in a rural area. The conclusion is open-ended, with a salute to the past and a thumbs up for the future.

\section{To summarise}

In this first Chapter I have attempted to outline the organizational detail of this project. I include the background motivation and contextual framework, plus the overall aim and potential significance of the study. Theoretical ideas of postmodern feminist theory that have resonated with the nature of my inquiry have been introduced as have the proposed methodological framework for both collecting and analyzing the data. Finally, a brief summary of the ensuing chapters is presented. Next, in Chapter Two I weave multiple threads of history to present a background and context within which this study nestles. 


\section{CHAPTER TWO: BACKGROUND AND CONTEXTUAL}

ISSUES

\section{Introduction}

History is no longer to be viewed as an inexorable progress...but random and chaotic. (Sim, 1996:96)

This section represents a partial and selective look at the context for midwives and rural midwives in particular, because of the place context has in shaping midwifery practice. I begin with a brief look at my own background and then go on to a potted history of midwifery in New Zealand to show how this has constructed current midwifery practice. Issues for midwives in rural areas of New Zealand do not appear to have been studied to any extent, and where rural maternity outcomes have been researched the midwives are rarely visible in the text. I have visited published research relating to rural midwifery and midwifeled maternity services in other westernized countries. These highlight many areas of practice with which New Zealand midwives can identify. Nevertheless, large differences remain in the cultural, political and practice environments described.

\section{Midwifery and midwives in history and place}

\section{Putting myself in the picture}

My passion for midwifery was kindled in Australia where I first trained as a registered nurse then as a midwife at Canterbury hospital in the Western suburbs of Sydney. I have always loved being off the beaten track so while on a working holiday in New Zealand it was no surprise that I ended up practising midwifery in rural areas. Midwives were in short supply during the late 1960's and early 1970's so there was plenty of work, to keep me solvent while I 
explored the countryside and became immersed in local community activities. Thus began my long love affair with New Zealand. The rural units were selfcontained, I knew the locals and there was a sense of continuity as woman friends, neighbours and colleagues moved through the cycle of pregnancy, birth and parenting. This also became my experience as my colleagues cared for me when my children were born. Since that time, the cottage hospitals where I gave birth and those in which I worked have closed.

In 1979 our family traded the crisp expanse of Central Otago for the lush country of South Otago. In Balclutha the maternity wing where I worked for many years, was part of the base hospital, which provided a full range of health services including surgery. Changes and improvements in our maternity unit were the dream of us all, and there was the sense that things could be different. The ward, which was too large and inefficient, was scheduled for alteration and refurbishment. This provided the catalyst for change. Not only was the physical layout altered, but so too was the whole thrust of our care. Our new maxim was to centre on the woman and her family's interest, which required us to rethink all of our policies and practices. While this journey was exhilarating for some, it caused discomfort for others. Some barriers were gone. We felt more free, though paradoxically more responsible and accountable.

\section{Jumping Without A Parachute}

1990 was a year of scary exhilaration. Two midwives from our team jumped into the unknown and formed the first Independent South Otago Midwifery service offering a range of 'midwife only' options for the women of South Otago; these included midwifery care throughout pregnancy, labour and birth, with six weeks postnatal follow up. Women could also choose a home birth - a first for South Otago since the inception of hospital birth services only in the twentieth century. To celebrate, the midwives booked a local hotel, filled it with 
balloons, invited the press, plus interested, and possibly, hostile parties among the public. Together we supported and agonized along with our colleagues as they learned new skills and explored the mysteries of claiming for services, ordering lab tests and writing prescriptions. In 1995 Guilliland and Pairman, (Department of Nursing and Midwifery, Victoria University of Wellington), published the Midwifery Partnership, which offered a timely practice model. This small publication, in tandem with the New Zealand College of Midwives (NZCOM) handbook for practice, helped steer us through some of the debates and antagonisms during that period (Guilliland \& Pairman, 1995; NZCOM, 1993).

The perennial review of our maternity services gathered speed. The ultimatum from hospital management came in 1994 requiring us to find a way of providing a continuity service for every woman in our area. This was the Otago Crown Health Enterprise's (CHE's) response to competition from the Independent Midwives, as well as a way of cost saving. We had been preparing for this development without really knowing it. We already had a model in place, so we met with all interested parties and after much discussion the new service was commenced.

I became one of three case-loading midwives offering continuity of care for women planning to birth locally. We also provided antenatal and postnatal care for those who for clinical or personal reasons were booked at the Queen Mary Maternity Centre in Dunedin, where tertiary level maternity services were available for a population of over 116,000 people (Statistics New Zealand, 2000). This was a new way of working in contrast to working in shifts. It was however not our only role. We still performed the administration and management functions for the unit, plus the provision of 24-hour, seven-day a week, unit cover. I barely noticed that I had been disestablished, so hectic was 
the change and the demands to prepare for it. No time to grieve or wonder why what had seemed so important to do before suddenly became irrelevant. I had changed, and we had changed. There was no going back. But how exactly had all this come about? What configuration of events provided the impetus that pitched us from a steady evolution into revolution?

\section{Midwifery in New Zealand}

\section{The early days}

Following European colonisation of New Zealand between 1840 and 1900 a system of charitable hospitals had been established. Despite the predominantly young population of the colony, birth facilities were not included. Births were attended by whoever in the locality was deemed appropriate. This could be, "a medical man, a midwife, traditional or trained, or the woman next door" (Cooper, 1998:37). Midwives were reliant on the goodwill of doctors for referrals, but they.were also sought out by women, according to their reputation and ability. Handywomen, (untrained and unregistered midwives) often assisted with the birth and would usually stay on to care for the woman and help with the family (Donley, 1998; Mein Smith, 1986).

\section{Registration and state control}

In 1904 Grace Neill, the then Assistant Inspector of Hospitals, introduced the Midwives Bill and Parliament voted to pass the Midwives Act, which lead to registration and state control of midwives. The blueprint for this move according to Cooper (1998), came from Britain where there was concern about the declining birthrate and the maternal and infant mortality rate.

Cooper (1998: 108), records, that pre 1904 the traditional New Zealand midwife was characterised as "...an elderly woman, educationally and professionally disadvantaged, who carried death and disease with her to all 
cases of childbirth she attended." However McNulty and McLellan, (1990) record that in the $19^{\text {th }}$ century one quarter of women giving birth in hospital died of puerperal fever, whereas those at home fared better, except where they were attended by a doctor. These findings however did not stop midwives being blamed for the increase in deaths related to infection.

In New Zealand, midwifery training began at the St. Helen's hospitals. Here, midwives learned to manage normal birth, and were introduced to the scientific wisdom of the day (Parkes, 1991). At this time midwives were classified as class ' $A$ ' midwives if they were trained, or class ' $B$ ' midwives if they had been in practice for more than three years and were considered to be of good character. However the list and opportunity for registration for the class 'B' midwives closed in 1907. At the St. Helen's hospitals, registered nurses could train for six months to obtain their midwifery qualification whereas 'direct entry' students were required to complete a twelve- month programme.

During the 1920's, approximately $65 \%$ of women had home births, or birthed in small units or homes. The latter were often run, and sometimes owned, by a local nurse or midwife, who called a doctor only if there was some difficulty with the birth. Of the remainder, approximately $4 \%$ were born in the state run St Helen's hospitals; $5 \%$ in hospital board premises or Salvation Army hospitals with the balance of $26 \%$ being confined in private hospitals (Mein Smith, 1986).

However, by 1935 hospital care became the norm with doctors attending all births. Now, $78 \%$ were born in maternity hospitals, $8 \%$ of these in the remaining St. Helen's hospitals, $27 \%$ in public and the remaining $43 \%$ in private facilities (Mein Smith, 1986). It is important to note however that Maori health matters had up until 1935 , been managed separately by the Division of 
Maori Hygiene. It was only after the election of a Labour government in 1935, that the health statistics of Maori women and children were included in the national data sets (Mein Smith, 1986). In 1938 records show that the Maori birth rate in hospitals was $17 \%$ compared to a total of $87 \%$ for Pakeha (Papps \& Olssen, 1997). Birth traditions varied between tribes and between classes within tribes. Women were supported by the whanau often by both male and female members. Active birth in squatting or kneeling positions was favoured and the popular perception was that Maori birth was risk free. However Papps and Olssen, (1997) report that this was a "romanticized viewpoint", and claim that, "both infant and maternal mortality rates were higher amongst the Maori than amongst Pakeha." It is suggested that new patterns of infection and poorer socio-economic conditions may have contributed to this finding. Nevertheless, by 1962 Maori and Pakeha women were giving birth in hospitals in equivalent numbers.

\section{In the wake of the Kelvin Commission}

The catalyst for some of the changes over this period was the realisation that New Zealand women were dying at a higher rate of infection than were women in other comparable nations. The Kelvin Commission, which was convened in 1923, was named for the hospital in which an outbreak of puerperal sepsis had occurred. The outcome was the campaign for 'safe maternity', which emphasized the need to institute antenatal care, standardize aseptic care, increase the inspection of premises, and improve the training opportunities for both midwives and doctors. In addition, hospitals had to separate their maternity care section and staffing from medical and surgical operations to try to reduce the contact with infectious agents (Mein Smith, 1986).

Jellet, who was the consulting obstetrician to the Health Department and an influential contributor to the debate at the time, held firmly to the view that normal birth care should be left to midwives who he believed managed this 
better than doctors. He encouraged the medical inspection of hospitals, the abolition of private hospitals and the establishment of a Chair of Obstetrics. Jellet however preferred birth to occur in large hospitals. This was in contrast to his colleague Paget who was the Inspector of Maternity Hospitals. Paget was an experienced rural doctor and supported the provision of small units in order to service the scattered populations in country areas (Mein Smith, 1986).

For doctors, these moves heralded the spectre of bureaucratic control and surveillance and were therefore vigorously resisted (Mein Smith, 1986). This was understandable when the reporting of a case of sepsis could (and did) close a maternity establishment, affecting medical income and reputation. With the founding of the Obstetrical Society in 1929, Dr. Doris Gordon mobilized women into demanding better services with a doctor in attendance. Pressure and lobbying from the women and from doctors needing opportunities for clinical experience eventually resulted in the opening of the twenty-six bed Queen Mary Maternity Hospital in Dunedin in 1937 (Mein Smith, 1986).

\section{The cost of medicalisation}

Maternity care is at the vanguard, where the engineering approach of modern medicine encounters the personal and emotional concerns of those it sets out to serve. (Garcia, Kilpatrick, \& Richards, 1990)

The assumptions behind the medical perspective are according to Davis (1981), predicated on the notion that disorders can be traced to a specific cause, are responsive to specific treatments, and exist independent of mental and external environmental conditions. While some conditions do conform to this description many do not, and require a mixed approach to management. Thus, resorting to a purely medical model when the cause or exacerbation may lie, in the social and emotional realm, is inappropriate. Davis (1981: 140) suggests: 
With childbirth,...the concern of many women is clearly that what should be in the normal course of events be treated as a natural human experience has been transformed into a 'star turn' for a high-technology medical specialty.

The medicalisation of birth brought an increased need for funding and personnel as more women delivered in the larger hospitals. This trend continued, despite consistently better outcome statistics from the small and scattered, state run St. Helen's hospitals. As the "midwives' scope for independent work was eroded, arguments for appropriating their teaching resources in favour of medical students were strengthened" (Parkes, 1991:172). Medical students began to be admitted to all St. Helen's hospitals from 1921, and the Nurses and Midwives Act in 1925 “...formalized the midwife's slide from independent practitioner to doctor's assistant" (Parkes, 1991:171).

For women, the attractions of hospital birth in the 1920s and 30s included the rest from family responsibilities, and the promise of pain relief with chloroform and twilight sleep (Donley, 1998). These sedatives resulted in an increase in both forceps deliveries and infection rates, plus the birth of heavily sedated babies. The response of the Kelvin Commission, rather than being aimed at the cause of the problems, was to draw up regulations resulting in an Act in 1925 for asepsis. These regulations lead to the instigation of shaving, draping and the delivery of women in theatres (Donley, 1998; Mein Smith, 1986).

In 1932, the St Helens hospitals were turned over to the local hospital boards. Mary Lambie, the Director of the Division of Nursing in the Department of Health objected because of the effect this would have on midwifery training and women's experience. Her efforts saved only four of the St. Helen's hospitals and these were eventually opened up for medical students by 1937 . Women were now subjected not just to the rigorous and immobilizing effects of the antiseptic procedures, but also to the indignity of multiple examinations and 
increased risk of infection during labour. Mein Smith (1986: 180), suggested that the emphasis on reducing mortality and morbidity "...ignored birth as an emotional experience resulting in treatment both frightening and degrading for many women."

Throughout this period it would seem that midwives were absent from the debate. According to Belgrave (1991:24), “[t]rained midwives, were prepared to accept subordination to the economic and professional demands of medical practitioners for the sake of their own precarious professional statuses." For instance, the Social Security Act of 1938, instituted free maternity care only if a doctor and not a midwife, cared for a woman. By 1939 maternity care was fully funded by the government with specialists allowed to charge extra, while home birth remained unfunded. Thus "the debate over midwifery in the 1920's was not between midwives and doctors but between a reforming Department of Health and the defenders of professional privilege" (Belgrave, 1991:24). This struggle Papps and Olssen (1997:18) suggest, was not only between doctors, midwives and authorities, but also between midwives and nurses, and "between women and the medical profession for control over their bodies during childbirth."

\section{Midwives, nurses and women}

In 1957 Flora Cameron, the Director of the Division of Nursing, "made the changes in the curriculum which subsumed midwifery into the nursing profession" (Donley, 1998: 99). This change consisted of the introduction of a six-month maternity component within the three-year programme. Nurses would now graduate with a double certificate in both nursing and midwifery. This change had first been mooted as a recommendation from the 1946 Committee of Inquiry into Maternity Hospital Staffing, but Flora Cameron's predecessor, Mary Lambie, had blocked its introduction on the basis that it was a superficial course that posed a threat to midwifery (Donley, 1998). 
The Carpenter report, commissioned by the Department of Health in 1971, recommended that a comprehensive educational programme in tertiary institutions replace the apprentice-based programme for nurse training. It was at this time that the word midwife disappeared from the title of the Act (Papps \& Olssen, 1997). With the last student graduating from a St. Helen's midwifery course in 1979, midwifery became a post basic certificate tacked onto the end of the undergraduate nurse education course. The subsequent change in the Nurses Regulations decreed that a nurse might carry out 'obstetric' care only under medical supervision (Donley, 1998).

Home births became increasingly rare over the 1960's and 70's. Midwives suitably experienced were hard to find, being both constrained by the intense criticism they endured from hospital based colleagues and the inability to earn a living from their profession (Daellenbach, 2000). Home birth activists reflect on this time recalling it as an opportunity to rediscover normal childbirth. "It was like an, 'underground laboratory,' where new ideas and forms of midwifery practice could be tried out away from the eyes of authorities and medical experts" (Daellenbach, 2000: 395). In concert with their beleaguered midwives, Home Birth Association members lobbied government for the return of midwifery autonomy, improved pay, and the establishment of a direct entry midwifery course.

In 1980, the Midwifery Section of the New Zealand Nurses Association, (NZNA) were prevented by the leaders of the NZNA from putting forward a submission about women's choice in birth. This submission asked that midwifery practice be recognized as different from obstetric nursing and that the ability to practise without first being a nurse be reinstituted. This position was at variance with that of the NZNA leaders and was therefore not supported 
by them (Papps \& Olssen, 1997). This galvanized women from consumer groups who subsequently opposed the 1983 Nurses Amendment Bill. This Bill allowed nurses and non-nurses to provide maternity care to women under the direction of a doctor, while decreeing that direct entry midwives could no longer conduct home births. To continue to practise domiciliary midwifery they were required to train as registered nurses (Tully \& Mortlock, 1999).

In 1983 the consumer movement Save the Midwives was born, and in 1989 the New Zealand College of Midwives was formed. One year later in 1990, following intensive lobbying by women and midwives, the Nurses Amendment Act restored midwifery autonomy. In its wake, Direct Entry Midwifery pilot courses began at Auckland Institute of Technology (AIT), and Otago Polytechnic in Dunedin (Papps \& Olssen, 1997).

The effect of the legislation and the change in midwifery education were seen as potential threats to other health professionals. Papps and Olssen (1997), argue that the superior status given to medicine, its skills and its alliance with science, influences how childbirth is perceived. Thus, the campaign that regained some choice in care for women and the return of professional status, for midwives, cannot be taken for granted. Over the last 100 years, the hospital has come to be the most common place for birth. Moreover, this is not just any hospital but one equipped and staffed for all possible contingencies. This has the effect of putting a question mark over those who would choose to birth at home or in small units, and those who support and encourage this choice. Abel and Kearns (1991), reported a homebirth rate of $65 \%$ in 1920 of the total childbearing population. By 1991 , this rate had dropped to $1 \%$. This rate is reported to be increasing and is thought to be between 7 and $10 \%$ currently (Smulders, 2002). 


\section{The case for rural birth}

\section{The effects of regionalisation}

In the early part of the century, Paget, the Inspector of Private Hospitals, had supported the retention of rural maternity units and cottage hospitals. He also promoted home birth as a cost effective and appropriate choice for women anticipating a normal birth (Mein Smith, 1986). This support was contingent on rural units enacting the Obstetric Regulations with regard to aseptic regimes and the maintenance of separate birthing and medical areas.

During the 1970's however, obstetric services were linked in with secondary services in a "formal regionalised perinatal care system." Thirty-three rural units "closed between 1970 and 1984 [and] most of these units were the only hospitals in the rural communities that they served" (Rosenblatt, Reinken, \& Shoemack, 1985:429). In 1982 the Maternity Services Commission Report advocated regionalisation of maternity care as a safer option for women. The future objective was for all women to give birth in an obstetric unit that could provide specialist obstetric, paediatric and back up facilities. Contributing to this was the Code of Risk Factors introduced by the Maternity Services Committee that, according to Donley (1998), swept women into the level two and three hospitals - level two hospitals providing surgical and paediatric services and level three, specialist services and advanced life support systems.

The regionalisation movement put a strain on the staff and resources and eroded the confidence of the rural practitioners. The consequent fall in birth numbers made many of the smaller hospitals uneconomic and precipitated closure, despite strong evidence that babies and women fared better, and had better outcomes in these smaller units (Donley, 1998). 


\section{The safety of rural birth}

The question mark that continues to hang over the safety of rural birth services is a legacy of the regionalisation project. A 1985 study found that there was an advantage for normal weight infants to be born in smaller obstetric units. It also found that there was no evidence to suggest that "a satisfactory outcome [was dependent] on a minimum number of deliveries" (Rosenblatt, et al., 1985:429). No further studies have refuted or overturned these findings, and it would seem reasonable to assume that with the improved emergency transport and other technical assistance now available, that birth in rural New Zealand is a safe and appropriate choice for women anticipating a normal birth.

In 1988, the neonatal morbidity outcomes and transfer patterns of urban and rural general practitioners were compared. The aim was to assess whether the number of deliveries attended per year by the practitioner influenced outcomes or transfer rates. "No association was found between the number of deliveries undertaken by general practitioners both urban and rural and maternal and neonatal morbidity" (Tilyard, Williams, Seddon, Oakley \& Murdoch, 1988: 207). Thus the competence of the general practitioner could be "interpreted as either the ability to detect abnormality and refer appropriately, or the ability to detect and undertake management of the abnormality as it arises" (Tilyard et al., 1988: 207 - 9).

Rosenblatt, et al., (1985: 431) found, that the lowest perinatal mortality rates occurred in the smallest hospitals but rose when hospital birth numbers increased. In addition, no threshold was detected below which obstetric care became unsafe. Furthermore:

...Even if all preventable perinatal deaths in Level One hospitals could be averted by closing these units - which is unlikely, since many of these babies would still die even if delivered in better-equipped centres - the 
impact on the perinatal mortality rate would be negligible. (Rosenblatt, et al., 1985: 431)

The findings therefore do not support the closure of small units on the basis of safety. Nor is there any foundation for suggesting that practitioners must manage a minimum number of deliveries (Rosenblatt, et al., 1985: 431).

In rural Canada, similar outcomes were found. Populations with small hospitals had "perinatal loss rates similar to the rates in those served by larger secondary or tertiary care facilities, even when all adverse outcomes were attributed back to local hospitals." The small community hospitals in Nova Scotia with less than 100 deliveries per year had the lowest perinatal mortality and morbidity rates in the province. More importantly, it seems that populations that do not have access to rural maternity care at their local hospital, have the worst perinatal outcomes (Canadian Medical Association's Joint Positions paper on rural maternity care, 1998:6).

As a result of these findings, the Canadian Medical Association produced a joint position statement on 'Rural Obstetrics,' which stated that:

[E]very woman in Canada who resides in a rural community should be able to obtain quality maternity care as close to home as possible. Whenever feasible she should give birth in her own community within the supportive circle of her family and friends. Respect for these women requires that public policy and clinical care guidelines support the provision of quality maternity care programs in rural Canada. (Canadian Medical Association's Joint Positions Paper on Rural Maternity Care, 1998:16)

Further, they noted that the lack of local maternity services leads to potential isolation and compromise for women who are unable financially to travel to other communities for routine care. Similarly, the lack of primary birth services will continue to erode resources and expertise for all aspects of maternity care. 
Of particular concern would be the lack of people with the skills to handle emergencies. Thus one objective was to confirm that maternity care in rural communities was effective, appropriate and safe even when caesarian section was not available on site (Canadian Medical Association's Joint Position Paper on Rural Maternity Care, 1998: 2).

In Britain, according to Campbell and McFarlane (1994), the number of isolated GP maternity beds halved between 1980 and 1990. Decisions about closure were made on economic grounds plus the notional risk of their distance from secondary services. These small units are generally staffed by midwives with a GP on call and were found to have comparable and sometimes better outcomes than units sited close to, or within, specialist units. An analysis of 50,000 births failed to show a higher risk in the GP units and little evaluation was done with regard to the cost of these changes. Such costs do not go away but are shifted to a multiplicity of sector and community areas where they are unable to be evaluated and tracked (Campbell \& McFarlane, 1994).

The 1992 Winterton Report (Tew, 1995: 215-6), found that the policy of encouraging hospital birth was unable to be "justified on the grounds of safety." Therefore, the provision of maternity care, should not be driven by, a "medical model of care based on unproven assertions." Moreover options for homebirth and birth in small maternity units ought to be supported. This report followed a comprehensive enquiry commenced in 1991 into maternity services in the United Kingdom. It began from the premise that poor outcomes were likely to be related to socioeconomic factors, rather, than the premise that birth was dangerous. It took women's concerns seriously, inviting submissions from all stakeholders and not just health professionals (Tew, 1995). 
Such desirable outcomes are a tribute to the skills of rural general practitioners, midwives and other staff in these units who would have been caring for women during sometimes, long labours. Also of significance would have been the environment in which the woman gave birth. The familiar and trusted faces of the practitioners and staff, plus the sense of being close to home, can be assumed to influence positively the woman's birth experience. However, in most instances the midwife would have been the person to alert the GP to concerns about progress or signals of distress. Similarly, they would have been present at the time of birth and required to assist if intervention or resuscitation was required. At times, the midwife may have been the only person present if the doctor was unavailable, and would be expected to take full responsibility for the safety of both the woman and her infant.

\section{The rural midwife}

Despite the mobility of populations, there, remains a sometimes, uneasy relationship between rural and urban populations and this sense of country/city divide may well have historical roots (Williams, 1975). For instance, the city inhabitants were considered learned and worldly, whereas country folk were regarded as backward and ignorant. However, this rigid historical, separation, is challenged by McLean, Landey and Ward (1999), who report that there was considerable movement of people and commerce even in $16^{\text {th }}$ Century Britain. So it would seem that any boundaries still in existence are extremely permeable.

Shorter (1982) suggested, that in the past there has been a clear divide between urban and rural midwives. Rural or traditional midwives worked in small country towns using trial and error, often struggling to earn a living with a poor and uneducated clientele. The rural midwife was generally regarded as ignorant and uneducated and was unable to summon help should she have a problem birth. In contrast, some urban midwives were highly regarded in their 
communities, had received some training in obstetrics, and in some areas were registered with a guild. Graduates from such training establishments as were available opted to work in the cities, shunning the poor pay and demands of rural work (Turner, 1992: 88).

If such notions persist today, they are inconsistent with the role that midwives play in rural areas. Davis (1987) observed that rural midwives needed additional skills to enable them to act promptly and appropriately in an emergency. Also acknowledged is the sense of isolation and lack of regular contact with peers, such contact being critical when a second opinion is needed, or, when there is a clash of commitments and distance is involved. Thus the rural midwife needs a comprehensive knowledge and wide range of skills to deal with all contingencies. They also need local support and established links for advice and referral with secondary services.

In 1996, the combined Regional Health Authorities whose responsibility it was to fund health services, in the public sector in New Zealand, introduced the concept of the Lead Maternity Carer (LMC). This notice consisted of a capped modular payment system for maternity care, which could be claimed by practitioners. Midwives, acting as a woman's LMC, could therefore offer a local birthing option where general practitioners had withdrawn from providing primary maternity services. Guilliland (1998:3), suggests that "[t]he reliance, on midwives as the predominant maternity service providers in towns and rural areas is not understood at a political and policy level." This lack of understanding can lead to a shortage of midwives in some areas, leaving the community without a maternity facility and women with no choice in regard to their care. Such a situation means that some women need to travel long distances to the town. 


\section{Just what is rural?}

It is difficult however to define succinctly what is meant by rural. New Zealanders travel frequently between centres and most have family or friends who live in a rural area. Some rural dwellers are within easy distance of large towns while others see themselves as clearly in a remote location.

Janes (1999: 297) defined a rural hospital "as a facility with no resident medical specialists, where acutely ill patients are admitted and cared for solely by generalist doctors, either general practitioners (GPs) or medical officers of special scale (MOSS)." Janes' list of thirty-six rural hospitals, serve approximately $10 \%$ of the New Zealand population; the most isolated being in the Chatham Islands.

A variable range of services is offered in rural facilities. Some maternity services are offered from premises that are equipped and staffed to offer 24hour emergency care on site, while others provide a domino service with the unit opened and staffed only as required. The degree of 'rurality' is frequently calculated as the distance from the nearest level two or three hospital. And while kilometre range is one determining factor, New Zealand's geological features may well be more relevant. For instance, mountain roads can be closed in adverse weather by snow or landslips, and such stormy conditions make flying hazardous. Some independent midwives practise in remote areas distant from major cities, whereas some on the fringes of towns may work with women in both rural and urban areas. Also, since the introduction of budget holding and the LMC concept, some urban midwives travel into rural areas while operating from an urban base. This activity severely affects the practice of some rurally based midwives, who see women being persuaded to birth out of the area. 
In the following section I take a whistle stop tour of what are classified as rural or small maternity units in North America, Europe and Australia. Geographical descriptions are absent and it isn't always clear how far the service or unit is from secondary services. What the studies do agree on though is the unique and critical contribution of the midwife to the improvement of maternal and perinatal outcomes.

\section{Birth in small and rural units in other westernized countries}

It is difficult from the published commentary and research to compare the New Zealand rural maternity service with that of other countries. Each has a history, political and economic context that makes any direct comparison problematic. However, common findings across the countries show that outcomes appear to be at least as good, and in some cases better, in rural areas than in the major centres. It is also clear that most countries are looking at how primary rural maternity services can be maintained, and in some areas re-introduced. And it appears that midwives in these areas share experiences and issues in common with their New Zealand peers.

\section{United States of America and Canada}

The birth centre movement is a comparatively recent trend in the United States. Early small samples from 'out of hospital' settings has helped to refine admission criteria and also to demonstrate the safety of alternative birthing options. Rates of transfer were compared from two freestanding birth centres in Southern California, and in addition the study looked at, the risk profiles of the women and the clinical practice guidelines. It was found that these benchmarks, while applied generally, were not useful for all units. The recommendation was that it would be more appropriate to take into account the individual characteristics, skill levels and experience of the practitioners when designing guidelines for transfer (Fullerton, Jackson, Snell, Besser, Dickinson \& Garite, 1997:9). However, these units were within easy reach of secondary services and do not reach the threshold for what would be considered a rural unit in New 
Zealand. Nevertheless, the notion of guidelines being based on site-specific criteria makes good sense.

Another study of 43 designated rural hospitals in Washington State looked at neonatal outcome measures as well as fiscal issues for individuals and the State. Depletion of practitioners with the requisite skills has resulted in some areas no longer providing primary maternity services or neonatal after care. Women resident in these areas therefore needed to travel to major centres where their stay was prolonged and extra costs incurred. The report concluded that provision of local maternity services "might decrease use of neonatal resources" (Nesbitt, Larson, Rosenblatt, \& Hart, 1997: 1).

While the above study centred on physician retention, midwives prepared to work in these rural areas struggle with issues of financial viability and restrictions on their practice. For instance, midwives in the United States do not have full admission privileges, which Vann (1998) sees as a hallmark of autonomous practice.

In 'out of hospital' birth centres in North America nurse midwives manage a phone triage service to help low- risk women avoid high-risk care. Key areas that contribute to this are the educational and informed consent processes that enable women to choose a low risk option whenever possible. To successfully perform telephone triage, the midwives require an extensive clinical knowledge, but where a call raises concerns they will visit. However, a primary anxiety for the nurse-midwives is the ever present threat of litigation should they err in their judgement (Barnes \& Dossey, 1999). This also concerns other midwives. Gordon (1990), cites the prohibitive cost of malpractice insurance in Arizona for nurse midwives as a disincentive to work in rural areas. Some 
respondents said they had gone 'bare' and were working without cover, as their earning capacity could not accommodate the cost of the insurance premiums.

In upstate New York, Stone, Brown, and Westcott (1996: 380), describe an innovative model of maternity care that is accessible, affordable, and cost effective, which replaced a predominantly medical model. The achievements of the collaborative service have been a reduction in cesarean sections, and an increase in the number of vaginal births. These include twins, breech, and vaginal births after caesarian (VBAC). The rate of VBAC over five years was increased from $68 \%$ to $94 \%$. Similar dramatic improvements were recorded in other areas. These included a reduction in episiotomies, an increase in vaginal breech deliveries, higher birth weights and greater client satisfaction. The improved outcomes are attributed to the support for women given during labour by the nurse-midwives whose aims were to keep the birth "experience as 'normal' as possible".

\section{Holland}

In Holland, midwives work as autonomous practitioners and have a long and valued history of home birth. The health services are financed by a public health insurance scheme, which covers $70 \%$ of the population; the remainder being covered by private insurance companies. About $50 \%$ of births take place in hospital where the women referred there by doctors do not have to pay. Midwifery is protected in that a GP cannot claim a fee reimbursement if a midwife is practising in the area, nor can an obstetrician if the woman has a normal birth (Bakker, Groenewegen, Jabaaij, Meijer, Sixma \& de Veer, 1996; Van Teijlingen \& Mc Caffery, 1987).

In rural areas, relationships between midwives and local GP's vary as they compete for deliveries. This is in contrast to their urban colleagues where GPs refer women to the midwives for pregnancy care. But despite these 
arrangements and their enviable record of normal birth, Dutch midwives are threatened by changes in funding and the increasing medicalisation of childbirth. For example, it is argued that an opportunity for a consultation with an obstetrician should be available without referral from the midwife (Van Daalen, 1988).

\section{Germany}

A pioneering autonomous birth centre in Berlin has been the catalyst for the development of a number of similar units. The original 'birth houses' are almost all run by independent midwives. Birth numbers are high at around 28 per month, the atmosphere is homely, and women have access to alternative therapies. No provision is made for forceps or vacuum extraction on site and only low risk women are considered, but this has been extended to some women who have had a previous caesarian birth. The midwives are rostered for 24-hour periods and care for the women throughout their labour and birth with postnatal visiting daily for at least ten days. Of the approximately 1,000 births, $94 \%$ are normal with a transfer rate of $15 \%$. Water births are increasingly popular and now represent $35 \%$ of the births (Travis, 1999).

\section{The United Kingdom}

In Britain as noted earlier, many isolated and so called 'GP units' primarily staffed and managed by midwives are threatened with closure on economic grounds (Campbell \& Macfarlane, 1994). Below are descriptions of some of these small and rural units across Britain, but as some of the stories are becoming dated it is possible that they no longer exist in the form reported. However, as examples of management options for midwifery led care, they are worth visiting. We are reminded that " $[t]$ he majority of babies born in the United Kingdom, have always been delivered by midwives, a fact often overlooked both by policy makers and research workers alike" (Campbell \& Macfarlane, 1994: 95). 
In Wales, midwives provide care using their full range of midwifery skills in the local maternity units. Once the women are fit and well, their postnatal care, is provided by nursing auxiliaries. The women, however, are first vetted by a doctor, either GP or obstetrician to confirm the place of birth (Lode, 1991).

In Wessex, a pilot project with shareholders employs five midwives, paid on salary. The midwives each carry caseloads of around 30 women per year, and according to Walmsley (1999), work in a 'midwifery model'. This involves taking all evidence into consideration and not just cervical dilatation as outlined in the partogram; a graphical representation of the observations taken during labour.

Woodcock (1994: 30) describes the Darley maternity unit in North Derbyshire, as one of the few isolated maternity units "to escape the wave of closures" of the 1980's. Their survival however has not been without a fight at times. They have no formal catchment area but women within a twenty mile radius, seek out their service. The eight midwives work as a team to provide midwifery led care for normal birth, referring when necessary to an obstetrician.

In Edgeware, a new midwife run centre grew out of the downsizing of the local hospital. A survey of the local women revealed that there was a demand for the service and midwives were recruited. Additional skills, such as cannulation, were accessed with their medical colleagues at the university. The midwives see themselves as very much in the spotlight, but realize that it is the women who will determine the success of the service (Jones, 1997).

\section{Australia}

In the Australian State of Victoria, midwives were surveyed on their work profiles, job satisfaction and their knowledge of the recent Birthing Services Review. Rural midwives were concerned about the closure of local units, plus 
problems of isolation. They also reported a lack of job satisfaction with the increasing trend towards the medicalisation of birth. However the authors signaled that there was room for cautious optimism if midwives "take advantage of opportunities to work in different models of care that allow for more autonomous practice" (Watson, Potter \& Donahue, 1999:230).

However, it would seem that such options are limited. For example, a birth centre in Launceston, Tasmania, was started in 1981 as a co-operative venture between midwives and consumers. Smallbane (1998), reports that it is still managed by consumers and provides a cost-effective place for birth, offering both home and birth centre delivery. Sadly, the service does not qualify for funding so is only available for those able to pay. Incredibly, midwifery services are deemed alternative medicine.

Rawling (2000: 145), describes a positive initiative, which aims to foster understanding between urban and outback services. Exchange partnerships were established with two Sydney hospitals and four in far west NSW. "Common objectives for both groups of midwives were to share their midwifery experiences with their local colleagues and to experience culturally sensitive care of mothers from indigenous and ethnic populations." For the midwives from the city it was a time "to appreciate the difficulties under which their country colleagues work and to share knowledge and give support in setting up new ventures." The evaluations from the participating midwives were overwhelmingly positive.

Organisational change and its impact on rural nurses, was studied in Australia. McCarthy, Hegney and Pearson (2000) found that staff would participate in the change process if those driving it consulted with and involved them. If the proposed changes created work overload and role insecurity, they would not be 
supported. For rural nurses, enforced change can result in a threat to full employment, and there is not always an option to go elsewhere when committed to an area for family reasons (McCarthy et al., 2000).

\section{Home birth in rural areas}

Most of the above studies refer to birth in rural units, but a small proportion of women, choose to birth at home in their rural area. Home for most women is a private safe place where they feel a strong sense of personal identity. Hospitals on the other hand, even homely birth units, are seen as other people's territory. Strangers can intrude and the woman may need to expend energy and effort to maintain a sense of control of her birth and environment. There is also the sense of being under surveillance, however benign (Abel \& Kearns, 1991).

Birth in the Netherlands is considered a normal life event, which has the advantage of not making the woman into a patient. Thus she can fulfill a natural and highly personal task. During and following a birth at home the woman is entitled to support from the 'Kraamverzorgster' or maternity aid nurse (Van Teijlingen \& Mc Caffery, 1987; Kloosterman, 1978).

In New Zealand, home birth statistics were reviewed from 1973 to 1993, and Gulbransen, Hilton, McKay, and Cox (1997:87-89) concluded that; "home birth was a safe and increasingly popular, though minor, option for New Zealand women." Thus, if it were deemed safe to birth in a rural unit with minimal equipment then it would seem that there is no additional risk of a home birth in a rural area. Durand (1992:452), also studied the safety of home birth for women attended by lay midwives in rural Tennessee. He found that "[1]ay midwife attended home births appear to have been accomplished with safety comparable to that of conventional births, [and with less] operative assistance." 
While some rural women will choose to birth at home, for many, distance from medical facilities, however unsophisticated, can have a psychological effect on how safe they and their families feel. Thus, arriving at a decision for home birth according to Vedam and Kolodji (1995), ought not to be done lightly and involves careful client selection. Their extensive list of criteria for a "good candidate" includes, not just medical and obstetric history, but also the woman's attitude to birth and her confidence in home birth in particular.

\section{The historical and political development of rural midwifery in summary}

In the early days of European settlement in New Zealand birth occurred at or close to home, attended by midwives or women, with assistance from doctors only if the birth was complicated. Thus to give birth in rural areas was a normal expectation. This pattern was to change inexorably over the intervening years. The medicalisation of birth in New Zealand was not just the result of successive legislation but was also related to changes in technology, women's expectations, lobbying and debate, plus movements in the social or political sphere. For example, the concern about infection rates and the introduction of aseptic principles for all births, plus the availability of birth analgesia lead to women choosing, or being persuaded, to birth in hospitals. The increasing involvement of doctors with normal birth as obstetrics became more specialized, contributed significantly to the movement from home to hospital. Midwives and women were caught up in these social and political moves, some promoting and supporting the changes, believing them to be beneficial for women, while others protested what they saw as medical capture of the birth process.

The relevance of this section for this work is that each midwife practising in a rural area will have been affected by aspects of the regulations around midwifery and certainly by the project of regionalisation. Many would have 
been active in the protests organized by local communities against closure of maternity homes or hospitals. In latter years, few could have avoided being caught up in the media debates articulating the differences between midwifery and medical discourses around women and birth.

While such evidence that exists assures healthy women that they can anticipate a safe birth in a rural area, there is the expectation that timely access to technological and specialist expertise should also be available if required. For New Zealand with its unique geography, unstable climate and small population this service poses challenges, and underscores the need for local expertise in primary birth care. This reality means that strategies used by other westernized countries to manage their maternity services for scattered populations, may not be all that relevant. However, isolation brings its own common issues so the experiences of other rural midwives may resonate with their New Zealand colleagues.

The political and regulatory history above provides a backdrop, to the 1990 decade during which there was considerable demographic, and economic change. In rural areas the reorganization of health services impacted significantly on the local population. This is explored in the next section.

\section{Recent history and developments}

For myself, indeed, I know now that I have traveled so much because travel has enabled me to arrive at new, unknown places within my own clouded self. (Laurens van der Post, b 1906)

Over the last ten years the health sector of rural South Otago has undergone rapid and revolutionary change. The introduction of contestability with regard to resources, the withdrawal by Crown Health Enterprises from the provision of rural services, and the subsequent formation of a local Trust, has changed 
forever the rural health landscape. The restoration of autonomy for midwives in 1990 following a change in the Nurses Act (1977) has introduced another stream of change for the maternity services in New Zealand. Rural maternity services cannot be sustained without midwives, who are skilled, experienced and prepared to do the on call cover required. However, capped funding, the decline in the fertile population, and difficulties around recruitment, logistical support, and financial viability, combine to challenge midwives, and reduce primary birth options for women.

\section{The changing demographic profile of rural South Otago}

In South Otago there has been a net population drift to the more populous urban centres. This area referred to as the Clutha district, borders Dunedin City and Central Otago in the north and Southland in the west, with its eastern border extending to the coast from Taieri to Owaka. Here, some of the once thriving country towns have become derelict with rows of empty shops, as businesses have moved north or ceased operating. This domino effect according to O'Leary (1990), occurs as the closure of one service undermines others, property values decline, and customers begin to bypass the local stores and businesses.

Similarly, the fluctuations in primary produce prices, increased mechanization of farming and extended areas of forestry, have reduced employment opportunities. This trend has been exacerbated by the amalgamation of what were once small, but viable family farming units, into larger holdings. The need to earn, an, 'off farm' income creates different stresses and introduces a new dynamic for rural families. The added, workload, of the remaining partner often contributes to the lack of traditional support activities in rural communities, as there is less time for outside commitments. And in some areas the influx of urban dwellers that either commute or start a small business create different 
demands and may not be as keen to integrate into the established community (Patterson, 2000).

According to the 1996 census, the population of the Clutha district was recorded as 18,006 . Of this 9,273 were male and 8,733 were female. Of the total population, $15.9 \%$ of people in the Clutha District were aged over 60 years. The population was largely of European descent, this group being $90.5 \%$ compared to a national average of $74.8 \%$. Maori were $8.3 \%$, correspondingly lower than the national figure of $15.1 \%$. The remaining Pacific Island and Asian groups were small at $0.5 \%$ and $0.7 \%$ respectively. But most significant for this study was the steady decrease in the number of women in the $15-35$ year age group, who are the section of the population most likely to access maternity services (Statistics NZ, 1986, 1991, 1996).

\section{Unleashing competition}

To understand the impetus for some of the changes in the 1990's requires at least some understanding of previous political and economic events. Beginning in the 1970's and continuing into the 1980's, deregulation was already happening in the United States, Britain and Australia. In New Zealand in 1984, the newly elected fourth Labour Government opened the books to find a rigidly controlled economy "burdened by huge overseas debt", and decisions were made to deregulate the economy at an unprecedented speed (Carew, 1987: 5).

Health services were not exempt from the economic reforms. In 1988, the report from the Hospitals and Related Services Taskforce, Unshackling the Hospitals, (1988) blamed poor management in the publicly funded health system for its failure to contain costs and achieve desired outcomes. The separation of the funder from the provider was recommended in order to create a "limited marketplace," thus making public health funding contestable. (Hospitals and Related Services Taskforce, 1988). In 1991 the green and white 
paper "Your Health and the Public health," signaled the introduction of these changes (Upton, 1991).

As previously stated, the Amendment to the Nurses Act 1990, restored autonomy for midwives, freeing them to develop and use their full range of midwifery skills. Thus, midwives were able to offer women antenatal and postnatal care in addition to their role during labour and birth. This change completely redrew the practitioner map for women and other health professionals alike. Overnight, a revolution had occurred after decades of entrenched patterns of work relationships (Patterson, 2000).

This change, lobbied for strongly by both midwives and women, would have been unlikely to succeed had the Treasury not been looking for ways to curb the escalation in health care costs. Medicine had a monopoly over most areas of the health service and the introduction of competition into the health arena was an expedient opportunity to try to loosen this grip. However, the decision was also based on the need for justice and pay equity, and not simply pragmatics (Tully \& Mortlock, 1999).

In the years between 1993 and 1996, both midwives and doctors could claim the same hourly rate from the Health Benefits schedule. Services were reimbursed on a fee for service basis and during this time increasing numbers of midwives left hospital employment to establish themselves as independent midwives in both urban and rural areas ("Timeline of maternity benefits negotiations", 1997).

However, in 1996 the Section 51 notice of the Health and Disability Services Act (1993), concerning the provision of Maternity Services, survived a stormy passage in the media, to emerge as the definitive document with regard to 
service specifications, and modular payment schedules, for all providers of primary maternity care. This saw the advent of the Lead Maternity Carer, (LMC), who held the budget, for each woman in her or his care. The Regional Health Authorities (RHAs) released this document without the agreement or support from the New Zealand College of Midwives, (NZCOM) or the New Zealand Medical Association, (NZMA) with whom they had been negotiating. The NZMA rejected it totally while the NZCOM agreed to continue to work with the RHAs on areas of rural and postnatal care. Midwives however, did not unanimously support this position. The funding on offer was considered by some independent midwives to be inadequate to sustain their practice. Others, working in shared care arrangements, felt that their relationships with their medical colleagues would be strained if they supported the NZCOM over this decision.

In 1998, the Transitional Health Authority (THA), until 2000, known as the Health Funding Authority (HFA), sent providers a "Revised maternity notice." This pragmatic document was the outcome of protracted debate between the THA and representatives of the provider groups involved in the discussions. Changes included the removal of the consultation regarding options for care, and the transfer of the six-week baby check payment to the General Medical Services (GMS) schedule. Some new single episode fees were introduced or modified, and home visiting travel supplements were detailed. Critical for rural areas was the inclusion of a "Non-Lead Maternity Carer rural emergency fee," which enabled the reimbursement for another practitioner to provide care in an emergency where the LMC was unavailable (Crombie, 1998).

Despite the accommodations to the document, the calls for a review of Section $51 \mathrm{did}$ not go away. Concerns were expressed about the number of General Practitioners (GP's) who had stopped providing LMC primary maternity care 
following the changes (Ferguson 1999). According to Guilliland (1999) this retreat was not just related to funding and conditions, but also to the closure of many small maternity units, plus the fee structure, which pushed rural practitioners into competition with one another. Guilliland asserts that; "[m]edicine and midwifery are distinct professions based on overlapping but different bodies of knowledge. They are inherently complementary but competition exaggerates their differences and impacts on their relationships" (Guilliland 1999, cited in Patterson, 2000: 123).

\section{From competition to integration in rural areas}

From 1995, cracks began to appear in the Government's commitment to untrammeled competition. The exhortation was for more co-operation, coordination and collaboration between healthcare providers. Speakers at a symposium in Hamilton, on the delivery of health services to smaller communities in 1995, were advocating integrative arrangements with various funding streams. The keynote speaker suggested that when dealing with rural communities, health authorities should "embed rather than insulate themselves" from provider and community networks. Such a strategy, he believed, may be more effective than the quest for autonomy with its unswerving adherence to the purchaser/provider split (Fougere 1995:21). The idea of "team organizations", was advocated by London and Ross (1995:106), where each team member "achieves their service potential." However it was important that "distortions of funding" did not inhibit this process.

McCormick (1995), however, favoured the retention of the purchaser/ provider split at the local rather than national level, with the development of coordinated care provider arrangements being charged with meeting the quality requirements of the purchaser. In so doing, the expectation was that integration of providers would be a natural outcome. Mills (1995) warned however, that it would be a mistake to think that rural populations in New Zealand can be easily 
categorized, or that blanket arrangements for health services could be applied. Rather, there needed to be careful consideration of the characteristics of any particular rural population. Rural communities are clearly not a homogenous group, but rather many groups, each having different health statuses, resources, cultures and needs, but often with strong community networks.

This mellowing in the Government's attitude was influenced in part by the coalition agreement, entered into with the New Zealand First party following the National Government's narrow election win in 1996. The health changes agreed to in the 1996 Coalition Agreement included changes in the thrust of the health portfolio. New Zealand First wanted the four Regional Health Authorities disbanded in favour of a Transitional Health Authority and an increase in health spending. This included free doctor visits for children under six, a larger mental health budget, and the abandonment of asset testing and hospital charges (New Zealand First, 1996-7).

By 1999, competition appeared to vanish altogether from rural health policy. The National Government claimed to recognize the diversity of rural areas and expressed keenness to develop "local arrangements." The aim was to foster "effective alliances and networks between providers at the primary level and between primary and secondary levels"; acknowledging that small rural c̊mmunities already had some "immportant ingredients ior succesśtủ integration" (Creech, 1999:32).

Thus evolutionary, rather than revolutionary, change was anticipated for the future, with the current distribution of services expected to remain in place for the next three years. In smaller centres, the intention was to address levels of skill among the local practitioners by providing expertise from larger centres (English, 1998; Creech, 1999). 
Recent changes continue this trend. In December 2000, the Minister of Health launched The New Zealand Health Strategy. This document provides for the setting up of District Health Boards, (DHBs) charged with ensuring appropriate and equitable health services for a given community. Funding is allocated on a population basis and the boards are required to negotiate with individuals and group health service providers to deliver government health priorities (King, 2000). The Primary Health Care Strategy followed in February 2001. The vision for the next five to ten years, being that, "[p]eople will be part, of local primary health care services that improve their health, keep them well, are easy to get to and co-ordinate their ongoing care" (King, 2001; vii). The direction indicated is that local populations will become enrolled with a health care provider organization, which will offer a comprehensive range of services (King, 2001).

\section{The local experience}

The demographic changes during the decade from 1990, plus the introduction of a population based model for funding health care, resulted in pressures to reduce services at the base hospital of Balclutha and other neighbouring service areas. Most controversial was the withdrawal of surgical and anaesthetic services, which enjoyed iconic status within the community.

Maternity services were also affected by the changes. The loss of elective or emergency cesarean section reduced the number of women choosing, or being deemed safe candidates, to birth locally. Thus for the period between 1993 and 1996 the number of births at the hospital declined from 117 in 1993/94, to 74 in 1995/96. However, the establishment of an independent midwife option saw the number of home births in the area increase, from one to nine (Unpublished Resource Utilization Data, collected by Balclutha midwives, 1996). 
For rural areas, the perception and the importance accorded to maternity services is dependent on the makeup and vision of the populace plus to some extent, the media both local and national. Women of childbearing age are the consumers of midwifery care and in South Otago this group represents a decreasing demographic in the community. These younger, rurally based women, although frequently active in local women's groups, rarely sit on local bodies, and are not actively sought out for comment by the media. Thus they are not around the table when maternity services are planned, making it difficult to sustain vigorous support for a range of maternity options. This is particularly so in sparse and aging populations whose main health and social concerns lie elsewhere.

\section{In summary}

The revolutionary changes of the 1990's have their genesis in the deregulation of the New Zealand economy in the 1980's, and health care services were not spared exposure to market forces. Midwives, having fought for and regained their ability to practise autonomously and claim for their services on an equitable basis, were caught up in this competitive model. Subsequent negotiations with funders over the payment schedules were fraught resulting in distrust and friction between doctors and midwives and among midwives themselves. A more moderate pace of change followed the Coalition Agreement in 1996, which advocated more health spending. Rural communities were beginning to organize and discuss future options for their health services. The South Otago community had been experiencing a steady decline in population and poor commodity prices for primary produce. In addition, they saw their hospital close and several services withdrawn. Maternity services remained but were under pressure from the funding constraints. How these changes were played out in the local community is explored in Chapter Five through an analysis of the local newspapers. 
In the next chapter, a journey in postmodern and postmodern / feminist ideas represents my search for theory to help explicate these complex and unpredictable changes and identify what, if anything can influence or mitigate their impact. In particular, the ideas will be related to the practice of midwifery in rural areas and to my intent to conduct research into rural midwifery practice. 


\section{CHAPTER THREE: IN SEARCH OF A THEORETICAL FRAMEWORK FOR THIS STUDY}

\section{Introduction: Getting started on the postmodern merry-go- round}

This chapter represents my pursuit of a theoretical framework for this project, in the hope of finding some insights into the changes my colleagues and I had experienced and thereby some opportunity to strategize for the future. I approached the literature with three broad questions. Firstly, what does a postmodern view of the world entail? And, secondly, what is the impact for women, and feminist research in particular, of a postmodern theory of knowledge and power? Thirdly, how can such a framework support me to design and conduct a study into rural midwifery practice? What follows is an account of my ride on what felt like a postmodern merry-go-round. I look first at the emergence of postmodernism then explore some of the main ideas that have contributed to the debates, and influenced research methodologies. The work of Lyotard is explored in some detail, as his overtly political ideas, I thought, may prove useful in my area of research. For feminists there is an inherent political imperative, which drives and informs their work. And while postmodernism opens some doors of opportunity, it also poses challenges to what feminists have worked and fought for. In particular, I look at the issue of subjectivity, gender, and the notion of feminism's role in regard to the critique of social and political phenomena.

\section{Stepping into the unknown}

The idea of postmodernism is fascinating, and challenging, rather like a giant jigsaw puzzle without a recognizable shape or boundary. It involved for me taking a step into the unknown and then choosing to structure what cannot be structured, and trying to capture a little of what, by definition, cannot be 
captured. Thus I chose to leave all the doors ajar- selecting from different theories where I felt there was some resonance with my project.

Butler (1994:153), asks, [w]hat is postmodernism? Is it a theoretical position or an historical event? Do we become postmodernist or are we so named when we debate "the subject", analyze discourse, or question, "totalising social descriptions." Thus, the search for some sense of what postmodernism is, or is not, demands at least a dip into the history of both modernism and structuralism, out of which postmodernism (and postructuralism) have arisen.

\section{Post structuralism and the end of the modernist dream}

The architect, Jenks, claims that the word modernism was first coined in the third century. However it is generally accepted that the modernist period in the history of the Western world, emerged in the 18th century (Appignanesi \& Garrett, 1989). Habermas, according to Harvey (1989), suggested that the project of modernity came into focus in the 18th century with the enlightenment, which resulted in the pursuit of human emancipation through objective science. In this period liberation from oppression was also promised by the theories of universal laws of morality (Harvey, 1989).

Postmodernist ideas began to emerge and flourish toward the end of the 19th century. The modernist dream was already being challenged and cracks began to appear in the explanatory power of the grand theories (Harvey, 1989). Positivism, which since the enlightenment, consisted of a binary logic of subject, objects and a linear teleological rationality, was also challenged with quantum physics making these concepts problematic. For instance, elementary particles have turned out to be more elusive than was once thought, and new developments in mathematics suggest that there are serious limits to our 
scientific knowledge, making truth increasingly complex, if indeed it exists at all (Heisenberg, 1991).

\section{Postmodern notions of representation, power and history}

\section{The arts}

Throughout history, the arts are frequently the most visible indicators of change; the emergence of new ideas, finding expression in all media. Tomlin (1999) describes the impact of postmodern ideas on the traditions of art.

It is a period where opposites, being equal cancel out any attempt to describe what cannot be described and where dissenting views all hold equal value...anything can be art and anyone an artist. It's a time of fashions, of rapid success and oblivion. (Tomlin, 1999:1)

Architects in the modernist period had discarded the ornate decorative styles of the past and developed the banal functional designs that marked the modernist period. These are now being replaced by a mix of styles with the addition of whimsical touches that challenge traditional notions of how a building should look. And just as the early impressionists broke the rules about color, perspective and form, artists in the 1960 to 1970 period began experimenting with new art forms including junk sculpture, earth and kinetic works (Appignanesi \& Garrett, 1989). Today, the effect of globalization threatens the artistic cultural traditions of nations and their indigenous communities. What were designs and styles bound to a cultural tradition are now being appropriated and mixed with other images resulting in a fusion effect.

Theorists, who challenged the 'taken for granted' ideas about art, language, truth, morality, and scientific objectivity, did not necessarily describe themselves as postmodernists, or their ideas as postmodern except perhaps Lyotard. The themes that recur within the writings of those philosophers and historians deemed to be postmodern focus on areas of representation. These 
include visual and textual forms; plus discourse and language games, with all of these elements linked to power dynamics. In addition, it is suggested that this combination of human interaction and communication affects how we read, construct and interpret our history.

\section{Language and texts}

In this work it is the language and texts that will be used as data sources and it is these elements that are seen as the vehicles that shape and create us. Derrida (1995) suggests that, language, has within itself all that is necessary in order for its own critique. Therefore, in order to examine current theoretical constructions, Derrida proposed a process of deconstruction to help uncover what was hidden (Appignanesi \& Garrett, 1989). In relation to written thought, Derrida saw that understandings of opposite terms, such as man versus woman, are always viewed hierarchically. So while language can be scrutinized with regard to its manners and culture- in other words custom and grammatical rules, it is the history of the concepts that can reveal more about its nature (Derrida, 1995). Thus in this study analysis of the language used must be viewed within the culture and the historical context if it is to make any sense.

Science according to Sarup (1993), also relies on our language in order to explain and promulgate its findings. Thus, scientific texts cannot claim to be pure and objective as they rely largely on metaphorical or rhetorical devices to convey meaning to the reader (Sarup, 1993). Therefore, construction of a truth and how the world is, is the product of our language and texts. However when rational thought is deconstructed in such a way as to reveal these hidden constructions, no firm result or interpretation can be reached. Rather, we are left with a fluid mass of different interpretations. So if Sarup's contention is right, then any construction arrived at will be at best a partial explanation. 


\section{Signs and symbols}

This deconstruction, Baudrillard (1997) applied to signs and symbols, which he saw as the concealed images of how we view our social reality. Baudrillard played with the notion of the simulacrum, a semblance, or make-believe image, which he illustrated in four, slightly changed, phases. The first was a realistic image, which was progressively distorted until the fourth image is unrecognizable as a derivative of the first. This, he argued, showed that there was no difference between reality and simulation. Our hunger for such simulated reproduction or, events, meant that the origin and context of these 'signs' would be distorted to such an extent that reality could not be distinguished from fiction (Sarup, 1993; Sim, 1999) - possibly the theme parks of our daily communication.

To simulate, according to Baudrillard (1997: 3), "is to have what one doesn't have." Even history does not escape and is seen as "...a lost referential, that is to say our myth"(p. 43). Signs and symbols have come to stand for objects and commodities. For instance, international signs or symbols are everywhere and are instantly recognized as representative of complex entities. Similarly, there is no escape from the fictional sense of public opinion, which has been moulded by such images.

For Baudrillard, any revolutionary act is doomed to failure as we are only left to play with the pieces or images that have been distorted and packaged for us. Thus, “... [life], is more a survival among the remnants than anything else" (Denzin, 1991:31).

\section{Of history and power mechanics}

This research project is set within an historical context, but if Baudrillard is right and we are only left with pieces and semblances, then any notion of 
historical certainty cannot be claimed. According to Foucault (1972) history was a myth if viewed as a series of connected events. He believed that there was discontinuity and "refoundation" with historical documents being used to rearrange and redefine history. Such activity meant that historians could not continue to preserve the privileged nature of history or assert that it is living and continuous. Rather history should be viewed as a "plethora" rather than a totality (Foucault, 1972:6-14).

In examining major historical events that had profound effects on the social arrangements of their day, Foucault traced back to a place where he believed there was a significant change or difference (Sarup, 1993). In this work he explored the histories of major social institutions, which he labeled as particular discourses, with specialized languages and power networks (Sim, 1999).

In later work, Foucault attempted to analyze "discursive practices" in order to see how they revealed knowledge and how such knowledge was linked with power. It is this linking of language with how knowledge is constituted and promulgated that is of interest in this work. Power was seen as having a special purpose. Laws and rules are maintained "...through [a] network of power relations" (Cox Dzurec, 1989:71). Therefore, knowledge about rule boundaries can endow a person with power, and prior knowledge about a power shift or, a change of rule or law, can constitute power. Individual ignorance and secrecy about the operations of power/ knowledge therefore allows power to be maintained. The compliant are rewarded and power becomes invisible and efficient (Cox Dzurec, 1989).

Thus for Foucault, power was not conceived of as the possession of an individual or an organization, but rather a network with threads extending everywhere. It was not a repressive or prohibiting tool, but one that is used to 
create new knowledge. Thus knowledge induces power, and power induces knowledge. Such power extends to every aspect of our "....social, cultural and political lives," not so much to punish and sanction but rather to persuade individuals to "internalize the norms and values that prevail within the social order" (Sarup, 1993:74). How such norms and values are constructed, then privileged, is also of significance for this study. The question for me is that if such opportunities exist to exercise power in every aspect of our lives, then, how is it that the preferred norms and cultural preferences of others can marginalise groups and individuals?

\section{Lyotard: Changing the rules of the game}

A possible understanding is suggested by Lyotard, who also saw power as "decentred and plural," and believed that resistance likewise must have multiple forms (Best \& Kellner, 1991: 56-57). However in contrast to other theorists Lyotard (1997) attempts to locate the emergence of the idea of "the postmodern" to the 1950s. He believed that the game rules had changed for science, literature and art and that there was a need to break with modern theory and methods as a way of furthering knowledge or making any claims to truth. In response he proposed a "plurality of discourses and positions against unifying theory" (Best \& Kellner, 1991:146-7).

\section{The politics of desire}

Lyotard's ideas began emerging in earlier work where he concentrated on the politics of desire (Best \& Kellner, 1991). This he saw as a disrupting and subverting force present in both life and death. He viewed such a force as necessary for liberation and creativity. This creative and liberating force was bound and structured by language rules, paralyzing and inhibiting the flow and intensity of desire; language being the vehicle defining and determining all phenomena. Such pantextualism saw the body and art as its binary opposites and therefore not equally valued by the society (Best \& Kellner, 1991). To 
showcase desire, Lyotard advocated the use of provocative art and music, such demonstrations being the micro politics of desire. However, these earlier ideas were in later works, "swept forward" and joined by a politics of justice, where he "proposes new guerrilla strategies of discursive skirmishes and raids" (Best \& Kellner, 1991:159). But as we are unable to imagine not being part of the hegemonic discourse, the only way to effect change is to occupy and destabilize such discourses, using the rules and tools open to us. Thus, we do not change the macrostructure but seek justice in a multiplicity of instances (Best \& Kellner, 1991).

Enter "paganism", which equates with a notion of anarchy, representing the particular moves or ruses used by those who wish to challenge and disrupt the dominant language games. In this context, paganism manifests as a concern for justice (Sim, 1996:61). The validity of such pagan discourses is always limited to context and "case by case" strategic interventions that are locally based and specific to the particulars of the situation (Best \& Kellner, 1991:160-1).

\section{The postmodern condition}

Lyotard (1997), limits his postmodern condition to a critique of modern knowledge, which he suggests, consist of metanarratives, which support and legitimate the claims of the dominant narratives, thereby excluding others. Such metanarratives subscribe to a common epistemology and moral perspective. Postmodern knowledge, by comparison, opposes such metanarratives as well as the grand schemes of legitimation. It promotes instead, heterogeneity, and plurality with innovative, pragmatic constructions, that are locally based, with agreed rules and prescriptions (Best \& Kellner, 1991).

\section{Language games}

In exercising the power of language, Lyotard (1997) suggests that messages are passed through individuals or nodal points. They are not simply handed on as received but in a form that reflects the position, history and processing of the 
individual. These games or discursive practices form the social bonds between people, and it is the social positioning of these 'handers on' of messages, which determine how the message is received, recounted and handed on to others. Thus the self according to Lyotard (1997:15), exists in the postmodern world as a complex and mobile "fabric of relations." So it would seem that while power is everywhere and can be exercised through the construction of knowledge by the vehicle of discourse or language games, it is the complex cultural norms that determine who can speak and when.

Knowledge in the computer age

However, in this computer age it is impossible to be unaware of the explosion and accessibility of information technology in the world today. Lyotard saw this phenomenon as the catalyst for major change in regard to how we perceive, value and transmit knowledge. He believes that what cannot be translated into computer language will be abandoned. Thus the ubiquitous use of computers means that the packaging of knowledge statements will have a particular prescription consistent with the way in which computers work. This computerized knowledge will become a commodity to be bought and sold and not necessarily related to training. Such technology will extend the gap between rich and poor nations with future wars over knowledge rather than resources (Lyotard, 1997).

\section{Legitimation and Performativity}

Lyotard saw as fallacious, the notion that knowledge is continuous, periodic, discontinuous or conflictual. Scientific knowledge cannot represent all knowledge but it exists in addition to and competes and conflicts with, narrative - this being “...the quintessential form of customary knowledge" consisting of stories, myths, legends and tales (Lyotard, 1997:7).

Scientific knowledge with its demand for legitimation is contemptuous of narrative knowledge, but the dilemma for those promoting a scientific narrative 
is how do you prove the truth? And how will the truth be dispersed? Science therefore needs the vehicle of the narrative to explain and disperse their ideas (Lyotard, 1997).

To sell an idea, the language needs to be appropriate to both the seller and the buyer and this is where technology comes in. It demands the least energy expenditure to achieve efficiency. This efficiency Lyotard saw as a defining principle, though he defined it in terms of performativity (Lyotard, 1997).

Paralogy

Information however can never be complete. There are limits on precise control, and postmodern science is awash with paradox and pragmatism. The raison d'être for scientists however is the generation of ideas and stories, and they are duty bound to verify them. But Lyotard contends that "consensus is a horizon that is never reached" and that it is not possible, nor prudent, to follow the search for a universal consensus, as such agreement is only part of a discussion and not an end in itself. Contrarily, its end is paralogy, where the everyday language games are played out, to achieve, or not achieve agreement, and frequently, to change the rules of the game (Lyotard, 1997:61).

Lyotard argues that we have moved beyond the need for grand narratives to an era where pragmatism can operate. Little narratives have the opportunity to flower without the threat of grand narratives "....seeking to extend their imperialistic authority" (Sim, 1996:45). However it cannot be thought of as a period of calm co-operation, but rather one of agonistics, or conflicts, which Lyotard saw as creative games of move and counter move. And while this is an attractive picture, how this fits with the stronger performativity narratives of major and sometimes minor institutions, is hard to visualize. 
Benhabib (1990:122), sees Lyotard's position on knowledge as a "vague neoliberal pluralism" or "contextual pragmatism" that is devoid of social critique and criteria against which to validate the discursive processes he proposes. Denzin, (1991, 39-41) agrees and suggests that Lyotard's explanation fails to create spaces for universal principles, or for the voiceless. Paralogy for instance, interpreted, as heterogeneity and paradox, would preclude any consensus ever being reached. Moreover, Lyotard's own account, of the collapse of metanarratives, is itself a metanarrative.

\section{On acting locally}

Both Foucault and Lyotard alluded to the "local" as the points where marginal discourses could be identified. These were the locations of resistance, or the genesis of alternative discourses which could either resist, or organize to challenge, the dominant ideological ideas (Foucault, 1972: Lyotard, 1997).

But what does local really mean? The term is an amorphous and vague concept and such a place is difficult to pin down, as no pure state exists. It is rather, according to Probyn (1990:187), "a fragmented set of possibilities that can be articulated into a momentary politics of time and place." Therefore, if local is to be used as a starting point from where deconstruction might begin, then the definition of the term must come from the incumbent. In other words the person/ researcher must define their locality in terms of both the physical and political environment/s.

In terms of this work the notion of local is a central theme. The project is small and local, focusing on a group of midwives within a matrix of competing and conflicting discourses. The participants reflect not only their collective histories and experiences but also their social milieu. Therefore such micropolitics would seem strategically useful 
Thus, in summary, postmodernists are suspicious of the truth claims of all forms of representation and history, whether this is in text, the spoken word, or in other representative media such as symbols and signs. The mechanisms by which power is exercised and institutions maintained are suggested to be that of narratives or discourses. Where dominant discourses are aligned with major institutions, the power becomes invisible. Change can be affected as marginal and oppositional narratives arise and challenge the metanarratives. Such challenge according to Lyotard (1997), perversely contributes to the performativity or renewal of the dominant narrative. To effect change, small, local petit narratives are advocated. How these postmodern ideas contrast with, or can contribute to, the aspirations of feminists is explored in the following section.

\section{A Place for Feminism in A Postmodern World?}

The fate of an epoch that has eaten of the tree of knowledge is that it must recognize that general views of life and the universe can never be the products of increasing empirical knowledge and that the highest ideas, which move us most forcefully, are always formed only in the struggle with other ideals which are just as sacred to others as ours are to us. (Weber, [n.d.] cited in Harvey, 1989:1)

Weber's words convey for me the sense of the decade of the nineties as a time of forging and tempering for those of us who struggled to provide midwifery services within the maelstrom of constant change. We found ourselves digging deep to find what areas of our work were important to preserve and what we could give away. There was also the realisation that other practitioners and management staff were caught up in the changes and likewise were reappraising their priorities. Part of this for me was the need to revisit my feminist roots with new eyes. 
Sarup (1993: 156), suggests that "feminism and postmodernism have emerged as two of the most important political - cultural events of the last decade," with both offering criticisms of philosophy with respect to the larger culture. The dilemma in reading much of the debate around this issue, is that while many writers seem to be describing what it is that they believe the social organization to be, there is entangled within, the drive to say how it could, or should be transformed. In feminist writing, these descriptions and prescriptions are interwoven, and it is this very political imperative that at first blush makes the combination of postmodernism and feminism appear to be very unlikely bedfellows.

But feminist thought is neither simple nor universal, even if it is almost always political. And it could be viewed as inherently postmodern because of its challenge to hegemonic narratives. But the hard won notions of subjectivity, gender difference, plus the hope for a more just future, appear to be put at risk if feminism embraces the postmodern too eagerly. Equally, feminists are motivated to avoid the pejorative, 'grand theory' label, which suggests an inability to adapt to new realities or tolerate scrutiny. Thus, there is a move to explore how a postmodern feminism can be forged, that is open and curious, while at the same time remaining vigilant for opportunities to contribute to a fairer society.

\section{Feminism as a postmodernist narrative}

With postmodernism questioning cultural certainties, including the possibility that the world and its contents are ultimately knowable, no certain way is left to judge history, truth, legitimacy, morality, subject or object. Thus, according to Sim (1999), if a postmodern perspective is adopted, the hope for an objective and understandable world cannot be anticipated. Which leaves us with texts created from partial perspectives, which according to Lincoln (1997:39), may be "...the best we can hope for." 
Yet, despite these assaults on what would appear to be the tenets of feminism, Flax (1990:41 -2) suggests, that, “...feminist theory more properly belongs in the terrain of postmodern philosophy." Postmodern discourses are all deconstructive and skeptical of beliefs concerning issues of truth, knowledge, power, subjecthood and language; all of which serve to legitimate our “contemporary Western culture.” And Sim (1999:7) agrees, “...feminism can also, be included under the heading of poststructuralism, in that it questions the supposed rigidity of gender categories." However, it would seem that some feminist thought can be equally rigid with regard to such categories.

Optimistically, McRobbie (1994:72-3) suggests, that - "Living across the fault lines of the postmodern condition might also give us reasons to feel cheerful". In this position, feminism is able to create discourses that can dispute and negotiate barriers and boundaries. This is reminiscent of Lyotard's idea of many language games, which give rise to institutions in patches. This local determinism may not endure, as other language games, or discourses emerge, and gain ground over time. Therefore, they become a stage in the discussion, and not the end; thus there is no possibility of a universal consensus (Lyotard, 1997:66).

\section{The implications for knowledge and research}

\section{Of gender and subjectivity}

Lather (1991:105), says that " ....all researchers construct their object of inquiry out of the materials that their culture provides, and values play a central role in this linguistically, ideologically, and historically embedded project that we call science." Part of this linguistic creation, are notions of subject and object. These socially produced entities can be constituted, reconstituted, renegotiated or 
remapped by language becoming "linguistically transformed representations" (Lather 1991: 21).

The anxiety for feminists is that postmodernism as a new master narrative could marginalise all that has been achieved. If postmodernism is to be embraced by feminists then gender becomes problematic, in that it is also up for deconstruction. Similarly, subjecthood could be lost if gender is abdicated with the risk that such a place of "nothingness" could be assumed and occupied by, dominant others (Thornham, 1999: 47-49).

But to deconstruct, according to Butler, (1994) is not to dismiss the idea of the subject, but rather to open up and question the term. Similarly McRobbie (1994:69), suggests “...postmodernism doesn't mean, that we have to do away with the subject but rather we ask after the process of its construction." For midwives it would seem that such a deconstruction would shake the foundations of our identity. But if we are the product of discourse and texts, and not some historic and unalterable product, then it would seem that continuation and regeneration is similarly achieved.

\section{What of the feminist project?}

If the building blocks of subjectivity and gender are removed, what then of the feminist project? While some feminists embrace the notion of postmodernity as a liberating opportunity, for others there is a great sense of anxiety as they see that the job of feminism in challenging the dominant ideologies will remain unfinished, in the same way that the enlightenment project has been abandoned.

\section{Issues of power for the marginalised}

Postmodernists discount critical theory as being too grounded to reveal 'truth'that is, not critical enough. But for marginalised groups it seems they just get to be subjects after a history of objectivity, only to lose out when subjectivity 
itself becomes problematic (Traynor, 1997:102). The postmodern vision according to Harstock (1990), is a dangerous approach for those in marginal positions.

It is tempting to suggest that midwives in rural areas are marginalised in relation to their urban peers and some other health professional groups. But the issue of power and empowerment are not simple and can be multilayered, fractured, changeable, and socially situated. For example, some women, because of their ethnicity, social or economic position experience power differently in some situations (Alice, 1999). And according to Lather (1991:111), postmodernism argues that no discourse, and this includes feminist, is innocent of the "Nietzachean will to power," as language is both the creator and carrier of our knowledge and truths. Thus, the logic of postmodernism appears to be that language creates the social reality, rather than reflecting it, thereby denying any possibility of an independent reality.

Best and Kellner (1991), pose the rhetorical question. If Foucault is right in suggesting that power flows through all the capillary levels of society, being taken up only subsequently by larger institutional structures, then, changing the form of the state, production modes, or the composition of society, will not address the flow of power. In other words, if power is so decentred, then a change in the structures will not make a difference, and all forms of political struggle would need to be both local and plural. This idea would suggest that the very marginality and local nature of the midwives' practice could be viewed as a strength that can be exploited for political aims.

\section{The feminist imperative to act}

The dilemma is how such local action can be sustained without a strong narrative with which we can identify. While feminism must be seen as primarily a social and political force, with the aim of changing the relations 
between men and women, all women do not experience life and opportunity in the same way. While gender plays a part in our histories, our social realities differ dramatically, as do our opportunities to act in our own interest. We inhabit different spheres so cannot speak for all. In effect, we can have only partial knowledge (Thornham, 1999). There is however a danger of drifting into a state of relativism as a defense against doing or researching anything that might be considered partial. However, deconstruction and postmodern arguments can disconcert opposition. McRobbie (1994:69-70), implies that "Its [opposition's] disorderly face is rude and impertinent in that it shows where power resides, hidden and quiet, and displeased at being exposed."

This quote evokes for me the memory of winkling crabs out of the holes beneath the mangroves. It was exciting until the crab emerged with its nippers raised and we had to run to save our bare feet. Fear is experienced at the thought of disturbing a powerful influence, but our reluctance ensures that the status quo is maintained, never knowing what might have been possible.

\section{Reflexivity}

There is also a requirement in the postmodern era, to critique ideology and the research approach itself. Lather (1991: 80), believes that we need to be subject to this reflexivity using such emancipatory tools as the "reversal of knower and known." However such reflexivity doesn't simply mean to reflect on, but is a continuous critical consciousness of what one is doing, thinking or writing. Thereby continually evaluating our own contribution to either domination or submission (Traynor, 1997:102).

So there is a tension here between passion for our causes and our desire to avoid the pitfalls of partiality. Appignanesi and Garrett (1989:73), warn us that reflexivity can slide inexorably into "politically correct hypocrisy." This may prompt us to ask the rhetorical question, "why do social research?", particularly 
when arguments about what is good, true or just, cannot be engaged in across cultures (McRobbie, 1994:65). However, if our anxiety about slipping into such traps causes us not to do social research, then there would be no counter for the determinations of sciences that avoid grappling with the complexity that is the stuff of our daily lives.

Traynor (1997:106), in acknowledging the end of the grand narratives, suggests that this leaves us with "no grounding or privilege," but with the ability for "trouble making." Not to emancipate or assume to liberate the oppressed, but rather to "cause trouble [for those] whose version of truth and rationality have achieved domination over others." It is simply the freedom to "play" and to argue our case with passion. This notion of play aligns with Lyotard's idea of "svelteness," that is a flexible, nifty and "metamorphic capacity" (Sim: 1996:97), with a "swarm" of narratives causing those proposing totalising solutions to stop and think. Thus an irritant, which might be antagonistic or pragmatic in turns, but always, seeking to undermine the authority of the grand narrative.

\section{A brave new world? Or, history repeating herself?}

Is is possible that postmodernism become its own grand narrative?

Overall, postmodern philosophy is to be defined as an updated version of scepticism, more concerned with destabilising other theories and their pretensions to truth than setting up a positive theory of its own; although of course to be sceptical of the theoretical claims of others is to have a definite program of one's own, if only by default. (Sim, 1999:13)

Jameson (1991), also is skeptical as to whether postmodernism exists at all; suggesting that it is possible its proponents are unaware of history and therefore unable to appreciate the unfolding of its events and teleological nature. Furthermore, if there is to be postmodernism, it should come at the end of modernism, not the beginning, as this could result in " $\ldots$ the mischief of premature clarification" (Jameson, 1991:xxii). 
It would seem that even Lyotard, who claimed to be postmodernist, viewed cultural history as a series of cycles. Modernist eras were followed by postmodern ones, somewhat like a pendulum effect, where the postmodern was a preparation for the next era of modernism, albeit with some changes more relevant to the new age. Thus, the changes in thought and behaviour today are but one of those cycles (Sim, 1999). And these cycles, Spencer (1999:169) cynically suggests, "are driven by the mandarins of a commercial culture, in order that they, and others, might turn a profit."

Harvey (1989:358) warns that there are serious "cracks in the mirror of postmodernism." There is fusion at the edges that suggest that postmodernism may be evolving into something different, but what? For instance, the very nature of the postmodern instability could yield to a new romanticism. This possibility, the author believes, would be more sinister than a return to modernist ideas where at least some ethical content could be expressed; possibly some unity with difference; or even a return to the project of the enlightenment, albeit with greater understanding.

Eagleton (1996:ix), in his critique of postmodernism, purports to walk us through the postmodern ideas. In leaving modernism behind and working through to a position of pre-postmodernism we "...come out roughly on the side where it started, which is by no means the same as not having shifted at all."

\section{The contribution of these ideas to the study design}

Like standing in front of a strange and captivating piece of sculpture. As I slowly walk around it each facet casts the light differently, plays with the shadows and by the time I start around again to confirm my perceptions it has changed again. Reading around the ideas of postmodernism has the same effect. I just think I have a handle on it and then I read another idea or conception, and I have to go around again. The dilemma is when to stop and move on accepting that the job is and 
never will be complete- or is it one of Bauldrillard's simulacra, an illusion of itself and making a fool out of me. (Journal entry, January 2001)

The essence of the postmodern argument is that the dualisms and structuralist theories, which have dominated Western thought since the enlightenment, and throughout the modernist period, are inadequate for understanding and explaining our complex world. Further, the causes and effects that make up, our day to day existence, are rooted in a non-linear history, replete with multiple cultural variations and understandings.

The rules of art have been the most visible signs of change. But all grand narratives and structuralist theories have come under the postmodern lens. Derrida (1995) developed deconstruction as a strategy to unravel texts and expose the ambiguity of language, concluding that clear understanding and interpretation was not possible. While Bauldrillard (1997), focused on signs and simulations and demonstrated with the notion of his simulacra how such signs have become progressively distorted so that the final representation no longer resembles the original. For Foucault, (1972) discursive practices and speech acts reflect the historical genesis of beliefs and claims to truth. Intertwined with such discourse is the idea of power, which flows through all levels of society and is taken up only subsequently by institutions. Thus, "Foucault exposes the links between power, truth, and knowledge, and describes how liberal-humanist values are intertwined with, and support technologies of domination" (Best \& Kellner, 1991:69). Lyotard (1997), in reviewing the condition of knowledge in the modern world, considered that society is made up of a series of metanarratives, which compete for legitimacy within this technological age where knowledge, is the commodity most in demand. His answer is paralogy, or the toleration of multiple language games. The proponents would act locally 
in a just cause, but could only be successful if they have access to the contents of the databases so that full information was available to all.

In relation to this project, postmodern ideas cast suspicion on all forms of representation, making all findings contingent. Thus, any exploration of data requires the understanding that the everyday discourse is replete with potential power plays. How this social bond is played out between the midwives and their community, or, between the pages of the newspapers has the potential to underwrite, disrupt or displace the language games of others. Such seemingly common language, if the postmodernists are to be believed, creates and shapes our beliefs with regard to how the world is, and also how such texts might act as a mechanism for inventing, sustaining or destabilizing hierarchies.

This power/ knowledge connection partially explains why those with access to information can define norms and thereby exert control (Foucault, 1972). An example might be health management denying imminent policy changes thereby circumventing the possibility of adaptation or revolt from those directly affected. Such a position suggests discourse constructs our social realm and casts doubt on questions of theory, research and history. In addition, traditional notions of object, subject, truth and rationality are exposed as social constructions manufactured and maintained by complex linguistic and power relations. Therefore, the search for new knowledge in these fluid and unpredictable times needs to incorporate and reflect the confounding notion that what we are, believe and do, is socially constructed. Therefore, researchers need to tread the tightrope between making sense of the phenomena they study, while constantly critiquing and reflecting on the process. In addition, this requires that we avoid the trap of making all things relative or resorting to despair and nihilism. 
Such uncertainty poses a dilemma for feminists whose reason for existence is to challenge and unsettle the dominant discourses that deny an equal place for women in the world. With the demise of the subject, and gender contested, feminists are divided on whether a postmodern feminism will serve the cause any better than did modernism. But increasingly the divisions within are forcing a rethink of what can be claimed as a common cause or reality. So cautious support is given to the possibilities of local actions against social and political domination.

The project under study is a discrete area where local issues predominate against a background of national change. It is possible that a postmodern/feminist view of the world can offer some ideas of strategic positioning in the situation where dominant discourses prevail at the expense of marginal ones. For the participants in this study, there may be opportunities to change the narratives that are passed on to others, and perhaps, as Lyotard suggests, develop the 'petit' narratives that serve to worry and discomfort the prevailing metanarratives.

While the apparently awkward alliance of feminism and postmodernism could provide a good tension for the exploration of midwifery narrative and experience, Thornham, (1999) fears that postmodern theory will appropriate feminism, thereby effectively silencing the collective voice, and the aspirations of women. For rural midwives in New Zealand, a feminist and collective voice has been seen as important in their quest for autonomy. Moreover, as an historically female profession whose work is about women, feminism contributes a social critique of gender relations, which might otherwise be lost in a sea of postmodern relativism. But an analysis of the discourses might provide some insight as to how such gender relations, and arguments of 
efficiency, affect the midwife's ability to articulate their difference, which is seen as the defining ingredient in their practice.

In a postmodern world, history cannot be viewed as a privileged and separate entity, but rather the recording of selected knowledge or narratives by those who had the power to name what should be included, or, excluded. This project is a mix of historical review and personal narrative. It is therefore subject to the same strengths and weaknesses as any other account, which relies on the constructions of others; overlaid by the predilections and constructions of its author. So I am mindful of this as I move into exploring the methods I have chosen, and the design of the study. 


\section{CHAPTER FOUR: STUDY DESIGN}

\section{Overview}

For this project, I interviewed five midwives and subsequently hosted them in a focus group session. The tapes and transcripts were then analyzed with a view to exposing the discourse positions of the midwives. In preparation for the interviews, I studied the complexities inherent in attempting to capture the voices and ideas of participants. Davidson and Tolich (1999), offered helpful advice about the questions to ask, while Lather (1997), explored the complexity of capturing paradoxical ideas. The focus group session, however, demanded a different approach so for this I depended largely on the advice about process offered by Krueger (1994), and Albrecht, Johnson and Walther (1993), for advice on facilitation. In addition I read the 1990 - 1999 copies of the Clutha Leader, which is the local newspaper for the South Otago area. The texts were analyzed for items about the changes in health care funding and delivery. These comments and statements were then explored using Lyotard's (1997) ideas of language games.

\section{Methodology}

\section{Capturing conversation and voice in text}

Words are the 'tools', with which we construct new knowledge in qualitative research. They are the medium with which we express relationships, our feelings, beliefs, aspirations, and ourselves. However such data is context bound as "...people live their daily lives in the moment, yet they also remain connected to their past, and hopeful for their future" (Roberts \& Taylor, 1998:272-3). Thus, the captured data are not just snapshots in time but are living moments that are at once past, present and future, with the slipping and sliding of ideas and constructions. 
In social research, according to Davidson and Tolich (1999:138-142), the quality of the data is dependent on the quality of the questions asked. They suggest that the first question should ideally be broad and open, with the subsequent questions and prompts, or "seat-of-your-pants questions," inserted when appropriate to focus on the research area. Therefore, in order for the participants to be able to talk freely, closed or leading questions should be avoided at the outset. Capturing a living, breathing, practice reality within the confines of text can be difficult, so Lincoln (1997:40), suggests that the researcher "start the voice," but allow the participant/s to complete the journey from the margins to the centre.

It is this approach I pursue in the interviews with the midwife participants in this study rather than a formal interview process. However such processes are rarely chronological. An interesting representation of time is captured by Mayes (1999:152) who, when studying the Italian frescos, observed that "...time collapses as it so often does in memory." The painter tells the story from beginning to end within the one scene. All the players are represented, and “...all time [is] eternally present." Time was also looked at by Polkinghorne (1997) who differentiated between the synchronic, or same time style, and diachronic, which moves through time. For example, practice is located in space and time with a temporary nature that can only be understood moment by moment, and not as a rational, linear process (Polkinghorne, 1997:10). Therefore, in order to capture more faithfully the nature of practice, as narrative, a storytelling format may be more useful. Such a style may enhance the validity of the writing and make the work more likely to be read by those whose attention we seek.

Lather (1997:234), while grappling with the complexity and the "web of paradoxes" for the women living with AIDS, decides to work with ".... broadly 
accessible multilayered weaving of method [that] fosters brooding about the issues." Thus, the texts of the women's stories are layered with excerpts from the author's research journal, unfolding the events not just in linear time, but also revisiting ideas, conversations and experiences. In this project I have chosen to adopt this idea as a way of recording my reflections on the process.

Lincoln (1997:40) also observes that we are not necessarily single persons but a "multitude of possibilities" who are revealed in different situations and contexts, with social "discursive conventions" ranging over the multitude of our social interactions.

It is therefore important how the researcher interacts with the participants, and represents the outcomes. Thus if this research project is to be co-constructed and evolving with the values and beliefs of both the participants, and the researcher represented, then both the process and the product need to portray these influences. (Ford-Gilboe, Campbell, \& Berman, 1995)

While voices can be captured on tape with all their freshness and spontaneity, the practical requirements for analysis, mean, that their words are converted to texts for the purpose of analysis. In this project, the objective is to uncover the discourses that the rural midwives use to construct, and make sense of their practice world. In order to look beyond the words I needed to explore the practical aspects of this process of analysis.

\section{Discourse Analysis}

Travel can reinforce the primitive urge to bring the new into the circle of the known. We see what we know how to see. If only we could recognize this [and] suspend the rush to judgement and compartmentalizing. (Mayes, 1999:178)

Language is, according to Hewison (1993: 223), central to "our understanding of the social world." It constructs and reflects what we perceive and experience as reality. Therefore, if discourse is the language that people use, then such 
language is much more than an exchange of information, or a system of linguistic rules. The patterns of thought, and the context, in which they are wrought, become the raw materials, which construct, and reconstruct the beliefs, truths and reasons, with which we maintain our relationships and institutions. In this thesis, I am interested also in how such language constructs, and or, maintains the dominant social and institutional narratives which influence how the midwives and possibly others, view and order their social position and practice.

\section{Discourse and power}

Foucault's 'discursive formations' were considered to be language statements that were inextricably linked in and around existing power relations within a particular given society. Thus in attempting to analyze such discourse the researcher would need to incorporate these contingent factors (Wetherall, 1999).

Gavey (1989) advises, that when analyzing texts, careful reading is required in order to discern such patterns and contradictions. By using a post-structural framework, Dickson (1990) suggests, that it is possible to indicate the types of discourse by inquiring as to how they arrived at the standard of truth. For example, how games of truth can take on a form of science, and can be used to control, or, how those who are the object of the controlling language and power games, exercise resistance. Thus, focusing on the themes of knowledge and power in the situation is different, from attempting to discern 'meaning' from the data.

In health research, Lupton (1992:145), saw that discourse analysis might help to expose patterns of thinking and add a linguistic approach to understanding the relationship between language and ideology. In particular such a process could explore the way in which theories define reality; such theories having power 
relations imbedded in their syntax, style, and rhetoric. In this work, I relate this to the way media and other public fora can set the agenda for how health issues are represented. Or, how professional groups, in this case midwives, define their role and area of expertise.

Rhetoric according to Davis (1999:162), can at times fail to describe what is actually happening in practice, describing instead what is assumed or desired. It can also be used to generate a way things could be. If this is said often enough and passed on within conversation new practice can emerge and fulfill the rhetoric. Such a pattern of discourse can shape thinking, thereby promoting a particular worldview whilst marginalising others. An example could be the rhetoric around safety and economics that surrounded the move to regionalise maternity services discussed in Chapter Two.

Powers (1996: 207) sees discourse analysis as a useful methodology for nursing inquiry. Not just for recording the rituals, ideas and practices, but also to capture the "conceptual and social conditions"; the assumptions made, and the effects of such discursive practices in the social world. A distinction is made between Foucauldian and feminist discourse analysis. In Foucauldian analysis there is a reluctance to assume "that oppression can be lessened" as power is likely to be simply rearranged into different patterns (Powers, 1996: 212). Thus, Foucault stopped short of statements recommending action fearing that they could be co-opted and become themselves repressive. In contrast a feminist discourse analysis inclines toward emancipation. Such a research process then requires involved, informed and willing participants, who participate with the understanding that a "preferential future" is possible (Powers, 1996: 212).

However in this venture Sarup (1993:97), asks if we can become "prisoners of discourse" never, knowing anything at all and with no option for emancipation? 
And it would seem that if we accept discourse as our whole reality, rather than a reflection of it, then there would seem little justification for seeking any change for individuals or their society. However, it would seem for me that a first step must be a better understanding of the complexity of the environment and social interaction. The danger of a hasty emancipatory plan may paradoxically end up meeting the purposes of the dominant discourse/s from which there was a desire to escape.

In this thesis, it is, the complexities of practice, timing and recollection, that I wish to explore and while an interview can capture a person's individual perceptions and ideas, we, are social animals. We work and live together within groups, adjusting to subtle verbal and non-verbal cues. So in addition to the interviews I have chosen to try and capture some of this group interaction and dynamic, in a focus group.

\section{Capturing conversation in a focus group}

According to Krueger (1994:6-7), a focus group is a “...carefully planned discussion designed to obtain perceptions on a defined area of interest in a permissive, non-threatening environment." Such groups may not necessarily try to reach a consensus or come to any decisions; rather their aim may be to elicit data in the form of insights, ideas, perceptions and opinions, without specific direction, whilst preserving freedom and spontaneity.

Communication in focus groups is not just with the interviewer but also between the group members. And as attitudes and perceptions are developed largely in social interaction, rather than in isolation, such a method of gathering data can be useful for research (McDougall, 1999). Holloway and Wheeler (1996) suggest that when these group dynamics work well, it can take the research in new and often unexpected directions. 
Shaw, Morrison and Peoples (1999:62-65) believe that the group action stimulates discussion and provides insights not achieved with other data collection techniques. Further, Kitzinger (1995:299-311) adds, that in a focus group there is also the opportunity to tap into other forms of communication, such as jokes, anecdotes, teasing and arguing. Thus "subcultural values and group norms," humour, consensus and dissent, can be identified.

\section{Group characteristics}

Group size according to Krueger (1994), should be small enough for everyone to be able to participate, yet large enough that there will be a diversity of ideas, perceptions and insights available. Morse and Field (1996), suggest selecting seven to ten participants who are homogenous and knowledgeable on the topic. Holloway and Wheeler (1996), also recommend that the participants have experiences and characteristics in common, suggesting that compatible groups are more productive. Though it is acknowledged that despite selecting for homogeneity, there may still be group hostility, domination and persuasion. In contrast Shaw, Morrison and Peoples (1999), favour a balance between homogeneity and heterogeneity in regard to the participants.

Regardless of the number or mix, for a group to be successful there needs to be according to Mc Dougall (1999), an atmosphere of trust, with confidentiality being a basic ground rule. Trust, however, may be difficult to achieve if others silence voices of dissent, or if there are members who seek to dominate; though on the other hand, more 'outgoing' members can help "break the ice" for shy members (Holloway \& Wheeler, 1996, 144-152).

Alice (1999:64) comments that, "the use of focus groups in feminist research has become more popular over the past few years. As a technique it produces considerable and often complex information in a comparatively short space of time." Group interaction is the focus of the session, with the participants 
challenging one another's viewpoints, rather than being directed by the researcher. However, researchers need to be cautious where the aim is to give voice to socially marginalised groups, and a balance needs to be struck between control and flow in such meetings (Morgan, 1997).

In this study as the participating group was already a given, there was no opportunity to select participants, or in any way to manipulate the size or composition of the group. In regard to community and occupational groups, Krueger (1994) suggests, that the history and social structure in such groupings may inhibit disclosure. There is also the tendency for the participants to focus on past issues and events rather than the subject under research. For example, when dealing with work groups who know each other well, as is the case in this study, it would be easy to miss cues and nuances that are known to group members, but not to the researcher.

As the facilitator I was conscious of the need to be able to think and listen at the same time. In Krueger's (1994:108) words, have a “...have a past - present time perspective throughout the discussion" (Krueger,). In addition I needed to exercise self-discipline in regard to my own opinions. These requirements posed an added challenge, as I was so familiar with both the participants and the area under discussion.

\section{Focus groups: Issues of Validity}

According to Krueger (1994:31) "Focus groups are valid if they are used carefully for a problem that is suitable for focus group inquiry." Thus the validity rests on the appropriateness of the method, plus the context and the conduction of the process. This suggests that a healthy skepticism is warranted as a variety of factors in the group, or the predilections of the researcher can influence the results. Results too are only generalisable with great caution, and then only to other similar persons and situations. 
In common with all research processes, the focus group is an artificial setting, which can threaten the validity of the data and restrict normal communication amongst members. Thus researchers need to, “...consider the entire episode of the group interview when interpreting focus group data" and be mindful that group responses and behaviours are subject to a range of social influences (Albrecht, et al., 1993:61).

In reflecting on these comments I anticipated that in the light of my relationship with and knowledge of the participants, and their knowledge of me, it would distort the nature of the conversation were I to change my demeanour. I therefore decided not to try to control either the interviews or the focus group in any predetermined fashion, but rather to engage with the participants in a way that was familiar and reflective of our shared histories.

\section{The Data Collection}

This section details the preparation and accomplishment of the data collection process. I also visit the issues of rigour and particular ethical considerations of this study.

\section{The midwife participants}

Since 1990 only six midwives apart from myself, have offered an LMC option for women in South Otago. Five of these midwives, who shared at least some of the years between 1990 and 2000, agreed to be interviewed for this research. They differed with regard to their midwifery experience, educational preparation, and the range of settings or countries in which they had practised. Some continue to offer this option, while others have moved on to other roles or taken time out for personal or family reasons. I chose to exclude midwives who have not offered LMC services, as their contribution to rural maternity services, while important, is qualitatively different. 


\section{Recruitment}

As I knew the midwives personally the initial contact was by letter to their home address. Because of our previous relationships and shared work roles, the first contact was arranged via a trusted colleague who acted as an intermediary to handle inquiries and pass on to me the names of those willing to participate. I was thrilled to discover that five, of a possible six midwives had offered to take part. I contacted them and arranged to meet for the interviews.

\section{The interviews}

Each participant who agreed to be interviewed was contacted by phone and a mutually convenient time was arranged for meeting and taping at their choice of venue. The interviews lasted between one and a half and two hours, and the midwives had ensured that we would not be disturbed. Four of the interviews were conducted in the midwife's private home, and for three of these I traveled to Balclutha, where I had previously worked. This helped me to re-set the scene in my own mind and be reminded of how far away it seemed to be from the city.

The interviews were informal and conversational in nature. Five broad open questions had been included in the recruitment letter (See Appendix C), and these were used as 'openers' or prompts during the interviews, where the topic/s did not arise spontaneously. These canvassed key experiences over the decade under study, remembered moments and experiences, special times and challenges, plus perceived influences on the individual's practice patterns.

A copy of the transcript of the interview was returned to the participant for checking. This was an opportunity to delete, add, or correct any aspect that the participant felt was warranted. 


\section{The Focus Group Session}

Following the completion and transcription of the interviews I planned a meeting of all the midwife participants for a focus group. A letter was sent to each participant with options as to a suitable day and venue. Also included was a list of the topics raised in the previous interviews (see Appendix E). These included previous education and training, the desirability of the continuity model of midwifery, constraints and demands of the role, the need for family and colleague support, plus the need for relief for professional development.

I had previously contemplated using an assistant to oversee tape recording and manage the environment, but despite the obvious benefits of having some assistance, I decided against it. A stranger, I felt, would change the dynamics of the group and possibly inhibit some of the discussion.

Preparation for the focus group session, included practical issues such as testing the venue for appropriateness and sound quality, plus back up tape recorder should there be a technical failure. The focus group session lasted about two and half hours and was followed by lunch. The tapes were subsequently transcribed and stored securely.

\section{Ethical aspects, concerns and issues}

My aim was to collect the data for this project while maintaining an ongoing relationship with my colleagues. These women have been my friends, colleagues and mentors over the years. So it was with some trepidation that I initially approached them to participate in my research.

Our work role relationships had varied. For instance, one I first met as a student on placement, while the others had been on staff while I was managing the maternity unit. I was concerned that the participants might feel some degree of coercion, or obligation to participate, or possibly agree out of a sense of loyalty. 
There was also the possibility that free discussion in either the interviews, or, the group process, might be inhibited because of our previous relationships, and that personal comments or controversial ideas might not be aired. I do not know what prompted their agreement to participate or influenced their responses, but I do know is that their generous contribution has made this work a living, breathing possibility.

My application to the Victoria University's Human Ethics Committee for ethical approval was granted with permission to proceed with the research in October 2000. In my application I had recorded my concern about the issues above and my decision to use an intermediary as the first contact for recruitment (see Appendix A).

Throughout this project I kept a research journal. It has been the vehicle of conversation with myself and records a rich mix of ideas, reflection, apprehensions, and celebrations, my confusion, irony, and resolve. It also tracks my decision trail, and flags the diversions, and changes of plans, which I believe, contribute to the trustworthiness and rigour of this project.

\section{Issues of confidentiality}

As this study was small, involving only a few midwives within a defined geographical area, it was not possible to guarantee that they would not be identified within the work. Their quotes in the text are numbered arbitrarily but the comments made are at times personal, so those who know the midwives may well be able to identity the speaker. Where the participant has referred to another person in the text by name I have represented this with a symbol, thus '*'. The tapes and transcripts have been kept secure in a locked filing cabinet and only the general themes and ideas circulated in advance of the focus group session. 


\section{Treaty of Waitangi}

To acknowledge the partnership inherent in the Treaty of Waitangi document I needed to reflect on how my research project would impact on the Tangata Whenua. The Cultural Safety Specifications for Provider Competencies and Qualifications in Maternity Services (1994:7) advise, that measures be put in place to provide a safe environment that avoids "cultural risks." Such measures need to address the structural and cultural frameworks which because of their ubiquitousness blind us to the realization that they can act as vehicles of oppression by requiring conformity. Polaschek, (1998), alludes to this:

Attempting to de-programme individuals of their societal influences, when the social structures which inculcate and reinforce those individual attitudes remain unaltered, does not seem to be an adequate strategy to achieve the changes which the concept of cultural safety aims at. (p.454)

As indicated in Chapter Two, Maori comprise only a small segment of the South Otago community who access the local maternity services. This means that it is critical for those providing or managing maternity services to ensure that such services are both acceptable and culturally safe. For Maori women and their families, their comparative isolation and marginalisation in a predominantly pakeha community potentially increases their vulnerability to unsafe cultural practices. It is possible that my project could in some way impact on the maternity services for Maori but I would be unable to predict what effect, if any, it will have. None of the participants in this study identify as Maori, and I have not directly approached local Iwi or Hapu in relation to this research project.

\section{Data analysis}

[T]he postmodern mind does not expect any more to find the allembracing, total and ultimate formula of life without ambiguity, risk, danger, and error, and is deeply suspicious of any voice that promises otherwise. (Bauman, 1993, cited in Schwandt, 1997:305) 


\section{The interviews}

In managing the data from the taped interviews I first listened to the tapes and took some notes soon after each recording. Once the transcripts were transcribed, I read them sometimes replaying the tapes to pick up the voice inflections, changes in speed or voice tone. I was looking in particular for statements or comments that signaled a particular philosophical viewpoint the stating of which was accompanied by a change in the voice tone or rate. I was also listening for statements of points of difference made by the participants when speaking about themselves in relation to others who held different ideological positions. Where difference was clearly articulated 1 was also looking for statements of resistance and how this was exercised in the rural midwife's work role. These elements I collated from the transcripts. Such critical analysis Lupton (1992) suggests can reveal dominant ideologies, ideas and patterns.

\section{The focus group}

The same process as outlined above I used when analyzing the data from the focus group. However, as I did not control the direction of the conversation, the topics flowed, one into another and traversed a lot of subject areas. Much of the discussion was future oriented rather than reflective, with much strategizing. This was reflective of the ongoing challenges for the midwives in the area. Powers (1996:212) says, "feminist research utilizes discourse analysis with informed participants with the openly moral agenda of reducing systematic oppression." Thus, these transcripts were read with an eye as to how the words of the midwives could be faithfully recorded in this work, while at the same time being scrutinized for the underlying discourse positions they revealed.

During the time I was recording the interviews and dealing with the transcripts, I was also reading the local newspapers for the time period under study. 


\section{The newspapers}

The Clutha Leader newspapers for the ten years between 1990 and 1999 were accessed at the Hocken Library in Dunedin. I visited frequently over a year, working through them by hand. I took copious notes and some photocopies of significant articles related to my project.

My original intention was to use these data as a backdrop to foreground the local context within which the study is based. As a first process I had recorded a chronological history of the decade, concentrating on the items that alluded to the health changes, discussions about the local health services, plus any references to the midwives and maternity services. It was during this activity, that I realized the local newspapers had their own story to tell. Amid the dramas over the years there were episodes and stories of disruption and conflict. There were also reports of local resistance to the changes happening in health care, both nationally and locally. There was certainly news of the midwives and the changes occurring in maternity care.

I began to play with Lyotard's notion of language games with regard to the newspaper texts. These local papers were full of rich detail about the community and it's members, but I have confined my area of analysis to the references to changes in the local health services, groups that emerged to challenge these, and comments on midwifery and maternity matters in particular.

\section{Playing the language game}

The social bond according to Lyotard (1997), is a product of language games. Such games require that there be a sender, an addressee and an object, to which the players refer. The addressee can either accept, or refuse to accept, the sender's words. For the sender to be successful they need to be invested with the authority to make the statement in relation to the referent or have a history 
of authority to deliver such a message. They then conform to the pragmatic rule and the right to occupy the post of sender. The sender may use whatever mode of language best suits the purpose of the message with each exchange becoming a move in the game.

If the receiver refuses to accept the message then the sender may need to repackage the message in a different style. The sender however needs cooperation in order to fulfill their role, and this pragmatic process may require the suspension of formal communication rules. In the texts, conflict and game playing was evident between the local interest groups, including midwives, and between the local community and outside agencies.

\section{In summary}

Lather, (1991) suggests that where one speaks for others there is the need to develop a self reflexivity to enable scrutiny of our research activity with regard to how we contribute to domination, despite our best intentions. As by choosing the object of discussion the researcher is given the power to name. In starting out to gather the data I had a sense of the surreal, of impostorship, asking myself what gives me the right to represent my friends and others in print.

In such qualitative research Aldridge (1993) suggests, that there is the need to tease out how the researcher understood the research process and how the results were interpreted. For instance where the past is being reconstructed there are issues about time and chronology. There is the possibility that what is salient today could be used to select and construct the events of the past, as the context in which the events took place cannot be replicated. This was certainly the case with this research. The participants were dealing with layers of memory about events within a rapidly changing environment, and making sense of this was not easy. These tangled stories I have attempted to unwind in Chapters Six and Seven. 
Thus the decision trail, in concert with my journal and the raw data from the participants, is offered as a transparent record of the process. My hope is that the reader will understand the directions the research took, and how I arrived at my conclusions, however evanescent and contingent.

In the next chapter, I attempt to synthesize the themes and discourses from the text of the local newspapers between 1990 and 1999. The intention is not just to add a local flavour to the contextual mix, but also to explore the contribution of the local print media with regard to the discourses and constructions applied to the reported events. It is possible that these micro politics have a significant part to play in shaping opinion and action in response to health issues in rural areas. 


\section{CHAPTER FIVE: THE LOCAL NEWS}

\section{Overview}

The local newspaper is frequently where the community politics and dramas are played out. The flavour and spin on the events depends on the local editing policy, what leaches through the filters of public relations, and who seeks to have their say. This was particularly true for the controversial and turbulent changes in the health system during the 1990's. Reading the local news was useful not only to plot a timeline of the changes but also to see who and what made the news.

The Clutha Leader is published three times a week, and is the local newspaper for the South Otago area. As part of this study, I looked at the 1990 to 1999 copy to jog my memory of the timing of some of the events, and to try to tease out some of the underlying discourses. Changes to the local health services didn't occur in a vacuum but were part of major national and local social changes. When reading the papers I looked particularly for any references to the health changes, the local response and protest action, plus any references to maternity services or the activities of the local midwives.

The events are grouped under two key areas. I first review the inexorable reduction in health funding in the wider Clutha area beginning in 1990. These funding reductions impacted adversely on the local hospital and its related health services. In response, energetic protests were initiated and led by prominent members of the local community. The success of these protest groups fluctuated depending on how well they were seen to have been meeting community expectations. Secondly, I look at the changes to maternity services and the emergence of a midwifery discourse. The local midwives did not have a high profile in regard to the protests despite the funding cuts to the maternity 
service. Rather they continued to change and adapt their services in response to their changed legal status and in response to the requests from women.

The changes in the health system were played out against a background of local dramas and everyday events. These included an eclectic mix of sport, club meetings, court news, shearing competitions and reports of adverse weather. Significant changes were also occurring in education, and local body politics; farming fortunes were in the doldrums; the local freezing works was downsizing, and several businesses that serviced the region stopped trading during this time. There was also shock and disbelief over the murder of two young women in the area.

\section{The inexorable reduction in health services}

The rationalization and reorganization of rural health services has been referred to previously. Changes have been in response to political, funding and demographic movements, plus technological advances and the availability of health professionals willing to work in rural areas. The pace and magnitude of change accelerated during the decade of the 1990's, and in Balclutha, as in many rural areas, protests about cuts in local health spending focused on the local hospital.

\section{The local hospital}

A rural community will fight to save its hospital even when it has lost its last apparent vestige of utility; the hospital ranks with the church and the school as one of those elements of rural society through which communities define themselves. (Rosenblatt, \& Moscovice, cited in Heydon, 1990)

The attachment and faith, that the local people had, in the bricks and mortar of their hospital, explains some of the public outrage over its demise. Following the establishment of the South Otago Hospital Board, cottage hospitals were built in 1924 at Milton and Owaka. (See Appendix G) Two years later, the base 
hospital was built on the hill at Balclutha, providing 96 beds. This was initially funded from local body levies with some support from Dunedin (Heydon, 1990).

Prior to the building of the hospital, seriously ill or injured patients waited in a holding station at Kaitangata for transfer to Dunedin, usually by train. Life threatening injuries from forestry and mining operations, coupled with the influenza epidemic at this time, accelerated the drive to establish both a hospital and a nurse training school ("Hospital result of long, hard fight" 1991).

\section{The cuts start to bite}

In May 1990 the first indications that all was not well came in the person of the chairman of the Otago Area Health Board (OAHB), who told the Clutha District Health Committee (CDHC), that the rural facilities were not selfsupporting. Further they were told that, "...part of the job of the CDHC was to counter rumours [that] rural services will be downgraded" ("Health board policy outlined," 1990). Throughout South Otago, cuts in services were beginning to bite. Locals complained about the cost of travel and the lengthy waits at Dunedin clinics. Meanwhile the closure of accident and emergency services at the Balclutha hospital resulted in some absurd events. The Clutha Leader recounted the case of a seriously injured farmer, having been brought to the hospital, being sent back to Owaka to see his GP for a referral to the hospital he had just left.

The rural members of the OAHB united in September, to criticize the budget cuts to rural areas, when Dunedin had been granted an increase. The local National Party MP at this time was promising support for rural services and surgical services in particular. He was to put a case for acknowledging the issues of sparse populations and their service costs. There was some optimism as a physician had, at long last been appointed. This helped secure the acute 
medical services at Balclutha, and moves were also underway, to set up a much needed, mental health team.

As December rolled in, items began to appear in the newspaper alluding to the trend towards specialist surgeons and the demise of the generalist surgeon. The points were made that all areas have a right to top technology and that the support mechanisms, in smaller hospitals, were unable to compete in this area. However local hopes were raised when the local MP was made speaker of the house. It was thought that his influence would benefit the area.

By July 1991, the public was shocked to hear that the 14 elected health boards and committees were to be disbanded in favour of four Regional Health Authorities (RHAs). With the dismissal of these members the OAHB now only had a chairman. Thus decisions were made at meetings with management staff behind closed doors. Small communities were to be offered the opportunity to manage their own services in a business like way within capped budgets. Reasons for the changes were explained by the OAHB Chairman who said, "[t]he government went to the cupboard and found it not so much empty but missing" ("Health service changes explained," 1991).

With surgery back on the front pages, the Clutha District Council (CDC), commissioned a social services impact report on what the closure would mean for the community. By November 1991, more was to follow as a report on surgical services recommended that all inpatient surgery should go to Dunedin. This recommendation was based on concerns about anaesthetic safety and clinical viability. The community reacted with shocked disbelief. The surgical services had been the point of difference for Balclutha and now the unthinkable was being recommended. It was this service cut that continued to divide and 
exercise the local population and dominate the local papers, for the next three and a half years.

The winter of 1992 was a harsh one for farming in the south. It was wet cold and bleak. Stock losses were high as the miserable weather continued through spring. Local businesses dependent on the financial fortunes of the farmers and the large staff at the hospital were equally despondent. There was the acute realization that the health and wellbeing of the community relied not just on a range of health services but also on favourable social, economic, and meteorological events. In February 1993, all major surgery was to cease and there was now the fear that the hospital itself might be lost.

Early in 1994, there were rumours that the decision about future hospital services had already been made without community consultation. The local MP stated that Otago health services were overfunded. In July the Southern Regional Health Authority (SRHA), stated that it would not buy surgical services from Balclutha, and the final report from the consultant group said that Balclutha was unlikely to be viable as a stand-alone operation. The locals felt betrayed and further protest was planned. Negotiations began with the SRHA over future service provision. At a rural symposium in 1995 attended by the Minister of Health, the idea of health trusts was promoted for rural areas ("Rural health groups on the right track." 1995). These words prompted the sole physician to announce his intention to leave, which left a large gap in local hospital cover that the GPs felt obliged to fill. This placed additional expectations on the doctors particularly since surgical and anaesthetic services had been withdrawn. To compensate, the SRHA planned to improve emergency services and provide upskilling wherever necessary. 
By January1996, the surgeons and the physician had left, the anaesthetist had taken up general practice, some services had disappeared and all other services were under a tight budget squeeze. In February 1996 a 'Utilization Review' of Balclutha hospital initiated by Health Care Otago (HCO) promised a smaller more efficient facility, but the public were suspicious, seeing it as a mechanism to further reduce or remove services ("Balclutha hospital under review." 1996).

With the upcoming general elections the decision about the hospital was put on ice but the suspicion was that the decision had already been made. In October the National party was returned to power and a new hospital at Balclutha was promised. The paper circulated a survey for locals to have a say in where the hospital should be built and there was passionate support for the existing site. In January 1997, there were hints of deals being done behind closed doors and that closure was imminent. These rumours were however denied by CHE and local hospital management. Meanwhile the Southland CHE was making plans to investigate the possibility of setting up health services in Balclutha. Following the leaking of this manoeuvre, the HCO declared it was not intending to withdraw from Balclutha. And in April hospital consultants were charged with producing a blueprint for the new building.

On August $7^{\text {th }} 1997$, it was announced that the new hospital on a town site, was to be owned and run by a community trust; its five million-dollar price tag to be repaid in five years. Included with the announcement were the site plans. The board then launched a major publicity and public information campaign with the by line that the old hospital was past its use by date. However, in September the Health Minister Bill English, warned, that all the needed funding might not be available. At this time, El Nino and la Nina were fully in control of the weather, which like the health reforms was both unpredictable and capricious. 
In December, a rural health forum was held, attended by the Minister of Health, representatives of all the national health committees, GP networks, South Link Health, the Otago Medical School, the local bodies' representatives, and Federated Farmers. The Minister of Health told the group that, "...rural areas are the real experts when it comes to deciding what, how and where they get their health services" ("Public Health Meeting"1997:1).

In December 1998, the local fire brigade, police, ambulance and the NZ army in a major logistical operation completed the transfer of equipment, records and remaining patients to the new main street facility. The hospital on the hill was empty.

\section{The outlying areas}

While the Balclutha people felt deserted and cut off by Dunedin, the small outlying hospitals felt rejected by Balclutha. There were the same propaganda campaigns and the reluctance for management at all levels to be candid about their intentions. Thus the same arguments of rationalization and efficiency were used to justify service reduction and the subsequent closures.

The transition of the small hospitals in Milton, Owaka and Lawrence, to Community Trust or Health Centre status, was not as dramatic a change as it was for Balclutha. Their services had been gradually reduced over a longer time period leaving them with the care of frail elderly and usually one or two medical beds. However this did not mean that these local populations were resigned to the changes. Owaka residents mounted a strong campaign to oppose further downgrading and closure of their hospital. Milton people too, were unhappy.

Public spats erupted between the smaller hospitals, Balclutha and $\mathrm{CHE}$ management. The Lawrence hospital representative suggested that surgical 
services could be cut at Balclutha so that funding could be redirected to maintain the rural hospitals ("Call for rural surgical cuts," 1991). Later, a Balclutha GP suggested that Lawrence hospital be closed to save the surgical services. However these were diversions from what was thought by many to be a sacrifice to save the Otago Medical School (Sijnja, "Sacrifices to save medical school," 1991). The relationship between the CHE and the medical school was close and symbiotic, as the future of the medical school depended on Dunedin hospital for teaching and specialist clinical experience.

Adding to the resentment was what was seen as asset stripping by the CHE. This had followed a series of denials from the CHE about their intentions for the old hospital in Owaka. For example, in May 1991 when the Owaka hospital was to be sold to the community for $\$ 1.00$, the equipment was removed including the beds, many of which had been purchased with local fundraising efforts. A similar future was anticipated for Milton with the plan to spread the savings from these closures across the services in Balclutha and Tapanui.

With the writing on the wall, the Lawrence hospital applied in 1991 to become one of eight pilot Community Trusts. A Trust was also formed to protect the Milton hospital. By July 1994 the Tuapeka Community Health Company was launched, and opened the Lawrence Health Centre in September 1997. Milton, Tapanui and Roxburgh hospitals later closed and were replaced by community owned trusts.

\section{The fluctuating fortunes of the protest groups}

The Friends of Balclutha Hospital was a group of hospital staff, GPs and concerned citizens formed in response to the events of 1991. They mounted a huge public awareness campaign and lobbied strongly, believing that the threat to the hospital and its services was real. 
In October, the local submission on the surgical services review was ignored and the Crown Health Enterprise Advisory Committee (CHEAC), recommended the cessation of all major surgery at Balclutha by June 30th 1993. This resulted in a protest march organized by the group. The local people were bussed to Dunedin where they marched from the Dunedin railway station to the Area Health Board offices to hand the board chairman a 73 page submission ("Protesters do Balclutha proud," 1992).

In April 1992, the group urged clubs, businesses and individuals to contribute money for the purchase of a laparoscope at a cost of $\$ 75,000.00$. This was in the hope of attracting more patients to Balclutha from other centres. But by May the ward closures announced at Dunedin hospital sent shivers up the collective Balclutha spine. Closures at Dunedin invariably rippled out to the rural areas, and entrepreneurial ventures might not be enough to sustain the surgical services.

In June 1992, the Hospital Board's consultation group held a rural health seminar, which was labeled a 'con job' by locals. No consultation had taken place. Instead solutions were sold to those invited. Meanwhile the laparoscope appeal exceeded expectations and the first laparoscopic surgery performed at Balclutha got top billing in the local and Dunedin press.

A different tack was taken in May 1993 when another local committee called the 'Ways and Means' was formed to meet with Parliamentarians to discuss a 'good news' plan. This meeting resulted in a rollover until July 1994 giving the group time to explore the possibility of a stand-alone entity. However, a feasibility study needed to be funded by the local community. To fund this the public were encouraged to sign over their recently acquired Otago Power shares. Despite a slow start half of the $\$ 80,000$ required for the feasibility study 
was raised with a Returned Services Association (RSA) telethon raising $\$ 17,000$ and a hospital review a further $\$ 2,500$. In September, the consultant firm of Coopers and Lybrand were commissioned to do the feasibility study.

In early December 1993, the much awaited, report from Coopers and Lybrand recommended the third of three considered options for the future ("Three options possible," 1993). The choice was to maintain the status quo at the hospital with the addition of a private wing. But hot on the heels of this news, a leaked Southern Regional Health Authority (SRHA), document suggested that surgery would cease at Balclutha and other small hospitals and that there would be hospital closures, as Otago was seen as overfunded ("Rural hospitals facing knife," 1993).

January 1994 brought the first rumblings of discontent about the direction taken by the hospital support group. The preferred option being considered was seen as a profit-making scheme for individual surgeons. Health Care Otago sent an ultimatum to the local committee, suggesting that they either take over completely or leave it to the Health Authority to run. The July deadline was approaching and there was a further appeal for donations and shares. The public responded by voting to support the completion of the study.

The undercurrents of discontent with the way the money had been spent rose to the surface in editorials and letters to the editor. The public was no longer united. The study was considered to be a waste of time and money and the process a 'mockery'. A protest march was planned and the public was urged to join. There was reluctance to give up the fight and yet another group was formed calling themselves the 'Concerned Citizens Group' who vowed to continue the protest. A member was quoted as saying that if our surgeons were 
confined to 'lumps and bumps' surgery it would "be like having a qualified accountant lick the stamps" (Horder, "No capitulation” 1994).

The Prime Minister hinted at a trial of a public/ private facility. Such a prospect would need to involve a health insurance group and this prospect brought a flurry of nervous letters to the editor. The move was described, as snuggling up to the private providers, by a Dunedin surgeon of the newly formed Otago Coalition for Public Health. He was quoted as saying "Its time we put the public back into public health" ("Public excluded from health discussions,"1994).

In February 1995, any agreement to a public private hospital concept was looking unlikely. The direction outlined by Health Care Otago was that the smaller hospitals would provide medical, elderly, mental health, maternity and community care, but that the SRHA would not buy surgical services from Balclutha. To cap it off the local Member of Parliament, in whom the community had trusted for support, stated that Otago health services were overfunded. The locals felt betrayed further protest was planned.

The final report from the consultant group said that Balclutha was unlikely to be viable as a stand-alone operation. Thus began negotiations with the SRHA over future service provision. The campaigners finally gave up the struggle for surgery and turned their attention to the preservation of the remaining services; this followed the SRHA assurance that these at least, would remain the same. However, there was shock and disbelief when it was revealed that the similar sized hospital of Ashburton, in the Minister of Health's own electorate, would be able to keep their surgical services. 
To show they hadn't been idle the Balclutha Hospital Support Group announced the 'One Stop Shop' concept plan in October. This would put GP practices, plus all other outpatient and inpatient services under the one roof. But in October the CHE announced further cuts to services, which included the removal of long term elderly care, at Balclutha, Cromwell and Oamaru hospitals.

On the $21^{\text {st }}$ March 1996 Health Minister Jenny Shipley came to town expressing positive ideas about the outcome of the ongoing review. At this stage those who were the most outspoken and at the forefront of the protest had been invited into the planning. Thus only a few voices were raised in protest. In June more job losses were signaled. Anonymous and bitter letters began to appear in the papers sniping at members of the CHE's Utilization Review Committee.

In 1996 the Hospital Action Group emerged and called for a new local Health Board. The mayor called for the various protest groups to unite, and the editorial column echoed these sentiments. In 1997 the calls for unity were heard, and a new group with members drawn from the main protest groups, plus a member of the hospital review team, metamorphosed into the Balclutha Hospital Support Board. But not all of the locals were appeased by the formation of this self-appointed board. And the sale of the much lauded laparoscope (originally purchased for $\$ 100,000$ and eventually sold to a Fiji hospital for $\$ 16,000$ ) also without mandate, brought further criticism.

In 1998 , there were letters to the editor indicating that the community did not unanimously support the newly formed board. One suggested that fairy tales were alive and well following the release of the consultant's report. The writer recommended that “...this group should receive a reward in the literary world 
for the most imaginative writing for 1997; [as] their incorrect ramblings make for spellbinding reading" (Anderson, "Heath," 1998). The secret activities of the Board prompted a call for resignations of Board members. There was also anxiety about rating increases, to fund projects driven by the board, without recourse to a local referendum. A small group continued to oppose the closure of the 'hospital on the hill', but their comments were relegated to the back pages while reports from the proponents of the new plan were given greater prominence.

The wheels were in motion and a news release from the Clutha Community Health Committee Project Co-ordinator announced that the town centre health facility was going to happen and that local GPs were being approached to take up the opportunities to work from the GP suites. In August 1999 it is reported that the newly named Clutha Health First, (CHF) was to be part of a South Island pilot for telemedicine in a joint initiative between the Medical School and $\mathrm{HCO}$ - the aim being to link Dunedin, Invercargill and Balclutha with specialist expertise. There was also talk of a mobile surgical unit coming to rural areas in the future. In September the now named Clutha Health Trust appointed a new manager, the board was elected, and colour spreads of the new facility dominated the news.

The full range of primary maternity services had survived the changes, and was an integral part of the Trust's facility and services. The next section explores the activities of the midwives and the changes to their services over the decade.

\section{Changes to the Local Maternity Services and the emergence of the 'midwife'}

The decade opened with the Clutha Leader detailing the birth decline in South Otago. Statistics showed that that between 1979 and 1989 there had been a decrease of 455 registered births in the area. This trend continued throughout 
the 1990's with a drop to 214 in 1991. By 1994, 197 were locally registered with 109 of these being born in the area. A further slump in 1997 saw 176 births recorded in the area, 88 of which were born in the local maternity centre or at home.

In taking a look at the past, Heydon (1990) reports, that in 1920 most babies in the area were born at home or in the 1-2 bed homes run by local maternity nurses or midwives. In 1921 when the South Otago Hospital Board (S.O.H.B.), was being set up maternity beds did not feature in their plans. However, by 1932 hospital boards were required to provide maternity care. This prompted the allocation of some designated maternity beds at Milton and Owaka, with Kaitangata becoming the Board's maternity hospital for both the Balclutha and Kaitangata areas. In 1980 progressive regionalisation and the closure of small maternity units, resulted in all maternity beds eventually being located at Balclutha. These had been managed in a traditional shift system consistent with base hospitals around New Zealand.

Glimmers of fresh ideas around birth filtered through in 1990 with the advertisement for childbirth education classes. These were to be provided by a childbirth educator from Dunedin invited by the local branch of Parents' Centre. Changes were also happening in the maternity ward. Long overdue renovations became the opportunity to improve the furnishings and physical layout. This included a so called 'birthday bed', a comfortable and adjustable piece of engineering which replaced the hard narrow theatre beds ("Just What The Doctor Ordered," 1990).

In November, local women belonging to Parents' Centre were beginning to make their voices heard. They asked for more childbirth choices, the option of 
home birth, plus a community midwife to provide home based care for those choosing early discharge from the hospital (Clutha Leader, 7/11/1990).

Changes however were quietly continuing in the maternity ward. To facilitate these, the midwives hosted a Rural Obstetrics Seminar, inviting speakers from a variety of areas including, midwifery education, obstetrics, anaesthesia and paediatrics. This was also an opportunity to present the changes in midwifery, such as the return to autonomy of practice and the formation of the College of Midwives, to a larger audience ("Maternity services changed," 1991).

In the past, birth notices appearing in the paper consistently thanked their GP by name. If the midwives were acknowledged they were referred to as the nursing staff, or, in some instances "the lovely ladies of ward 5" ("Birth notices," 1990). But now the word midwife had begun to creep into some of the birth notices; even our names, as one notice read, "thank you to Jean for the catch of the day" ("Birth notices," 1991). The midwives were no longer invisible.

Photographs of local women and their babies were published weekly. This cooperative arrangement between a local photographer and hospital management was popular with the women and their families and great publicity for the local maternity service. Later in the year, two of the Balclutha midwives began antenatal classes with an emphasis on active birth.

Amid the changes and public protest, two of the midwives from the Balclutha maternity centre started an independent midwifery service with the support of the other midwives and management. It was at this time, that direct entry midwifery education, was being attacked by the OAHB General Manager. He stated, that the Board, "would not employ any midwives who graduated from 
the Otago Polytechnic Midwifery course without general nursing training”. The reason given was the threat to midwifery services in rural areas. He went on to say, "I don't think mothers care one way or the other about separately trained midwives, so long as the person is properly trained" (Bolitho, "Balclutha bound by policy," 1991).

The maternity centre launched the Baby Friendly Initiative in January 1992, which was part of an international drive to promote and protect breast-feeding. By now the midwives' names were appearing regularly in the birth notices and advertisements for their services were appearing in the paper. The birth of the first baby for the independent service was also celebrated and publicized.

While there had been no overt threat to maternity services there was the sense that these services were equally vulnerable. As if to preempt this David Trantor, whose campaign for rural services saw him walk the length of the country, opened his June letter with excerpts from Rosenblatt's et al., (1985) research on the safety of rural birth (Trantor "Health reforms," 1993).

In 1994 a local home birth support group was established. The independent midwives and staff in the maternity centre took advantage of this opportunity to publicize the philosophical and service changes in local maternity care. International Midwives' Day was celebrated with a gift for the woman who gave birth on the day, and this tradition continued over the ensuing years.

On July $19^{\text {th }} 1996$ the legislative change to Section 51 of the Health and Disabilities Act 1993, (concerning the provision of maternity services), resulted in the announcement of a new maternity package by four RHAs. This introduced the Lead Maternity Carer (LMC) concept, referral guidelines and specifications for information and care planning options, referred to earlier in 
Chapter Two. The General Practice Association (GPA), in the wake of this announcement asked its members not to take part in the new proposed system; warning that the funding constraints represented a potential danger to women. Women were urged not to get pregnant. However the midwives took advantage once again of International Midwives Day to explain the complexities and benefits of the LMC concept for the newspaper ("Changes explained," 1997). In 1998 there was the opportunity to publicize not just their service but also the New Zealand College of Midwives' (NZCOM) website, which both midwives and women could access for information and networking ("Midwives on the net," 1998).

The maternity unit opened in the new downtown facility and on the 10th of December 1998 photos of the first baby to be born at Clutha Health First (CHF) appeared. However in January 1999 it was realized that a helipad had been left out of the plans. This gap was highlighted when a baby needed urgent transfer and had to be taken to a nearby carpark to board the helicopter.

In 1999, the maternity services were once more under the spotlight with the review by the National Health Committee. Women were asked their opinions about the current maternity services with regard to their quality, ease of access, and choice. Nationally, women reported a high level of satisfaction with the current maternity services. However, rural women in a focus group told the Maternity Services Review that they received less services. The CHF manager refuted this perception, suggesting that this was an overview, and that women's individual needs were being met in Balclutha ("Less choice in maternity services," 1999).

However the insecurity continues. 


\section{Game playing}

In an attempt to explore the complex layers of move and countermove that punctuated the events over this period, I have as indicated in Chapter Four, played with Lyotard's (1997) concept of language games. My recollections of the changes during the decade, I now realize were most unreliable. In re-reading the local news, not only was I was surprised by the sequence of events, but even more so by the complexity and number of groups that emerged, changed and disappeared over that time. For me, it was the war of words that echo in my memory.

\section{A Lyotardian analysis of the Clutha Leader and midwifery discourses}

Lyotard's notion of language games, if employed to look at the events reviewed above, suggests that those who sent the directives with regard to service reduction were invested with some historical or current positional authority. And it would be reasonable to assume that these changes in direction did not emanate solely from the $\mathrm{AHB}$ and $\mathrm{CHE}$ management but that these organisations were simply conduits passing on the requirements from others whose authority they accepted. Similarly, at the local level in Balclutha, those who initially opposed the changes with such vehemence were in positions of influence within the local community. Thus, their interpretations of how these threats should be met and opposed also had the air of authority.

Such an idea explains to some extent the variety of approaches and guises that were employed to sell the changes. In addition how well this pragmatic approach worked, when members of the protest groups, who were most strongly opposed, were co-opted by management to become members of the review team. Thus not only did the project have the contribution of their skills and local status, but also the energy was diverted away from protest. They in turn became the senders of the message to those who had at an earlier stage stood beside them in protest. 


\section{Pragmatics and efficiency}

Lyotard (1997), argues, that the pragmatic outcome is a relentless pursuit of efficiency. This could be railed against but always in the end required an accommodation. The idea of efficiency was a constant theme used to rationalize the changes. There were also the moral arguments about over-resourcing of the South; the suggestion being that rural areas were soaking up funds that could be more usefully spent elsewhere in New Zealand. Such arguments, plus other language games that suggested that rural communities could manage their own health care, had the effect of softening up the opposition for the decisions that were already in place. There was also the argument for the greater good in respect of the Medical School. In this instance, survival was said to be dependent on the re-directing of funding in order to preserve clinical education and practice opportunities for the students.

\section{Moving margins}

There were margins within margins. The rural town of Balclutha was marginalised in relation to Dunedin, while the smaller rural hospitals in other towns in South Otago, were marginal in relation to Balclutha. Within the rural populations the people were further split by economic, social and cultural differences. And while these divisions could be overlooked when there was a common cause, they were thrown into sharp relief when their leaders were seen to be pursuing self-serving opportunities.

The privileging of the surgical services, as the focus of protest, appeared to be accepted by the community. But when compromise in the shape of private surgical facilities was proposed, it was bitterly opposed by the section of the community, who, held fast to a free and public health service ideal. To give up the fight was seen as an act of betrayal. But in the climate of privatization and 
competition, to cling to the idea of a fully funded public health service, was regarded as an outdated concept- a marginal aberration.

Also missing from the debates were women's voices. Men occupied the senior management roles in the health structures, were the GPs, business leaders and spokespeople for the protest groups. They represented the local council, and edited the local newspaper. Similarly, there did not appear to be any significant contribution from Maori in relation to their local health needs and priorities. While it is not possible to project what, if any difference, this would have made to the outcomes, a more balanced representation would have better informed the debate.

\section{Midwifery out of the shadows}

Over the years the Balclutha midwives had struggled daily with the restrictions on their practice, which largely emanated from the medical model of birth management in place. Smoldering away had been the desire for change, and in 1990 this opportunity was realized. It was it seemed, an advantage to be out of the limelight. Apart from occasions when the midwives sought out the opportunity to be interviewed, or to place an advertisement in the news, the maternity changes didn't attract attention. The focus for protest was on what were seen as flagship services such as surgery and medicine, which diverted the attention of the doctors and management. Thus the maternity staff were not expending energy and emotion defending their service in the public sphere. Nevertheless, the pressure, to economize further, continued. The response was to reorganize the maternity service, abandon the expensive shift system, and offer a CHE based LMC option. While the workload and responsibilities increased for the midwives this was offset by the opportunity to practise more flexibly. 
In New Zealand during the early 1990's the morale of midwives was high. The midwifery model had become the dominant midwifery narrative among midwives and many users of the maternity services. The capping of the budget with the modular system, the improved outcomes and client satisfaction, meant that it was also an efficient model. Thus midwifery care was fulfilling Lyotard's pragmatic rule.

Part of what made these changes happen were the language games around birth, midwifery and autonomy. For example the naming, or rather, re-naming of the midwife, was traceable in the birth notices in the news. So too was the reclamation of a scope of practice that was centred on expertise and experience in normal birth. Hewison (1993) illustrates, how the renaming of words used to describe aspects of childbirth, are used by midwives to differentiate their social model from the medical one. For example 'birth' rather than 'delivery'. There was also a feminist statement in insisting on calling clients, women, rather than patients. Such a process however did not occur in a vacuum. It was part of the metanarrative from the New Zealand College of Midwives and the women, with whom they had aligned, in their common aim to extricate midwifery from medicine and nursing; both in practice and education.

\section{Summarising the local news and the language games}

It was the perceived, then real, threat to the surgical services that caught the imagination and fired up the community more than any other crucial health issue in the locality. Men who were prominent and vocal within the community led the protest groups that informed and rallied the local community. Over the decade there was an inexorable withdrawal of resources, which no amount of protest or organized lobbying could halt. Many of the moves were planned out of the public eye, with locals lulled by reassurances or persuaded by moral arguments about rural overfunding and the need for efficiencies. 
The cracks in unity had always been present in the community but differences had been plastered over in the interests of presenting a united front in the face of threat. Disappointment however, was not just reserved for the outsiders, for whom there was already distrust, but also for those protest group members, who, appeared to change allegiance or were seen to be self-serving.

The maternity service survived the changes albeit in a leaner form. Out of the spotlight the midwives took full advantage of their newly won right to practise autonomously and to promote a midwifery model of care to the local women. These changes were welcomed not just by the midwives and their clients, but also by the funders who saw the opportunity to contain costs and meet their requisite service specifications.

Thus all groups, to a greater, or lesser extent, participated in the language games during the decade. How successful the local groups were in securing any advantage is difficult to tell but protest in any form possible appeared to be the only alternative to capitulation. Clearly, groups who were fulfilling political policy directives had the best chance, of securing a stake in the new health environment. How successful the changes have been, and in particular how local maternity has fared in the new environment, is canvassed with the participant midwives in the next two chapters. This assessment, plus their memories and reflections, form the richest layers of this research project. 


\section{CHAPTER SIX: TALKING WITH MIDWIVES}

This space is in between the collection and the writing. It is a time of massaging, squeezing, ignoring, being captivated, and a little afraid. It is making excuses, procrastinating but getting ready. (Journal entry, July 2001)

\section{Overview}

In this chapter I explore the transcripts of the five midwives who agreed to participate in my study, using a postmodern feminist discourse analysis. The study looks at the changes that occurred over the decade of the 1990's, and the challenges then and now, of sustaining rural midwifery practice. Excerpts from the participant's transcripts are represented, in italics. Each transcript is numbered one to five with the last number representing the relevant page number in the transcript. I used the five broad open questions (see Appendix C) only when the topics did not arise spontaneously. The transcripts were first listened to, then, read with a view to finding some common patterns and statements.

The conversation digressed often returning to the topic or some other area of interest. Changes in midwifery were recalled, as were the local difficulties that had been, or still were being experienced. Some of these I had forgotten while others remain vivid memories. Events that had loomed large for me, were often not recalled, or not seen as particularly significant by the midwives. And some shared events had been experienced variously. For instance, I was surprised at how little the radical health changes of the time were recalled.

Setting out to interview the five midwives I have known and with whom I had worked over the period, under study, was for me an anxious process. However, 
once we were over the initial nervous moments the conversations flowed freely. Each interview was taped with the participant choosing the time and venue.

\section{Working in rural practice and the challenges of the decade}

\section{Arriving in rural practice.}

For the midwives in this study, arriving in South Otago had little to do with their midwifery practice. Rather, each had moved to the area for family reasons. With them they brought a unique history of experience and educational preparation. And those who had previously worked in rural areas anticipated that work in this rural area would be equally rewarding.

I was looking at working in Rangiora, which was the rural hospital, which was closest to the farm that my future husband lived on. [I] discovered that I really enjoyed rural practice. So I always wanted to work in rural because of the continuity that you could provide there. So I never wanted to work in a base hospital I always wanted to work in rural. Well particularly because I tended to do night duty and doctors never really wanted to get out of bed at night. You tended to find that you were doing more things by yourself without lots of interruptions from other people and so you were seeing women through (Trans.1: 12).

I had come direct from working [In Rhodesia] in the bush to Cromwell and down the South teaching the local GP there how to do vacuum extractions and that saved us having a lot of transfers down to town (Trans.2: 3).

And for another there was experience of teaching midwives in Papua New Guinea where men tended to be excluded from childbirth and the

"... midwives tended to do things that were the role of the obstetrician such as breech deliveries and removal of retained placentas..."(Trans $3: 2$ ). 
While, one came for 14 weeks. “... and I haven't left yet, and that was six years ago" (Trans 4: 1).

In 1980, another was working in the rural maternity ward without midwifery education and found that:

So, often you were out of your depth and I enjoyed the birth, but, not knowing what you were doing is really rather scary. I hated the system but took the bull by the horns and thought about doing midwifery. The Advanced Diploma of Nursing (ADN) was all that was available at this time and .... [s]o that's how I became a midwife (Trans 5: 2).

\section{Leaving the familiar: Learning curves and closing the gaps}

The different educational preparation, previous experiences and exposure to rural practice impacted on how easily new skills were learnt, or historical practice patterns adapted for the LMC role. All talked about their learning curves, which included practice and business management skills, as well as the challenges of changing their role within the community. Differences in education and experience were thrown into sharp relief following the changes in 1990. The midwives identified areas of knowledge they needed to work on before feeling ready to assume responsibility for total midwifery care.

So yeah my training wasn't great...I think probably... yes I mean, I think those were the gaps, when you're really responsible for your practice... because you could sort of get yourself through because you didn't take responsibility... you always handed on [as] you were in a shared care doctor type [relationship]. About every month I write another list of things that I need to update on ... all the things that I didn't learn in my training (Trans 5:4-5).

The need to quickly update skills was also an issue for the more experienced midwives.

We had never done venipuncture as such and never done any suturing. Those were two big things, although we did courses on how to do it, it was always a bit daunting just to stick a needle in someone and suture (Trans.3: 6). 
...and antenatal work was also a challenge. ...but I had never done anything much antenatal so there was that huge learning curve about looking after women from early pregnancy [that I] just didn't have a clue about. I think when you set out in practice and you have always worked with medical practitioners, in a rural area when you set up in independent practice you have to be able to do everything. So you had to feel fairly confident that you could do this. [We] had the skills required and some of those skills we had never needed. And I don't think you ever feel 100\% confident in it; we just have to keep plodding on and working on it (Trans, 1:7-9).

The lack of business skills was also cited as a challenge.

...but perhaps too big for me being not so organized and business like. It was the book work and [from] having never done any books at all to having to keep records... and you didn't get paid until you had done book work... and GST...I didn't want to have to bother about things like that (Trans 2:9).

...we had meetings and meetings before we set it up to decide how we were going to do it...um I mean it was all new stuff [it was] so exciting but I was very nervous too (Trans, 1:6).

\section{Helping each other to grow}

In 1992 the independent service was launched in style.

[Going independent]...it was "scary fun" Yeah when I think about it now what a cheek we had. Sending out invitations to all the GP's and local surgeons and anyone around town... there were clinical issues, but we were reassured of this fantastic support from the staff in the local hospital, yourself, and the other staff, plus Queen Mary at the end of the line- they were supportive in those early days (Trans, 2:5).

The support of colleagues and those staffing the unit were vitally important to enable the LMC midwives to function and survive. The midwives felt that this support enabled them to overcome criticism from those who opposed their move. This signaled, not just a concern for their colleague, but also an 
indication of their faith in both the ability of the woman to birth locally, and of the midwife to provide her care.

I was fortunate that the other midwives tended to know when you'd had a grueling time and [they] would just cover for you until you had a chance to have some sleep. Sometimes you got about four hours before the next work popped up - also had some visits to fit in too before you went on the ward or something. But we were fortunate that the three of us that were doing continuity at the time [and] seemed to be aware of each others' situation and [we] would very often ask for help (Trans.3: 5).

In one instance two midwives found themselves unable to back each other up as their women were labouring at the same time and the midwife in the local unit had to cover for them both.

"... I ended up being in hospital having two babies all within a minute apart of each other...so poor '*' was dashing between the rooms" (Trans.4: 11).

A bonus of the new experience of autonomous practice was that it brought rural midwives together with midwives working independently in the urban areas. For some this was the first time that they had met and talked together.

So there were all these midwives that we really hadn't had anything to do with before and we sort of all got together there and networking with that group was really exciting (Trans 1:7).

Thus we were a disparate group brought together with a common purpose within a particular time in history. In the next section I explore three common discourse or language games that emerged from the texts. 


\section{A rural midwifery discourse?}

What I say and do always has a multiplicity of meanings, ambiguities, plays and these are not always coherent...therefore if we are unable to express ourselves and comprehend ourselves we may be even more opaque to others. However if we betray ourselves unintentionally others may well understand us better than we do ourselves. (Young, 1990:310 \& 311)

\section{Mapping the rural midwifery discourse/s}

The reflections, ideas and opinions of the midwives collapsed in time with a mix of past and present memories, plus thoughts for the future. Thus, a picture was painted of cross currents, tensions, contradictions, conflicts and rewards that represented the landscape within which they work and live.

In mapping the discourse positions of the rural midwives three discourses or language games emerged and appear to construct and reconstruct the midwives who work in this rural area. These I have teased out of the texts. They include their faith in the possibility of normal birth, a sense of rural difference, and their embedded relationship and visibility within their community. These discourses melded at the edges thus any separation I have suggested is both artificial and arbitrary.

\section{Seeing is believing: The discourse of normal birth}

The defining representation of these midwives was their grounded belief in the possibility of normal birth. This confidence about birth extended to birth being able to occur at distance from secondary care facilities. Thus the belief was not just that it was reasonable for women to confidently pursue normal birth but that it was safe to pursue this event close to home in a rural locality. This faith persisted despite the midwives having to deal with unanticipated acute situations within their rural practice, or having at times to transfer urgently to secondary services. 
There was rarely any surprise about how well the women managed and it was from women that the midwives believe they learnt or re-learnt much of what midwifery was all about.

[W]omen were actually making up their own minds about how they wanted things to happen and...so that was what really changed my opinion about birth and how it could happen (Trans 1:5).

...because it fundamentally came down to whether the woman could do it or not, it wasn't really anything to do with me. You know what I mean I knew that I had the skills to help or to recognize the abnormal and that was what we were trained to do (Trans 4: 25).

Just that relationship, and with woman and looking after them from that first pregnancy test and telling them about this new scheme and just being thrilled that women were happy to and wanting to try it and wanting to do it (Trans 1:7).

...we have got good autonomy like the last two births of mine were normal births and I mean they have been wonderful that is because we are that little bit distant...we have got that autonomy... and that is really quite nice (Trans, 5: 16).

...because I had quite a lot of primips that came through my practice, and they said "but you haven't got epidural in Balclutha". And I said "no but we have a beautiful deep birth pool" (Trans, 1: 20).

I remember the first posterior baby that I had...she had a posterior the first baby and then she delivered her second one the same....quickly standing up (Trans, 4:18).

\section{The birth of homebirth}

In South Otago home birth had not been an option until the independent service began.

Yeah [homebirth] was really enthusiastically used for a while there. Whether it was just a glitch or the type of woman coming through, I think in one year the most I had was twelve and that was wonderful. And of all the women that have chosen home births only one was transferred and that was a private thing (Trans 2: 12). 
I was at a homebirth, away in the background there, in the garden and talking to the cat, then going inside when she felt like pushing and staying by the fire (Trans, 5: 7).

Following a first home birth the feedback for the midwife was very affirming.

....and it was the letter I got from him that I thought so special and he said how...it had made him feel so much closer to his partner and he had found it to be really special involving him and I thought "gee this is good" (Trans 1: 8).

And the joy of being the second midwife at a home birth.

...so I would get out of bed and go to the birth. And then go home and go back to sleep and wake up and think it was all a pleasant dream really... so that was quite nice (Trans 4: 10).

\section{A discourse of rural/urban difference}

The integration and mobility of the New Zealand population makes it difficult to imagine a 'country-city divide'. But even with this mobility, provincial areas and their populations tend to develop a strong sense of their rurality and identify strongly with local issues.

It may well be that midwives on city boundaries, or in small towns, also identify as rural. In fact there may be a continuum of a degree of rurality, with those in easy reach of secondary services having different issues to those who work in the more remote areas. But regardless of how geographical areas are defined by others, the midwives in this study saw themselves as intrinsically rural and this appeared to be a defining difference.

Griffith (1996), looked at what motivates midwives to work in different areas and suggested that it may be that a highly medicalised working environment 
shapes the beliefs and ideas of those who work there. Equally this may occur for those who work in rural areas with minimal technology. However, it may also be that individuals are attracted to work in the areas that best match their beliefs about birth, whatever their rhetoric to the contrary (Griffith, 1996).

Garcia et al, (1990: 4) suggest that:

Most mothers travel hopefully, trusting that medical intervention will not be necessary... whereas health professionals may be from the opposite view and all pessimistic travelers. The management of this anxiety, [explains] some of the organisational aspects and bureaucracy in institutions.

The rural midwives appear to also travel hopefully and support women choosing to birth locally.

I have often thought if I was to start up again in just a small way, I would stick up a bloody notice somewhere - "taking bookings for women birthing in Balclutha only." People are going to town and they don't need to (Trans. 2:19).

It is much nicer to have your baby in Balclutha, you know you are not listening to somebody else down the corridor giving birth while you are in early labour. You know you have got the place to yourself and it's just got that lovely pool now and it is just so good... and I do water births and it is good (Trans. 1: 22).

The rural midwives in this study, considered that the totality of their work was unseen and unappreciated, and that the births that proceeded without fuss were not witnessed by others. Thus their day-to-day work was invisible. This they believed was partly due to a lack of understanding of the breadth of the rural midwife's expertise and knowledge of the woman and her family.

...just trying to keep them (the woman) going and yeah, there is a definite misunderstanding with rural to what we are doing (Trans, 1: 22). 
Often they were required to act alone in emergency situations if other health professionals were not readily accessible.

There was once I had to do a breech delivery unexpectedly, arrived in second stage basically. It was a concealed pregnancy. There was no one else around who could do a breech delivery...but it didn't faze me I knew exactly what I should be doing and um I was very relieved to find the baby was okay (Trans, 3: 6).

Road and weather conditions played a part in the logistics of working in the rural area. At times this is a bonus on a good day making it a pleasure to be out and about. One pleasant memory for me was having lunch by the Clutha River between visits. However, also memorable, were the snowstorms and floods.

I really love getting out in the country [but] I remember striking a road that was very loosely shingled and almost rolled the car one day. Ah that gave me a fright. [I thought] this is a pretty risky occupation I've now got. [And] years ago when we worked in Hawke's Bay and had to transfer all our complicated deliveries out [I] had several plane trips. The children were quite small. It was quite scary in a small single engine plane looking at your home down below and wondering if you were going to get home safely to your kids (Trans. 3: 9).

I remember it snowing... when I was driving through the night and there were snow drifts...I went to Waitahuna; it was a scary night because there were no road markings on the road so you couldn't see where the road finished and where the ditches were. We drove slowly even though we were going to someone in premature labour ...it was horrible (Trans. 4: 14).

\section{The trials of transfer}

This difference between practice realities was highlighted at crisis points when transfer to secondary services occurred. Transfer of women or infants to an urban centre is a part of rural midwifery practice. It is however for most rural midwives an anxious and at times fraught process. Not only are they dealing with the events that have prompted the transfer, but frequently the spoken or 
perceived censure, of their urban peers. They sensed that they were seen as the 'yokel' when in fact they had a wide range of skills and scope of practice.

Transfer was not an easy thing to do, “...it was just necessary thing to do and you just went" (Trans. 2: 7).

[Y]ou know you have got that time if you need to transfer. But you are also watching and always questioning. Yeah...you really do feel a responsibility...with the distance and isolation...especially as its not easy to pick up a telephone and talk to a paediatrician. Sometimes you might have questions that seem rather silly, or think you should know them... sometimes [it] is very difficult to do (Trans. 5:13).

Creasy (1997), looked at women's experience of transfer in labour, and found that while women were frequently disappointed with their labour outcomes, their feelings were ameliorated by aspects of care such as information, explanation, debriefing and continuity of care from familiar practitioners. If the person they knew had also been present at the crisis point this was even more valuable to the women. Thus, while transfer is an inevitable possibility for a proportion of locally booked women, it need not be a negative one. And "while such trust does not rely totally on a previous relationship, it is easy to see how it is more likely to occur within one" (Creasy, (1997, cited in Patterson, 2000: 130).

Transfer can occur after many hours of labour and there is always the tension of deciding whether it is appropriate to stay in support or return with the ambulance.

By the time you get to town with somebody who has been distressed in an ambulance... you are absolutely drained you know, just trying to keep them going. So yeah that is very hard, it's a dilemma either way whether you handle the care or you don't. 
Yes I get stuck in Dunedin. I either handle the care, or don't continue to care for women and come back in the ambulance. [I] leave them with the core, or, I stay and can't get back unless I get my husband to come through and get me or something...which is done in the middle of the night (Trans. 1:21).

Well [one time when I transferred] they said they were too busy to take over from me and I had been up for about 30 hours at this point and had absolutely had it (Trans. 4:5).

It wasn't always easy coping with an ambulance trip. Tiredness was one problem but for some travel sickness was also an issue.

I tend to get car sick in the back of an ambulance. So that was never a wonderful thing to transfer for something. I always think that ambulances should be made like limousines, [it's] more like being in the back of a truck (Trans. 3:9).

The expectation that the midwife transferring in would deal with the technology was also a problem.

It is not a very favourite place to work because you don't know where things are and people don't really help. Even if you are support person or support midwife you have got to go and find things and sometimes wander around and get lost. It's very medicalised there...can't shift things around how you want to (Trans. 5: 17).

Attitudes too could add to the tension.

People would make silly little comments in front of the woman and you knew the conversation got all hushed up when you went out to the [desk]. You have to be big and brave... I mean you have to have a helluva lot of confidence to do it (Trans. 5: 20).

However, if the midwife worked for a while in the secondary service or cared for some of her clients there, they found it easier, though this acceptance 
appeared to be conditional on the observation of particular mores and institutional norms.

So you became known on the 'core team' and then have clients or whatever. Because you already know the way they work...what they would like to happen, who you could annoy and what you could ask certain people to do and what you couldn't (Trans. 4:21).

The hospital politics are acknowledged by Cochrane and Murphy (1993: 264), who suggest "[i]t is difficult for a nurse or midwife to be assertive in the interests of the ...client without incurring the disapproval of the doctor."

Savage (1990: 336), comments on the service organization that contributes to these situations. "Because midwives stay with women during labour, they understand birth. And yet because of the way we have set up the system, we have almost destroyed that for many midwives."

For all that the interface is fraught, there is also some understanding of some of the frustrations and issues that confront their urban colleagues.

But it is not easy for them. [They are] short staffed and the services [are] less and less designed for them to look after women in labour really... isn't it? (Trans. 1:22)

Sandall (1997), found that of the three models of care studied, the one, which provided flexible woman-centred care, was associated with the lowest rates of burnout amongst midwives. Other characteristics associated with this mode of practice include a sense of occupational autonomy, social support and meaningful relationships with the women. Models of care that lacked these characteristics were less sustainable and were frequently associated with disillusionment. 
So while there were frustrations and tensions for the rural midwives, it would seem that these elements could easily be incorporated into their practice. Rural communities however, are complex entities and maintaining a comfortable place within them is a daily task.

\section{A discourse of community embeddedness: The weight on your shoulders}

A sense of immersion in their community was common to all the midwives interviewed. The community confers on them status and respect but also expects a strong commitment in exchange. This mantle of responsibility at times weighed heavily on the midwives with an expectation that they would always be available. Thus the midwives saw the relationship with their community as a tensioning of support and censure, affection and rejection.

I think it is the weight on your shoulders... you're always putting a lot of energy into watching. I don't know if all the midwives do that (Trans. 5:13).

The only problem was people calling me all the time...but maybe that is a problem in the rural because I don't think (midwives) find that in town...Yeah eleven at night the phone would start ringing... every night (Trans. 4:29-30).

Just sometimes there is difficulty in being a permanent member of the rural area in that you are... people know who you are, and when you make a mistake its heavier...because you can't hide from it. [In a] rural community everybody knows what everyone else is doing... everywhere you go people know what you do and you can't hide from what you are doing. [Even though you are isolated] you really stick out in the community. Which is good and which is bad (Trans. 5: 22).

Langley (2001) made me nod and smile in recognition, as she described her caseload adventures in rural Wales; the skirmishes with wandering stock, the winter road conditions, and her conspicuousness in the community. She comments: 
Knowing and living with your caseload has its good and bad points. Getting to know generations of a family and 'catching' siblings and cousins is a privilege. Being accosted next to the frozen peas, as you are about to throttle one of your children is not. (p.318)

Just doing the normal everyday activities and household shopping reminds you of how visible you are. There is no opportunity to pass unrecognized or to avoid being approached.

It takes you an hour and a half to go shopping. Don't take the kids because they get sick of you stopping and talking to all the babies and mothers and grandmothers who tell you- "Oh my daughter is having another baby". So you become very much part of the community, its good as long as things are going okay (Trans. 5: 22-3).

In an effort to preserve some privacy the midwives made decisions about how they managed the visits.

I don't think it was anything to do with the travel that stopped me doing all the antenatal [visits] in the community just felt that a lot of women didn't really want that. Some of them were in town and would have far rather come to my home and I did that for a while, but I didn't really like having my home open to everybody (Trans. 2: 11).

Thus, the community although referred to as a single unit is seen as a complex entity and perceived as having supportive but also a prescriptive capacity.

\section{In summary: Discourses of harmony, contradiction and conflict}

This combination of ideas and realities of rural practice painted by the midwives distinguishes it from urban practice. The midwives, suggested, that to work successfully in a rural area the midwife needs to believe in the possibility of normal birth and have the confidence to support women in their own locality to achieve this. The midwives also acknowledge a more integrated and conspicuous relationship with their community, which is a part of their rural identity and rural difference. This difference is accentuated at the point of 
transfer and interface with urban secondary services, where they believe their skill, knowledge and work reality is poorly understood.

These components of what I have named as a rural midwifery discourse emerged as statements within the transcripts. While expressed slightly differently in each interview they conveyed a common discourse position. However there are discourses within the rural midwifery discourse, and within each of the components of which it is comprised.

Women, according to the midwife participants, affirm the discourse of normal birth by demonstrating their ability to birth, at home or in the rural unit. However for a proportion of the women, transfer will be required. This apparent contradiction was a reality acknowledged as part of rural practice and did not appear to warrant special mention. Neither was it seen as in any way a reason for not offering a rural birth option. Thus, the midwives were prepared to support women who chose to birth locally, while at the same time remaining alert to the possibility that transfer or emergency care, might be required.

Contradiction and conflict was also a part of their relationship with their urban peers. Common to all the transcripts were statements about the tensions they experienced with urban secondary services when transferring a woman, or, working with her in the hospital setting. These included a lack of logistical support when needed, and sometimes, critical comments being made about the woman's care prior to transfer. These interactions marginalised the expertise of the rural midwife, particularly in relation to proficiency with technical and secondary care apparatus. Conversely, the rural midwife participants' statements indicated an understanding of the 'core' midwife's position, which was seen as lacking autonomy in relation to her midwifery skills. 
Similar contradictions were a part of the complex position with their community. While the community was seen as supportive it was at times unreasonably demanding. The midwives were valued but this position was not wholly secure, being contingent on their practice living up to expectations. Examples of this were statements about being watched, high expectations of availability, and being unable to go about their personal lives without being approached on work related issues.

These complicated discourse positionings concur with both feminist and postmodernist ideas. While the complex mix of discourses would seem to manipulate and constrain the rural midwives, they demonstrate their ability to use different positions whenever these are useful. Thus, rather than being puppets, the participants demonstrate that they are able to use discourses that serve their purposes and to ignore those that threaten to marginalise their rural identity and beliefs. Moreover, they balance the contradictions to do what they believe is important work.

In the next chapter, the midwives pick up some of the discourses from the interviews, add a current and future perspective and debate the pros and cons within the focus group. 


\section{CHAPTER SEVEN: A FOCUS ON RURAL MIDWIFERY PRACTICE}

Gossip, anecdote, information, experiences, wisdom, old wounds, new wounds, cross talk, passion, despair, weariness, toughness and humour. The soup, of the focus group. (Journal entry, July, 2001)

\section{Overview}

The meeting for the focus group was like a reunion. Some of us had been out of touch for some time, so there was some catching up to do. We met at a pleasant venue in rural South Otago with lunch ordered to follow the session. I set up the tape recorder and we settled around the fire with coffee. The main themes and ideas that had emerged from the individual interviews, had been collated and sent to the participants previously, plus, on the day there were a few starter topics circulated should we need them. The topic list included the issues and challenges that had been raised in the interviews, plus thoughts on future sustainability. I did not formally establish any ground rules and while there was some cross talk, the discussion was successfully captured on tape.

The most commonly occurring ideas, beliefs and ideological statements that emerged from the interviews had been collated and included in the post interview letter to the participants. These covered individual education and training, the need for business skills, the impact on family and social life, the positive aspects of rural practice, the need for support and access to clinical and educational updates. It was suggested that these were only some of the possible topics that might be discussed. In addition it was suggested that we could also look at future strategies for rural maternity services, as these had also been raised in the interviews. (See Appendices E and F).

How much the direction of the discussion was influenced by my starter questions and how much by the participants' interests was hard to tell. Tierney 
(1990:30), suggests, that when translating stories, we can only capture and reproduce them with a limited insight. Thus "[if] postmodernism has created an ideology of doubt, it stands to reason that our research endeavors also need to reflect that doubt". Which leaves me wondering if we would have covered the same ground had we started without a point of reference.

\title{
The local changes and 'team' discourse
}

The talk began with discussion around what was happening in the local area at the present time. The midwives still in practice locally, had concerns about the Trust's plan to provide an LMC option in addition to their facility role. This, independent midwives said, would be in direct competition with their service. It had the potential to make both options uneconomic, plus divide what was already a small team.

But the way it is being handled now means that we are being put into a very competitive environment...and...um we are going to be...you know... because it is competitive it means there is not a lot of sharing... it means that there is a degree of secrecy as to what is happening and the strategies (FG. 2).

There was also the fear that it would threaten the viability of the maternity unit if both services became uneconomic.

\begin{abstract}
Absolutely, yeah so it has threatened services, whether the women choose to go to [the Trust service], or... if the women stay with us and use our services [then the Trust service] is not viable financially, [and] it threatens the whole thing-it threatens the facility (FG 1).
\end{abstract}

The midwives were unsure as to how well women were being informed of their choices for birth, and opinion was mixed as to whether or not this happened. Clearly the midwives were getting some women referred to them from local GP's who did not act, as LMCs, and for the most part relationships were cordial and collegial. However where a local midwife felt unable to continue to work 
with a local GP, or conversely, a GP refused to work with a local midwife, then for some women this meant that they would not be able to choose to have both practitioners involved in their care. In this circumstance the woman would be referred to the Trust for midwifery services.

\section{Fearing a return to the past}

Also of major concern were the planned changes to DHB s and Primary Healthcare Organizations (PHOs) (The New Zealand Health Strategy, 2000). The midwives were anxious as to how these events would affect their work and income. Should primary maternity funding be devolved they believed that they would be compelled to join a PHO and thereby lose their independent status.

...I picked up my mail from down at the hospital yesterday evening and ...one of the things was [about] a providers group meeting thing-you know? to do with that DHB thing. And one of the things that it said ... was um would the GP's be willing to work for a salary? It has got me very worried because you know if obviously they are looking at putting a package together for our area and if they are looking at putting together a primary providers package in our area that includes us doesn't it? (FG 1).

It just worries me that we will be sucked into that perhaps without any real say-so $(F G, 3)$.

The notion of a 'team' approach was not popular.

"It would be a huge step backwards" (FG 1). And if the change "was the team approach it would be with that strong medical model which we don't need" (FG 2).

Yes because you know where we started... well I know where I started, I know where my history began here, and it does feel like turning the clock right back, and going through all that struggle again... I don't have the energy for that ( $F G 1)$.

Yeah, I have to say it looks a bit gloomy at the moment really. But we have struggled through things before (FG 1). 
I just think we keep on and keep on struggling because I can't see an answer, I really can't ( $F G$ 3.).

\section{A sense of missing the boat}

It was thought that they had to some extent missed the best opportunity for developing the maternity services. For instance, had the team of midwives as a group, gone independent, and put in a bid to manage the service and staff the unit, the current situation might not have happened.

[managing the service is what] we should have done (FG 1).

I know, I know, we should have then it would have been acceptable (FG 3).

While the decision not to team up initially was regretted there was also an acknowledgement that some of the midwives felt unprepared at that time for the challenge- particularly at such a time of uncertainty and change.

But it was too hard to do [then] because you needed everybody (FG 3).

We lacked the experience, we lacked the energy, the business knowledge, to be able to go ahead and do that. We had sort of airy-fairy ideals that would work but we didn't have the knowledge (FG 3).

\section{Advertising and promotion: Borrowing from the discourse of competition}

To help secure the service, women needed to know about it and feel confident to use it. There was the sense of the need to boldly advertise the service. The signage from the first independent midwifery service had worked well to evoke interest and comment from locals and those passing through Balclutha.

And we know that we need [to put up a hoarding] do something like that (FG 1). 
Being nice doesn't work. It doesn't work you have to be strong You have to be nice and strong (FG 3).

You do, you can't namby pamby...we have done that and wangled around things that didn't work. You just have to get straight to the point (FG 1).

When asked about advertising in the local newspaper;

I do a little and I am going to be increasing.... and I am thinking about maybe doing once a month or something, you know regular and I am going to put something on the local radio station which is very cheap advertising...And I have got a hoarding which I have been given permission by the council to put up down at the bottom of my lane... and we are hoping to get a visible presence down in town there (FG 1).

This included looking at the possibility of using an empty shop front.

But I mean we are looking at that now because we are in this competitive environment at the moment so we need to get competitive (FG 1).

But promotion requires time and energy and some knowledge of effective marketing.

I think it is something that we need to put some energy into as well.

And that is the difficulty often we don't have the skills for marketing (FG 2).

I think that there is a business womens' magazine full of those things and a Dunedin contact for short business courses (FG 5).

You could always work with a marketing student to do a project (FG).

Yes my son is doing marketing (FG 2).

I think marketing is a big thing (FG 5).

Ask the council if you could have a sign put on the post, [at the entrance to town]. Like some towns have doctor you could have midwife (FG 3). 
However the midwives didn't have a clear idea of what numbers they had, or how this related to the total number of potential clients in the area. This meant that planning was a guessing game.

But you know if the local women decided to have a local midwife as a care provider, I'm sure there would be plenty of work for three or four midwives. But the existing pool of women that we have there is really not enough for one and a half or two really. Is there? For thinking about income. Yes for fulltime (FG 1).

And there was a belief that local women were unaware of what was available.

Because they haven't heard it all before, It's all word of mouth its parents you have to talk to. The rural women's network and...talk about this and the opportunity and who is involved...(FG 4).

\section{Introducing new graduates to the rural midwifery discourse}

There was unanimous agreement that for the future of rural midwifery you needed keen new graduates.

Well I think for a new graduate, a team of midwives probably works best because then you have got different people that you can call on... And I think there are things you know you need to learn (FG 4).

There was the hope that the midwives could attract a new graduate to their team who could help with some call relief and in return they could provide mentorship. However, uncertainty about the future makes this difficult.

Yeah ...[what] I have been hoping would happen is that we would have a new grad come to the area and set up practice and we would mentor and support her and we would all be cooperative and work in together. ... There is not enough work for people to work in a [competitive] way in this area and it puts our service under threat really (FG 1).

Oh you have to get keen young new grads. We had that here with '*' and '*' that was good. But there haven't been any keen new grads since (FG 3). 
No but I know it will happen I was confident in time that we would get someone. But there is too much talk about the facility going. If you could say if it was only '*' and I [there]... there is definitely room for another grad. But because we have this threat of a whole new set up, it has been too uncertain of what the workloads would be [which would make it difficult] to attract a new grad (FG 1).

\section{Suggestions for managing workload}

It was acknowledged that rural practice put different demands on a new graduate. Thus, how they were prepared and supported was critical. It was suggested, that, "you marry them off to locals" (FG 3). Such a strategy would keep them in the community. However, there was the issue of young families to be taken into account when younger midwives worked in rural areas. Some strategies for managing caseload finances and family were debated and these issues became entangled with philosophical ideas within the discussion.

[One] way around that would be to set up a business and everyone take a salary from that business and so that all the money from the work you are doing goes into that and... (FG 1).

[If you have] individual caseloads, So what '*' is saying if you miss the bus (birth) you miss the money (FG 4).

The only way to avoid that would be set up a structure [where] you have got a business and you are paid a salary from that and therefore if you miss a birth you don't necessarily miss the money (FG 3).

If you did do that [you need good leadership] in the area that could guide a team into a proper business management. I could see it would work (FG 5).

I think you have to get on really well to do that, and I think you have to be on a very equal partnership... without any notion of, I am the senior partner and you are the junior partner. I think you really have to have a great deal of trust in one another. Some people could do it and some people couldn't (FG 1).

I think you have to learn to be able to do it. I don't think I did it very well at all. I think you have actually got to be able to learn to let go and 
have confidence in your partners. I think it is a learning process ( FG, 3).

The midwives reflected on the pressure following the Section 51 legislation to compete for clients (Notice Pursuant to Section 51 of The Health and Disability Services Act 1993 Concerning the Provision of Maternity Services, 1996).

We all wanted to be there, it is part of the job working in partnership and continuity [and] that places you in competition (FG 4).

I know but we have to relearn that bit (FG 3).

There was also the sense that something special might be lost if a midwifery team approach was adopted.

We have got these ideals and its such a strong part of your philosophy for autonomy of practice. I guess it is you know the added extra bits that they get the midwifery. [And] the midwife gains a lot really (FG 5).

\section{Educational preparation for rural practice}

The degree of confidence a new graduate has about working in rural areas may depend on what exposure she is offered in her midwifery education programme to this area of practice.

... my feeling is that if you want to train a rural person especially a rural woman to do that job then you have to [offer her the opportunity to train] in her rural area as much as possible (FG 1).

Financial support from the community was thought to be one way of making this a possibility.

There was however much discussion on the current length of the rural placement for student midwives. This was thought to be too short and there was even the radical suggestion made, that the length the rural placement be 
increased and the urban placement decreased. In Otago the rural placement occurs in the third year of the Direct Entry Midwifery course and is of four weeks duration, whereas other clinical placements are considerably longer.

Well I can't see any reason why she can't spend her whole time in rural apart from her classes attached to a midwife. It might be one day a week, or, something that she actually spends in Dunedin and her travel and some of her fees get sponsored. And she does a city experience. And she can go to somewhere like National Women's [Auckland] for a fortnight (FG 3).

With the third year students that I have had, a lot of them seem to be really rapt in rural practice while they are here, and they say that is great to be able to do that whole package... knowing that you have the skills to deal with given situations. But when it comes to the point actually setting up practice what seems to terrify them is not having the specialist backup readily available. And you know that a lot of them seem to feel as new grads that they don't have the skills to be able to work in a rural area without having it right there (FG 1).

And from someone who had come as a new graduate.

That could be just another more experienced practitioner [available] right at the time. Making it fourteen weeks continuity within an independent midwife working in a base hospital but only four weeks rural...there is no competition really. The reason I stayed was because I had fourteen weeks here (FG 4).

There was a discussion on the number of births the student might experience.

Its silly really, I said to '*' when I came here and did the rural placement I probably had about 14 or 15 babies that I actually caught and I learnt so much more than when I went to Invercargill for a month and caught forty babies. You know. You need to know what happens at what stages. Otherwise what if you are in a rural area and this happens (FG 4).

However, even with support and confidence in their rural area, new graduates feel that they are under greater scrutiny when they transfer to the base hospital. 
A woman being cared for by a new graduate experienced a post partum haemorrhage.

They could have one, (more experienced practitioners) but it didn't do for a new grad to have one the whole house fell down. You were under much more scrutiny (FG 4).

\section{Rural meets urban: The discourse of difference}

As in the individual interviews, the comparison between rural and urban working patterns was aired. While there was a perception that things were improving, areas of conflict and anxiety remain.

I think the attitude to country midwives has changed when I first went there [to Queen Mary] the fact that I was friendly and welcoming I think that gave the cue to the other midwives to be more helpful (FG 5).

While this was conceded there was report that the memory for rural problem births was longer than for town ones.

They have a long memory for anything a rural midwife has been involved in but a very short memory for their own There was one up there that you just wanted to get back into the lift if she was there (FG 3).

And for another the problem was not feeling comfortable to practise in her usual way.

I often find trying to maintain a midwifery model in that setting intimidating...you feel that the protocols...impose on what you are doing. Yes well what you are doing with the woman... and the beds in the middle and I don't sort of work here... and you need to take control and shift things around and they like the CTG on admission which might be totally unnecessary. And you feel that you must do this (FG 2). 
There was, the acknowledgement that it was also difficult for the hospital core staff, who felt that they would be held responsible if something went wrong. Thus they insisted that they needed to be fully informed of everything that was happening. This however meant that the lines of responsibility became blurred, as each was unsure where their individual responsibility lay.

One of the midwife participants, now working in the hospital setting explains the dilemma for core staff:

But if you are an experienced practitioner [in the secondary service] after a while you get called into a problem and it does make you nervous especially if the person seems to be making the wrong decisions. It is a worry (FG 5).

Clearly some of the problems are around communication. Not just about the clinical aspects but also around the level of logistical support required by the rural midwife when she is working with a woman in the base hospital.

I think, from a rural practice coming through it's not possible to be totally familiar with all the equipment. And to me that's the skill that the base hospital have, and you know I am certainly feeling a lot more confident coming in there now, [but] it sometimes makes you feel ...when you ask somebody how ...oh she is a midwife she should know. If you don't know what you are doing when you come in here you shouldn't be coming in here (FG 1).

The rural midwives also expressed uncertainty as to what the skill level was of their urban colleagues.

I notice a big difference coming to town, as there is no individual responsibility about being able to cope with problems. You can trace someone to help with it. We didn't have that luxury [in Balclutha] (FG $5)$. 
One day I had a flat baby and the [core midwife] said, "you know what you are doing". And she was surprised. I mean it was just what do you do isn't it? Not hang around waiting for some expert to come (FG 5).

It used to quite frighten me at times working in the secondary hospital because when I was in Clutha the other midwives on duty... they knew what to do in a baby emergency. She had to run for the bloody machine (FG 3).

Talk then returned briefly to the local unit.

\section{The legacy of the past}

There was the feeling that the management had been supportive in the past and that everyone was involved if there were meetings. Now the local midwives are not involved in decisions about the maternity unit services. There was also the observation that:

These community trusts are medically run and midwifery is struggling to keep a profile (FG 5).

There is a community feeling because it is a community orientated Trust that it's not a real hospital. And that is why some of the women choose to go to Dunedin. It's a small birthing centre thing - Although we didn't have much different up the hill. It hasn't got the hospital thing-it's a perception thing (FG 2).

A lot of that was around the rhetoric...they kept on threatening you know [during the arguments over surgical services]...that how ghastly it was going to be here, and we wouldn't be able to do caesarian sections. That was the big thing. So it wasn't going to be safe for women to have their baby here. It could have been said differently without pulling the shroud out. They struggle to put it away now (FG 1).

It was time for wine and lunch.

\section{Summary}

The focus group session was a ramble rather than a session with focused objectives. The discussion traversed the past, present and future issues and events of their midwifery practice. The talk at times was of despondency and 
frustration and a reluctance to yet again expend the energy to continue the struggle. But these sentiments were countered by expressions of toughness, optimism and resilience.

As in the individual interviews (Chapter Six) the discourse positions of the midwife participants were simultaneously cohesive and contradictory. At other times they described strategies of resistance. The rural midwives articulated as a group the elements of a rural midwifery discourse that emerged in the individual interviews; the tenets of which underlay their determination to find solutions for the current problems.

There was strong support from the midwife participants for the maintenance of a viable local maternity unit; but strong opposition to a shared care team approach as a way of achieving this goal. The 'team' discourse was seen as a threat to their autonomy, and if they were to resist this, they needed to look for options that were consistent with their midwifery discourse. Thus the resistance discourse is recast as alternative strategies. The midwife participants were planning to use marketing and commercial ideas. Ironically, these same market orientated practices had been used against the maternity services during the 1990, decade, ostensibly, in the pursuit, of efficiency and public equity (See Chapter Four). In this instance, the midwives were using these strategies as a counter move, to management strategies proposed by the local doctors and Trust management.

Attracting midwives into the area was the other main strategy. For new midwives to be able to work in the rural area it was considered that they would need a degree of mentoring and exposure to rural practice. Thus, they would understand how rural practice differed from urban practice-that is understand the difference and hence articulate a rural midwifery discourse. For all its' 
challenges, the participants were in agreement that midwifery in rural areas, was worth the fight.

In the next chapter the topics and discourses from the data are further explored and expanded with the ideas suggested for future possibility. 


\section{CHAPTER 8: A GAME PLAN FOR THE FUTURE}

\section{Overview}

The rural midwives agreed that rural maternity services continue to be in the news, and that this is set to continue as practitioners, work through the implications of the recent changes in both funding and healthcare organization. In this study, they demonstrate that, philosophically, they have aligned themselves with women rather than with other health professionals. And as both the women and the midwives in the rural area generally occupy marginal places within the community, this would seem to compound their lack of influence with regard to the allocation of health resources. However, such positioning, may prove to be a strength, if strategies are employed that harness the energy and passion that such an alliance can generate. The rural midwives have indicated how critical it was to work with the local community particularly in regard to the maintenance of current maternity facilities. They also acknowledged that a safe rural maternity service needed comprehensive and functional links for referral and transfer. Whatever mix of future strategies are employed, the midwives recognized that sound financial planning was needed, which took into account the fluctuations in their rural birth numbers.

The focus group showed that, if midwives were to live and thrive in rural areas, issues of sustainability would need to be addressed. These include logistical support and relief for family and recreational pursuits, educational and professional development opportunities, and the introduction and support of new graduates into rural areas. But whatever strategies are in place, the ability to articulate with confidence the essence, or difference, of their service, knowledge, and skill, will be vital. So, too, will a habit of alertness to changes in the political and technological winds, which may require challenge or accommodation in the future. 


\section{Positioning in the new environment: Rumblings and promises}

Pressure, for changes to maternity services continued to feature in the media, following the data analysis. In the wake of the announcement that doctors in Queenstown were quitting maternity care, the local newspapers ran alarmist stories of unsafe and under-serviced maternity care in rural areas (Williamson, "Mayoral alert over birthing risk", 2001). The local mayor initiated a petition for presentation to the Minister of Health, which asked for a return to the way services, had been delivered in the past ("Petition fallen on deaf ears", 2001). The petitioner's request was rejected but not before considerable damage was done to public confidence in the safety of rural maternity services.

This publicity highlights the anxiety already felt by midwives about the change to District Health Boards (DHBs) and the plan for Primary Health Organizations (PHO). The midwife participants in this study felt that, as the maternity budget would likely be devolved to these organizations that they would have to join or be left out in the cold. The biggest fear was the potential for a return to the past with a doctor led team- such an arrangement possibly meaning a return to the shift system, and the demise of the LMC midwife option. Thus, there was despondency that their hard won gains for choice and continuity of care options for women could be lost as they competed with other more dominant models of care.

The Primary Health Care Strategy document (King 2001: 5), offers the vision for "a system where services are organized around the needs of a defined group of people." Such 'systems of services' are to be funded by the DHBs, and while health care practitioners can choose not to join, they are encouraged to do so. There are assurances that the control and decision making around the service provision is intended to be collaborative and agreed between the practitioners and the community. Thus "Primary Health Organizations must be able to 
demonstrate that all their providers and practitioners can influence the organization's decision-making, rather than one group being dominant" (King 2001:5).

There is also the promise that the payments to LMC practitioners under the new arrangements will be the same for all, thus removing the inequity, which has existed since 1996 (Health Funding Authority, 2000). Once these changes are in place the savings made from the re-organization of maternity services will contribute to improved payments for LMC's (Ministry of Health, 3 September 2001).

Access to local maternity services is according to Nesbitt (1996: 164), both ethically sound and cost effective. In the past, "[r]ural units often suffered, from economies of scale"- the low numbers and one to one labour care being seen as wasteful. In the United States of America, managed care organizations are moving into rural areas and there is concern that units offering one to one care will be seen as wasteful of resources. Thus low volume units might be closed. However it was also possible that the outcome statistics for these units are better than urban-based services, and it may cause these organizations to review their policies (Nesbitt, 1996). After all, it affirms the efficiency discourse.

Taking into account the findings of this study, if the DHB document is enacted as proposed it would seem that there is a viable opportunity for midwives to continue to offer a full primary LMC service to the local community. The success of this will depend on how fairly rural midwives are treated at the local level. Even more critical for the survival of a rural midwifery service, is the continuance of equitable payments that are not exposed to local whim. For instance a local organization should they hold the budget for maternity care, 
In December, a rural health forum was held, attended by the Minister of Health, representatives of all the national health committees, GP networks, South Link Health, the Otago Medical School, the local bodies' representatives, and Federated Farmers. The Minister of Health told the group that, "...rural areas are the real experts when it comes to deciding what, how and where they get their health services" ("Public Health Meeting"1997:1).

In December 1998, the local fire brigade, police, ambulance and the NZ army in a major logistical operation completed the transfer of equipment, records and remaining patients to the new main street facility. The hospital on the hill was empty.

\section{The outlying areas}

While the Balclutha people felt deserted and cut off by Dunedin, the small outlying hospitals felt rejected by Balclutha. There were the same propaganda campaigns and the reluctance for management at all levels to be candid about their intentions. Thus the same arguments of rationalization and efficiency were used to justify service reduction and the subsequent closures.

The transition of the small hospitals in Milton, Owaka and Lawrence, to Community Trust or Health Centre status, was not as dramatic a change as it was for Balclutha. Their services had been gradually reduced over a longer time period leaving them with the care of frail elderly and usually one or two medical beds. However this did not mean that these local populations were resigned to the changes. Owaka residents mounted a strong campaign to oppose further downgrading and closure of their hospital. Milton people too, were unhappy.

Public spats erupted between the smaller hospitals, Balclutha and $\mathrm{CHE}$ management. The Lawrence hospital representative suggested that surgical 
services could be cut at Balclutha so that funding could be redirected to maintain the rural hospitals ("Call for rural surgical cuts," 1991). Later, a Balclutha GP suggested that Lawrence hospital be closed to save the surgical services. However these were diversions from what was thought by many to be a sacrifice to save the Otago Medical School (Sijnja, "Sacrifices to save medical school," 1991). The relationship between the CHE and the medical school was close and symbiotic, as the future of the medical school depended on Dunedin hospital for teaching and specialist clinical experience.

Adding to the resentment was what was seen as asset stripping by the CHE. This had followed a series of denials from the CHE about their intentions for the old hospital in Owaka. For example, in May 1991 when the Owaka hospital was to be sold to the community for $\$ 1.00$, the equipment was removed including the beds, many of which had been purchased with local fundraising efforts. A similar future was anticipated for Milton with the plan to spread the savings from these closures across the services in Balclutha and Tapanui.

With the writing on the wall, the Lawrence hospital applied in 1991 to become one of eight pilot Community Trusts. A Trust was also formed to protect the Milton hospital. By July 1994 the Tuapeka Community Health Company was launched, and opened the Lawrence Health Centre in September 1997. Milton, Tapanui and Roxburgh hospitals later closed and were replaced by community owned trusts.

\section{The fluctuating fortunes of the protest groups}

The Friends of Balclutha Hospital was a group of hospital staff, GPs and concerned citizens formed in response to the events of 1991. They mounted a huge public awareness campaign and lobbied strongly, believing that the threat to the hospital and its services was real. 
In October, the local submission on the surgical services review was ignored and the Crown Health Enterprise Advisory Committee (CHEAC), recommended the cessation of all major surgery at Balclutha by June 30th 1993. This resulted in a protest march organized by the group. The local people were bussed to Dunedin where they marched from the Dunedin railway station to the Area Health Board offices to hand the board chairman a 73 page submission ("Protesters do Balclutha proud," 1992).

In April 1992, the group urged clubs, businesses and individuals to contribute money for the purchase of a laparoscope at a cost of $\$ 75,000.00$. This was in the hope of attracting more patients to Balclutha from other centres. But by May the ward closures announced at Dunedin hospital sent shivers up the collective Balclutha spine. Closures at Dunedin invariably rippled out to the rural areas, and entrepreneurial ventures might not be enough to sustain the surgical services.

In June 1992, the Hospital Board's consultation group held a rural health seminar, which was labeled a 'con job' by locals. No consultation had taken place. Instead solutions were sold to those invited. Meanwhile the laparoscope appeal exceeded expectations and the first laparoscopic surgery performed at Balclutha got top billing in the local and Dunedin press.

A different tack was taken in May 1993 when another local committee called the 'Ways and Means' was formed to meet with Parliamentarians to discuss a 'good news' plan. This meeting resulted in a rollover until July 1994 giving the group time to explore the possibility of a stand-alone entity. However, a feasibility study needed to be funded by the local community. To fund this the public were encouraged to sign over their recently acquired Otago Power shares. Despite a slow start half of the $\$ 80,000$ required for the feasibility study 
was raised with a Returned Services Association (RSA) telethon raising $\$ 17,000$ and a hospital review a further $\$ 2,500$. In September, the consultant firm of Coopers and Lybrand were commissioned to do the feasibility study.

In early December 1993, the much awaited, report from Coopers and Lybrand recommended the third of three considered options for the future ("Three options possible," 1993). The choice was to maintain the status quo at the hospital with the addition of a private wing. But hot on the heels of this news, a leaked Southern Regional Health Authority (SRHA), document suggested that surgery would cease at Balclutha and other small hospitals and that there would be hospital closures, as Otago was seen as overfunded ("Rural hospitals facing knife," 1993).

January 1994 brought the first rumblings of discontent about the direction taken by the hospital support group. The preferred option being considered was seen as a profit-making scheme for individual surgeons. Health Care Otago sent an ultimatum to the local committee, suggesting that they either take over completely or leave it to the Health Authority to run. The July deadline was approaching and there was a further appeal for donations and shares. The public responded by voting to support the completion of the study.

The undercurrents of discontent with the way the money had been spent rose to the surface in editorials and letters to the editor. The public was no longer united. The study was considered to be a waste of time and money and the process a 'mockery'. A protest march was planned and the public was urged to join. There was reluctance to give up the fight and yet another group was formed calling themselves the 'Concerned Citizens Group' who vowed to continue the protest. A member was quoted as saying that if our surgeons were 
confined to 'lumps and bumps' surgery it would "be like having a qualified accountant lick the stamps" (Horder, "No capitulation” 1994).

The Prime Minister hinted at a trial of a public/ private facility. Such a prospect would need to involve a health insurance group and this prospect brought a flurry of nervous letters to the editor. The move was described, as snuggling up to the private providers, by a Dunedin surgeon of the newly formed Otago Coalition for Public Health. He was quoted as saying "Its time we put the public back into public health" ("Public excluded from health discussions,"1994).

In February 1995, any agreement to a public private hospital concept was looking unlikely. The direction outlined by Health Care Otago was that the smaller hospitals would provide medical, elderly, mental health, maternity and community care, but that the SRHA would not buy surgical services from Balclutha. To cap it off the local Member of Parliament, in whom the community had trusted for support, stated that Otago health services were overfunded. The locals felt betrayed further protest was planned.

The final report from the consultant group said that Balclutha was unlikely to be viable as a stand-alone operation. Thus began negotiations with the SRHA over future service provision. The campaigners finally gave up the struggle for surgery and turned their attention to the preservation of the remaining services; this followed the SRHA assurance that these at least, would remain the same. However, there was shock and disbelief when it was revealed that the similar sized hospital of Ashburton, in the Minister of Health's own electorate, would be able to keep their surgical services. 
To show they hadn't been idle the Balclutha Hospital Support Group announced the 'One Stop Shop' concept plan in October. This would put GP practices, plus all other outpatient and inpatient services under the one roof. But in October the CHE announced further cuts to services, which included the removal of long term elderly care, at Balclutha, Cromwell and Oamaru hospitals.

On the $21^{\text {st }}$ March 1996 Health Minister Jenny Shipley came to town expressing positive ideas about the outcome of the ongoing review. At this stage those who were the most outspoken and at the forefront of the protest had been invited into the planning. Thus only a few voices were raised in protest. In June more job losses were signaled. Anonymous and bitter letters began to appear in the papers sniping at members of the CHE's Utilization Review Committee.

In 1996 the Hospital Action Group emerged and called for a new local Health Board. The mayor called for the various protest groups to unite, and the editorial column echoed these sentiments. In 1997 the calls for unity were heard, and a new group with members drawn from the main protest groups, plus a member of the hospital review team, metamorphosed into the Balclutha Hospital Support Board. But not all of the locals were appeased by the formation of this self-appointed board. And the sale of the much lauded laparoscope (originally purchased for $\$ 100,000$ and eventually sold to a Fiji hospital for $\$ 16,000$ ) also without mandate, brought further criticism.

In 1998 , there were letters to the editor indicating that the community did not unanimously support the newly formed board. One suggested that fairy tales were alive and well following the release of the consultant's report. The writer recommended that “...this group should receive a reward in the literary world 
for the most imaginative writing for 1997; [as] their incorrect ramblings make for spellbinding reading" (Anderson, "Heath," 1998). The secret activities of the Board prompted a call for resignations of Board members. There was also anxiety about rating increases, to fund projects driven by the board, without recourse to a local referendum. A small group continued to oppose the closure of the 'hospital on the hill', but their comments were relegated to the back pages while reports from the proponents of the new plan were given greater prominence.

The wheels were in motion and a news release from the Clutha Community Health Committee Project Co-ordinator announced that the town centre health facility was going to happen and that local GPs were being approached to take up the opportunities to work from the GP suites. In August 1999 it is reported that the newly named Clutha Health First, (CHF) was to be part of a South Island pilot for telemedicine in a joint initiative between the Medical School and $\mathrm{HCO}$ - the aim being to link Dunedin, Invercargill and Balclutha with specialist expertise. There was also talk of a mobile surgical unit coming to rural areas in the future. In September the now named Clutha Health Trust appointed a new manager, the board was elected, and colour spreads of the new facility dominated the news.

The full range of primary maternity services had survived the changes, and was an integral part of the Trust's facility and services. The next section explores the activities of the midwives and the changes to their services over the decade.

\section{Changes to the Local Maternity Services and the emergence of the 'midwife'}

The decade opened with the Clutha Leader detailing the birth decline in South Otago. Statistics showed that that between 1979 and 1989 there had been a decrease of 455 registered births in the area. This trend continued throughout 
the 1990's with a drop to 214 in 1991. By 1994, 197 were locally registered with 109 of these being born in the area. A further slump in 1997 saw 176 births recorded in the area, 88 of which were born in the local maternity centre or at home.

In taking a look at the past, Heydon (1990) reports, that in 1920 most babies in the area were born at home or in the 1-2 bed homes run by local maternity nurses or midwives. In 1921 when the South Otago Hospital Board (S.O.H.B.), was being set up maternity beds did not feature in their plans. However, by 1932 hospital boards were required to provide maternity care. This prompted the allocation of some designated maternity beds at Milton and Owaka, with Kaitangata becoming the Board's maternity hospital for both the Balclutha and Kaitangata areas. In 1980 progressive regionalisation and the closure of small maternity units, resulted in all maternity beds eventually being located at Balclutha. These had been managed in a traditional shift system consistent with base hospitals around New Zealand.

Glimmers of fresh ideas around birth filtered through in 1990 with the advertisement for childbirth education classes. These were to be provided by a childbirth educator from Dunedin invited by the local branch of Parents' Centre. Changes were also happening in the maternity ward. Long overdue renovations became the opportunity to improve the furnishings and physical layout. This included a so called 'birthday bed', a comfortable and adjustable piece of engineering which replaced the hard narrow theatre beds ("Just What The Doctor Ordered," 1990).

In November, local women belonging to Parents' Centre were beginning to make their voices heard. They asked for more childbirth choices, the option of 
home birth, plus a community midwife to provide home based care for those choosing early discharge from the hospital (Clutha Leader, 7/11/1990).

Changes however were quietly continuing in the maternity ward. To facilitate these, the midwives hosted a Rural Obstetrics Seminar, inviting speakers from a variety of areas including, midwifery education, obstetrics, anaesthesia and paediatrics. This was also an opportunity to present the changes in midwifery, such as the return to autonomy of practice and the formation of the College of Midwives, to a larger audience ("Maternity services changed," 1991).

In the past, birth notices appearing in the paper consistently thanked their GP by name. If the midwives were acknowledged they were referred to as the nursing staff, or, in some instances "the lovely ladies of ward 5" ("Birth notices," 1990). But now the word midwife had begun to creep into some of the birth notices; even our names, as one notice read, "thank you to Jean for the catch of the day" ("Birth notices," 1991). The midwives were no longer invisible.

Photographs of local women and their babies were published weekly. This cooperative arrangement between a local photographer and hospital management was popular with the women and their families and great publicity for the local maternity service. Later in the year, two of the Balclutha midwives began antenatal classes with an emphasis on active birth.

Amid the changes and public protest, two of the midwives from the Balclutha maternity centre started an independent midwifery service with the support of the other midwives and management. It was at this time, that direct entry midwifery education, was being attacked by the OAHB General Manager. He stated, that the Board, "would not employ any midwives who graduated from 
the Otago Polytechnic Midwifery course without general nursing training”. The reason given was the threat to midwifery services in rural areas. He went on to say, "I don't think mothers care one way or the other about separately trained midwives, so long as the person is properly trained" (Bolitho, "Balclutha bound by policy," 1991).

The maternity centre launched the Baby Friendly Initiative in January 1992, which was part of an international drive to promote and protect breast-feeding. By now the midwives' names were appearing regularly in the birth notices and advertisements for their services were appearing in the paper. The birth of the first baby for the independent service was also celebrated and publicized.

While there had been no overt threat to maternity services there was the sense that these services were equally vulnerable. As if to preempt this David Trantor, whose campaign for rural services saw him walk the length of the country, opened his June letter with excerpts from Rosenblatt's et al., (1985) research on the safety of rural birth (Trantor "Health reforms," 1993).

In 1994 a local home birth support group was established. The independent midwives and staff in the maternity centre took advantage of this opportunity to publicize the philosophical and service changes in local maternity care. International Midwives' Day was celebrated with a gift for the woman who gave birth on the day, and this tradition continued over the ensuing years.

On July $19^{\text {th }} 1996$ the legislative change to Section 51 of the Health and Disabilities Act 1993, (concerning the provision of maternity services), resulted in the announcement of a new maternity package by four RHAs. This introduced the Lead Maternity Carer (LMC) concept, referral guidelines and specifications for information and care planning options, referred to earlier in 
Chapter Two. The General Practice Association (GPA), in the wake of this announcement asked its members not to take part in the new proposed system; warning that the funding constraints represented a potential danger to women. Women were urged not to get pregnant. However the midwives took advantage once again of International Midwives Day to explain the complexities and benefits of the LMC concept for the newspaper ("Changes explained," 1997). In 1998 there was the opportunity to publicize not just their service but also the New Zealand College of Midwives' (NZCOM) website, which both midwives and women could access for information and networking ("Midwives on the net," 1998).

The maternity unit opened in the new downtown facility and on the 10th of December 1998 photos of the first baby to be born at Clutha Health First (CHF) appeared. However in January 1999 it was realized that a helipad had been left out of the plans. This gap was highlighted when a baby needed urgent transfer and had to be taken to a nearby carpark to board the helicopter.

In 1999, the maternity services were once more under the spotlight with the review by the National Health Committee. Women were asked their opinions about the current maternity services with regard to their quality, ease of access, and choice. Nationally, women reported a high level of satisfaction with the current maternity services. However, rural women in a focus group told the Maternity Services Review that they received less services. The CHF manager refuted this perception, suggesting that this was an overview, and that women's individual needs were being met in Balclutha ("Less choice in maternity services," 1999).

However the insecurity continues. 


\section{Game playing}

In an attempt to explore the complex layers of move and countermove that punctuated the events over this period, I have as indicated in Chapter Four, played with Lyotard's (1997) concept of language games. My recollections of the changes during the decade, I now realize were most unreliable. In re-reading the local news, not only was I was surprised by the sequence of events, but even more so by the complexity and number of groups that emerged, changed and disappeared over that time. For me, it was the war of words that echo in my memory.

\section{A Lyotardian analysis of the Clutha Leader and midwifery discourses}

Lyotard's notion of language games, if employed to look at the events reviewed above, suggests that those who sent the directives with regard to service reduction were invested with some historical or current positional authority. And it would be reasonable to assume that these changes in direction did not emanate solely from the $\mathrm{AHB}$ and $\mathrm{CHE}$ management but that these organisations were simply conduits passing on the requirements from others whose authority they accepted. Similarly, at the local level in Balclutha, those who initially opposed the changes with such vehemence were in positions of influence within the local community. Thus, their interpretations of how these threats should be met and opposed also had the air of authority.

Such an idea explains to some extent the variety of approaches and guises that were employed to sell the changes. In addition how well this pragmatic approach worked, when members of the protest groups, who were most strongly opposed, were co-opted by management to become members of the review team. Thus not only did the project have the contribution of their skills and local status, but also the energy was diverted away from protest. They in turn became the senders of the message to those who had at an earlier stage stood beside them in protest. 


\section{Pragmatics and efficiency}

Lyotard (1997), argues, that the pragmatic outcome is a relentless pursuit of efficiency. This could be railed against but always in the end required an accommodation. The idea of efficiency was a constant theme used to rationalize the changes. There were also the moral arguments about over-resourcing of the South; the suggestion being that rural areas were soaking up funds that could be more usefully spent elsewhere in New Zealand. Such arguments, plus other language games that suggested that rural communities could manage their own health care, had the effect of softening up the opposition for the decisions that were already in place. There was also the argument for the greater good in respect of the Medical School. In this instance, survival was said to be dependent on the re-directing of funding in order to preserve clinical education and practice opportunities for the students.

\section{Moving margins}

There were margins within margins. The rural town of Balclutha was marginalised in relation to Dunedin, while the smaller rural hospitals in other towns in South Otago, were marginal in relation to Balclutha. Within the rural populations the people were further split by economic, social and cultural differences. And while these divisions could be overlooked when there was a common cause, they were thrown into sharp relief when their leaders were seen to be pursuing self-serving opportunities.

The privileging of the surgical services, as the focus of protest, appeared to be accepted by the community. But when compromise in the shape of private surgical facilities was proposed, it was bitterly opposed by the section of the community, who, held fast to a free and public health service ideal. To give up the fight was seen as an act of betrayal. But in the climate of privatization and 
competition, to cling to the idea of a fully funded public health service, was regarded as an outdated concept- a marginal aberration.

Also missing from the debates were women's voices. Men occupied the senior management roles in the health structures, were the GPs, business leaders and spokespeople for the protest groups. They represented the local council, and edited the local newspaper. Similarly, there did not appear to be any significant contribution from Maori in relation to their local health needs and priorities. While it is not possible to project what, if any difference, this would have made to the outcomes, a more balanced representation would have better informed the debate.

\section{Midwifery out of the shadows}

Over the years the Balclutha midwives had struggled daily with the restrictions on their practice, which largely emanated from the medical model of birth management in place. Smoldering away had been the desire for change, and in 1990 this opportunity was realized. It was it seemed, an advantage to be out of the limelight. Apart from occasions when the midwives sought out the opportunity to be interviewed, or to place an advertisement in the news, the maternity changes didn't attract attention. The focus for protest was on what were seen as flagship services such as surgery and medicine, which diverted the attention of the doctors and management. Thus the maternity staff were not expending energy and emotion defending their service in the public sphere. Nevertheless, the pressure, to economize further, continued. The response was to reorganize the maternity service, abandon the expensive shift system, and offer a CHE based LMC option. While the workload and responsibilities increased for the midwives this was offset by the opportunity to practise more flexibly. 
In New Zealand during the early 1990's the morale of midwives was high. The midwifery model had become the dominant midwifery narrative among midwives and many users of the maternity services. The capping of the budget with the modular system, the improved outcomes and client satisfaction, meant that it was also an efficient model. Thus midwifery care was fulfilling Lyotard's pragmatic rule.

Part of what made these changes happen were the language games around birth, midwifery and autonomy. For example the naming, or rather, re-naming of the midwife, was traceable in the birth notices in the news. So too was the reclamation of a scope of practice that was centred on expertise and experience in normal birth. Hewison (1993) illustrates, how the renaming of words used to describe aspects of childbirth, are used by midwives to differentiate their social model from the medical one. For example 'birth' rather than 'delivery'. There was also a feminist statement in insisting on calling clients, women, rather than patients. Such a process however did not occur in a vacuum. It was part of the metanarrative from the New Zealand College of Midwives and the women, with whom they had aligned, in their common aim to extricate midwifery from medicine and nursing; both in practice and education.

\section{Summarising the local news and the language games}

It was the perceived, then real, threat to the surgical services that caught the imagination and fired up the community more than any other crucial health issue in the locality. Men who were prominent and vocal within the community led the protest groups that informed and rallied the local community. Over the decade there was an inexorable withdrawal of resources, which no amount of protest or organized lobbying could halt. Many of the moves were planned out of the public eye, with locals lulled by reassurances or persuaded by moral arguments about rural overfunding and the need for efficiencies. 
The cracks in unity had always been present in the community but differences had been plastered over in the interests of presenting a united front in the face of threat. Disappointment however, was not just reserved for the outsiders, for whom there was already distrust, but also for those protest group members, who, appeared to change allegiance or were seen to be self-serving.

The maternity service survived the changes albeit in a leaner form. Out of the spotlight the midwives took full advantage of their newly won right to practise autonomously and to promote a midwifery model of care to the local women. These changes were welcomed not just by the midwives and their clients, but also by the funders who saw the opportunity to contain costs and meet their requisite service specifications.

Thus all groups, to a greater, or lesser extent, participated in the language games during the decade. How successful the local groups were in securing any advantage is difficult to tell but protest in any form possible appeared to be the only alternative to capitulation. Clearly, groups who were fulfilling political policy directives had the best chance, of securing a stake in the new health environment. How successful the changes have been, and in particular how local maternity has fared in the new environment, is canvassed with the participant midwives in the next two chapters. This assessment, plus their memories and reflections, form the richest layers of this research project. 


\section{CHAPTER SIX: TALKING WITH MIDWIVES}

This space is in between the collection and the writing. It is a time of massaging, squeezing, ignoring, being captivated, and a little afraid. It is making excuses, procrastinating but getting ready. (Journal entry, July 2001)

\section{Overview}

In this chapter I explore the transcripts of the five midwives who agreed to participate in my study, using a postmodern feminist discourse analysis. The study looks at the changes that occurred over the decade of the 1990's, and the challenges then and now, of sustaining rural midwifery practice. Excerpts from the participant's transcripts are represented, in italics. Each transcript is numbered one to five with the last number representing the relevant page number in the transcript. I used the five broad open questions (see Appendix C) only when the topics did not arise spontaneously. The transcripts were first listened to, then, read with a view to finding some common patterns and statements.

The conversation digressed often returning to the topic or some other area of interest. Changes in midwifery were recalled, as were the local difficulties that had been, or still were being experienced. Some of these I had forgotten while others remain vivid memories. Events that had loomed large for me, were often not recalled, or not seen as particularly significant by the midwives. And some shared events had been experienced variously. For instance, I was surprised at how little the radical health changes of the time were recalled.

Setting out to interview the five midwives I have known and with whom I had worked over the period, under study, was for me an anxious process. However, 
once we were over the initial nervous moments the conversations flowed freely. Each interview was taped with the participant choosing the time and venue.

\section{Working in rural practice and the challenges of the decade}

\section{Arriving in rural practice.}

For the midwives in this study, arriving in South Otago had little to do with their midwifery practice. Rather, each had moved to the area for family reasons. With them they brought a unique history of experience and educational preparation. And those who had previously worked in rural areas anticipated that work in this rural area would be equally rewarding.

I was looking at working in Rangiora, which was the rural hospital, which was closest to the farm that my future husband lived on. [I] discovered that I really enjoyed rural practice. So I always wanted to work in rural because of the continuity that you could provide there. So I never wanted to work in a base hospital I always wanted to work in rural. Well particularly because I tended to do night duty and doctors never really wanted to get out of bed at night. You tended to find that you were doing more things by yourself without lots of interruptions from other people and so you were seeing women through (Trans.1: 12).

I had come direct from working [In Rhodesia] in the bush to Cromwell and down the South teaching the local GP there how to do vacuum extractions and that saved us having a lot of transfers down to town (Trans.2: 3).

And for another there was experience of teaching midwives in Papua New Guinea where men tended to be excluded from childbirth and the

"... midwives tended to do things that were the role of the obstetrician such as breech deliveries and removal of retained placentas..."(Trans $3: 2$ ). 
While, one came for 14 weeks. “... and I haven't left yet, and that was six years ago" (Trans 4: 1).

In 1980, another was working in the rural maternity ward without midwifery education and found that:

So, often you were out of your depth and I enjoyed the birth, but, not knowing what you were doing is really rather scary. I hated the system but took the bull by the horns and thought about doing midwifery. The Advanced Diploma of Nursing (ADN) was all that was available at this time and .... [s]o that's how I became a midwife (Trans 5: 2).

\section{Leaving the familiar: Learning curves and closing the gaps}

The different educational preparation, previous experiences and exposure to rural practice impacted on how easily new skills were learnt, or historical practice patterns adapted for the LMC role. All talked about their learning curves, which included practice and business management skills, as well as the challenges of changing their role within the community. Differences in education and experience were thrown into sharp relief following the changes in 1990. The midwives identified areas of knowledge they needed to work on before feeling ready to assume responsibility for total midwifery care.

So yeah my training wasn't great...I think probably... yes I mean, I think those were the gaps, when you're really responsible for your practice... because you could sort of get yourself through because you didn't take responsibility... you always handed on [as] you were in a shared care doctor type [relationship]. About every month I write another list of things that I need to update on ... all the things that I didn't learn in my training (Trans 5:4-5).

The need to quickly update skills was also an issue for the more experienced midwives.

We had never done venipuncture as such and never done any suturing. Those were two big things, although we did courses on how to do it, it was always a bit daunting just to stick a needle in someone and suture (Trans.3: 6). 
...and antenatal work was also a challenge. ...but I had never done anything much antenatal so there was that huge learning curve about looking after women from early pregnancy [that I] just didn't have a clue about. I think when you set out in practice and you have always worked with medical practitioners, in a rural area when you set up in independent practice you have to be able to do everything. So you had to feel fairly confident that you could do this. [We] had the skills required and some of those skills we had never needed. And I don't think you ever feel 100\% confident in it; we just have to keep plodding on and working on it (Trans, 1:7-9).

The lack of business skills was also cited as a challenge.

...but perhaps too big for me being not so organized and business like. It was the book work and [from] having never done any books at all to having to keep records... and you didn't get paid until you had done book work... and GST...I didn't want to have to bother about things like that (Trans 2:9).

...we had meetings and meetings before we set it up to decide how we were going to do it...um I mean it was all new stuff [it was] so exciting but I was very nervous too (Trans, 1:6).

\section{Helping each other to grow}

In 1992 the independent service was launched in style.

[Going independent]...it was "scary fun" Yeah when I think about it now what a cheek we had. Sending out invitations to all the GP's and local surgeons and anyone around town... there were clinical issues, but we were reassured of this fantastic support from the staff in the local hospital, yourself, and the other staff, plus Queen Mary at the end of the line- they were supportive in those early days (Trans, 2:5).

The support of colleagues and those staffing the unit were vitally important to enable the LMC midwives to function and survive. The midwives felt that this support enabled them to overcome criticism from those who opposed their move. This signaled, not just a concern for their colleague, but also an 
indication of their faith in both the ability of the woman to birth locally, and of the midwife to provide her care.

I was fortunate that the other midwives tended to know when you'd had a grueling time and [they] would just cover for you until you had a chance to have some sleep. Sometimes you got about four hours before the next work popped up - also had some visits to fit in too before you went on the ward or something. But we were fortunate that the three of us that were doing continuity at the time [and] seemed to be aware of each others' situation and [we] would very often ask for help (Trans.3: 5).

In one instance two midwives found themselves unable to back each other up as their women were labouring at the same time and the midwife in the local unit had to cover for them both.

"... I ended up being in hospital having two babies all within a minute apart of each other...so poor '*' was dashing between the rooms" (Trans.4: 11).

A bonus of the new experience of autonomous practice was that it brought rural midwives together with midwives working independently in the urban areas. For some this was the first time that they had met and talked together.

So there were all these midwives that we really hadn't had anything to do with before and we sort of all got together there and networking with that group was really exciting (Trans 1:7).

Thus we were a disparate group brought together with a common purpose within a particular time in history. In the next section I explore three common discourse or language games that emerged from the texts. 


\section{A rural midwifery discourse?}

What I say and do always has a multiplicity of meanings, ambiguities, plays and these are not always coherent...therefore if we are unable to express ourselves and comprehend ourselves we may be even more opaque to others. However if we betray ourselves unintentionally others may well understand us better than we do ourselves. (Young, 1990:310 \& 311)

\section{Mapping the rural midwifery discourse/s}

The reflections, ideas and opinions of the midwives collapsed in time with a mix of past and present memories, plus thoughts for the future. Thus, a picture was painted of cross currents, tensions, contradictions, conflicts and rewards that represented the landscape within which they work and live.

In mapping the discourse positions of the rural midwives three discourses or language games emerged and appear to construct and reconstruct the midwives who work in this rural area. These I have teased out of the texts. They include their faith in the possibility of normal birth, a sense of rural difference, and their embedded relationship and visibility within their community. These discourses melded at the edges thus any separation I have suggested is both artificial and arbitrary.

\section{Seeing is believing: The discourse of normal birth}

The defining representation of these midwives was their grounded belief in the possibility of normal birth. This confidence about birth extended to birth being able to occur at distance from secondary care facilities. Thus the belief was not just that it was reasonable for women to confidently pursue normal birth but that it was safe to pursue this event close to home in a rural locality. This faith persisted despite the midwives having to deal with unanticipated acute situations within their rural practice, or having at times to transfer urgently to secondary services. 
There was rarely any surprise about how well the women managed and it was from women that the midwives believe they learnt or re-learnt much of what midwifery was all about.

[W]omen were actually making up their own minds about how they wanted things to happen and...so that was what really changed my opinion about birth and how it could happen (Trans 1:5).

...because it fundamentally came down to whether the woman could do it or not, it wasn't really anything to do with me. You know what I mean I knew that I had the skills to help or to recognize the abnormal and that was what we were trained to do (Trans 4: 25).

Just that relationship, and with woman and looking after them from that first pregnancy test and telling them about this new scheme and just being thrilled that women were happy to and wanting to try it and wanting to do it (Trans 1:7).

...we have got good autonomy like the last two births of mine were normal births and I mean they have been wonderful that is because we are that little bit distant...we have got that autonomy... and that is really quite nice (Trans, 5: 16).

...because I had quite a lot of primips that came through my practice, and they said "but you haven't got epidural in Balclutha". And I said "no but we have a beautiful deep birth pool" (Trans, 1: 20).

I remember the first posterior baby that I had...she had a posterior the first baby and then she delivered her second one the same....quickly standing up (Trans, 4:18).

\section{The birth of homebirth}

In South Otago home birth had not been an option until the independent service began.

Yeah [homebirth] was really enthusiastically used for a while there. Whether it was just a glitch or the type of woman coming through, I think in one year the most I had was twelve and that was wonderful. And of all the women that have chosen home births only one was transferred and that was a private thing (Trans 2: 12). 
I was at a homebirth, away in the background there, in the garden and talking to the cat, then going inside when she felt like pushing and staying by the fire (Trans, 5: 7).

Following a first home birth the feedback for the midwife was very affirming.

....and it was the letter I got from him that I thought so special and he said how...it had made him feel so much closer to his partner and he had found it to be really special involving him and I thought "gee this is good" (Trans 1: 8).

And the joy of being the second midwife at a home birth.

...so I would get out of bed and go to the birth. And then go home and go back to sleep and wake up and think it was all a pleasant dream really... so that was quite nice (Trans 4: 10).

\section{A discourse of rural/urban difference}

The integration and mobility of the New Zealand population makes it difficult to imagine a 'country-city divide'. But even with this mobility, provincial areas and their populations tend to develop a strong sense of their rurality and identify strongly with local issues.

It may well be that midwives on city boundaries, or in small towns, also identify as rural. In fact there may be a continuum of a degree of rurality, with those in easy reach of secondary services having different issues to those who work in the more remote areas. But regardless of how geographical areas are defined by others, the midwives in this study saw themselves as intrinsically rural and this appeared to be a defining difference.

Griffith (1996), looked at what motivates midwives to work in different areas and suggested that it may be that a highly medicalised working environment 
shapes the beliefs and ideas of those who work there. Equally this may occur for those who work in rural areas with minimal technology. However, it may also be that individuals are attracted to work in the areas that best match their beliefs about birth, whatever their rhetoric to the contrary (Griffith, 1996).

Garcia et al, (1990: 4) suggest that:

Most mothers travel hopefully, trusting that medical intervention will not be necessary... whereas health professionals may be from the opposite view and all pessimistic travelers. The management of this anxiety, [explains] some of the organisational aspects and bureaucracy in institutions.

The rural midwives appear to also travel hopefully and support women choosing to birth locally.

I have often thought if I was to start up again in just a small way, I would stick up a bloody notice somewhere - "taking bookings for women birthing in Balclutha only." People are going to town and they don't need to (Trans. 2:19).

It is much nicer to have your baby in Balclutha, you know you are not listening to somebody else down the corridor giving birth while you are in early labour. You know you have got the place to yourself and it's just got that lovely pool now and it is just so good... and I do water births and it is good (Trans. 1: 22).

The rural midwives in this study, considered that the totality of their work was unseen and unappreciated, and that the births that proceeded without fuss were not witnessed by others. Thus their day-to-day work was invisible. This they believed was partly due to a lack of understanding of the breadth of the rural midwife's expertise and knowledge of the woman and her family.

...just trying to keep them (the woman) going and yeah, there is a definite misunderstanding with rural to what we are doing (Trans, 1: 22). 
Often they were required to act alone in emergency situations if other health professionals were not readily accessible.

There was once I had to do a breech delivery unexpectedly, arrived in second stage basically. It was a concealed pregnancy. There was no one else around who could do a breech delivery...but it didn't faze me I knew exactly what I should be doing and um I was very relieved to find the baby was okay (Trans, 3: 6).

Road and weather conditions played a part in the logistics of working in the rural area. At times this is a bonus on a good day making it a pleasure to be out and about. One pleasant memory for me was having lunch by the Clutha River between visits. However, also memorable, were the snowstorms and floods.

I really love getting out in the country [but] I remember striking a road that was very loosely shingled and almost rolled the car one day. Ah that gave me a fright. [I thought] this is a pretty risky occupation I've now got. [And] years ago when we worked in Hawke's Bay and had to transfer all our complicated deliveries out [I] had several plane trips. The children were quite small. It was quite scary in a small single engine plane looking at your home down below and wondering if you were going to get home safely to your kids (Trans. 3: 9).

I remember it snowing... when I was driving through the night and there were snow drifts...I went to Waitahuna; it was a scary night because there were no road markings on the road so you couldn't see where the road finished and where the ditches were. We drove slowly even though we were going to someone in premature labour ...it was horrible (Trans. 4: 14).

\section{The trials of transfer}

This difference between practice realities was highlighted at crisis points when transfer to secondary services occurred. Transfer of women or infants to an urban centre is a part of rural midwifery practice. It is however for most rural midwives an anxious and at times fraught process. Not only are they dealing with the events that have prompted the transfer, but frequently the spoken or 
perceived censure, of their urban peers. They sensed that they were seen as the 'yokel' when in fact they had a wide range of skills and scope of practice.

Transfer was not an easy thing to do, “...it was just necessary thing to do and you just went" (Trans. 2: 7).

[Y]ou know you have got that time if you need to transfer. But you are also watching and always questioning. Yeah...you really do feel a responsibility...with the distance and isolation...especially as its not easy to pick up a telephone and talk to a paediatrician. Sometimes you might have questions that seem rather silly, or think you should know them... sometimes [it] is very difficult to do (Trans. 5:13).

Creasy (1997), looked at women's experience of transfer in labour, and found that while women were frequently disappointed with their labour outcomes, their feelings were ameliorated by aspects of care such as information, explanation, debriefing and continuity of care from familiar practitioners. If the person they knew had also been present at the crisis point this was even more valuable to the women. Thus, while transfer is an inevitable possibility for a proportion of locally booked women, it need not be a negative one. And "while such trust does not rely totally on a previous relationship, it is easy to see how it is more likely to occur within one" (Creasy, (1997, cited in Patterson, 2000: 130).

Transfer can occur after many hours of labour and there is always the tension of deciding whether it is appropriate to stay in support or return with the ambulance.

By the time you get to town with somebody who has been distressed in an ambulance... you are absolutely drained you know, just trying to keep them going. So yeah that is very hard, it's a dilemma either way whether you handle the care or you don't. 
Yes I get stuck in Dunedin. I either handle the care, or don't continue to care for women and come back in the ambulance. [I] leave them with the core, or, I stay and can't get back unless I get my husband to come through and get me or something...which is done in the middle of the night (Trans. 1:21).

Well [one time when I transferred] they said they were too busy to take over from me and I had been up for about 30 hours at this point and had absolutely had it (Trans. 4:5).

It wasn't always easy coping with an ambulance trip. Tiredness was one problem but for some travel sickness was also an issue.

I tend to get car sick in the back of an ambulance. So that was never a wonderful thing to transfer for something. I always think that ambulances should be made like limousines, [it's] more like being in the back of a truck (Trans. 3:9).

The expectation that the midwife transferring in would deal with the technology was also a problem.

It is not a very favourite place to work because you don't know where things are and people don't really help. Even if you are support person or support midwife you have got to go and find things and sometimes wander around and get lost. It's very medicalised there...can't shift things around how you want to (Trans. 5: 17).

Attitudes too could add to the tension.

People would make silly little comments in front of the woman and you knew the conversation got all hushed up when you went out to the [desk]. You have to be big and brave... I mean you have to have a helluva lot of confidence to do it (Trans. 5: 20).

However, if the midwife worked for a while in the secondary service or cared for some of her clients there, they found it easier, though this acceptance 
appeared to be conditional on the observation of particular mores and institutional norms.

So you became known on the 'core team' and then have clients or whatever. Because you already know the way they work...what they would like to happen, who you could annoy and what you could ask certain people to do and what you couldn't (Trans. 4:21).

The hospital politics are acknowledged by Cochrane and Murphy (1993: 264), who suggest "[i]t is difficult for a nurse or midwife to be assertive in the interests of the ...client without incurring the disapproval of the doctor."

Savage (1990: 336), comments on the service organization that contributes to these situations. "Because midwives stay with women during labour, they understand birth. And yet because of the way we have set up the system, we have almost destroyed that for many midwives."

For all that the interface is fraught, there is also some understanding of some of the frustrations and issues that confront their urban colleagues.

But it is not easy for them. [They are] short staffed and the services [are] less and less designed for them to look after women in labour really... isn't it? (Trans. 1:22)

Sandall (1997), found that of the three models of care studied, the one, which provided flexible woman-centred care, was associated with the lowest rates of burnout amongst midwives. Other characteristics associated with this mode of practice include a sense of occupational autonomy, social support and meaningful relationships with the women. Models of care that lacked these characteristics were less sustainable and were frequently associated with disillusionment. 
So while there were frustrations and tensions for the rural midwives, it would seem that these elements could easily be incorporated into their practice. Rural communities however, are complex entities and maintaining a comfortable place within them is a daily task.

\section{A discourse of community embeddedness: The weight on your shoulders}

A sense of immersion in their community was common to all the midwives interviewed. The community confers on them status and respect but also expects a strong commitment in exchange. This mantle of responsibility at times weighed heavily on the midwives with an expectation that they would always be available. Thus the midwives saw the relationship with their community as a tensioning of support and censure, affection and rejection.

I think it is the weight on your shoulders... you're always putting a lot of energy into watching. I don't know if all the midwives do that (Trans. 5:13).

The only problem was people calling me all the time...but maybe that is a problem in the rural because I don't think (midwives) find that in town...Yeah eleven at night the phone would start ringing... every night (Trans. 4:29-30).

Just sometimes there is difficulty in being a permanent member of the rural area in that you are... people know who you are, and when you make a mistake its heavier...because you can't hide from it. [In a] rural community everybody knows what everyone else is doing... everywhere you go people know what you do and you can't hide from what you are doing. [Even though you are isolated] you really stick out in the community. Which is good and which is bad (Trans. 5: 22).

Langley (2001) made me nod and smile in recognition, as she described her caseload adventures in rural Wales; the skirmishes with wandering stock, the winter road conditions, and her conspicuousness in the community. She comments: 
Knowing and living with your caseload has its good and bad points. Getting to know generations of a family and 'catching' siblings and cousins is a privilege. Being accosted next to the frozen peas, as you are about to throttle one of your children is not. (p.318)

Just doing the normal everyday activities and household shopping reminds you of how visible you are. There is no opportunity to pass unrecognized or to avoid being approached.

It takes you an hour and a half to go shopping. Don't take the kids because they get sick of you stopping and talking to all the babies and mothers and grandmothers who tell you- "Oh my daughter is having another baby". So you become very much part of the community, its good as long as things are going okay (Trans. 5: 22-3).

In an effort to preserve some privacy the midwives made decisions about how they managed the visits.

I don't think it was anything to do with the travel that stopped me doing all the antenatal [visits] in the community just felt that a lot of women didn't really want that. Some of them were in town and would have far rather come to my home and I did that for a while, but I didn't really like having my home open to everybody (Trans. 2: 11).

Thus, the community although referred to as a single unit is seen as a complex entity and perceived as having supportive but also a prescriptive capacity.

\section{In summary: Discourses of harmony, contradiction and conflict}

This combination of ideas and realities of rural practice painted by the midwives distinguishes it from urban practice. The midwives, suggested, that to work successfully in a rural area the midwife needs to believe in the possibility of normal birth and have the confidence to support women in their own locality to achieve this. The midwives also acknowledge a more integrated and conspicuous relationship with their community, which is a part of their rural identity and rural difference. This difference is accentuated at the point of 
transfer and interface with urban secondary services, where they believe their skill, knowledge and work reality is poorly understood.

These components of what I have named as a rural midwifery discourse emerged as statements within the transcripts. While expressed slightly differently in each interview they conveyed a common discourse position. However there are discourses within the rural midwifery discourse, and within each of the components of which it is comprised.

Women, according to the midwife participants, affirm the discourse of normal birth by demonstrating their ability to birth, at home or in the rural unit. However for a proportion of the women, transfer will be required. This apparent contradiction was a reality acknowledged as part of rural practice and did not appear to warrant special mention. Neither was it seen as in any way a reason for not offering a rural birth option. Thus, the midwives were prepared to support women who chose to birth locally, while at the same time remaining alert to the possibility that transfer or emergency care, might be required.

Contradiction and conflict was also a part of their relationship with their urban peers. Common to all the transcripts were statements about the tensions they experienced with urban secondary services when transferring a woman, or, working with her in the hospital setting. These included a lack of logistical support when needed, and sometimes, critical comments being made about the woman's care prior to transfer. These interactions marginalised the expertise of the rural midwife, particularly in relation to proficiency with technical and secondary care apparatus. Conversely, the rural midwife participants' statements indicated an understanding of the 'core' midwife's position, which was seen as lacking autonomy in relation to her midwifery skills. 
Similar contradictions were a part of the complex position with their community. While the community was seen as supportive it was at times unreasonably demanding. The midwives were valued but this position was not wholly secure, being contingent on their practice living up to expectations. Examples of this were statements about being watched, high expectations of availability, and being unable to go about their personal lives without being approached on work related issues.

These complicated discourse positionings concur with both feminist and postmodernist ideas. While the complex mix of discourses would seem to manipulate and constrain the rural midwives, they demonstrate their ability to use different positions whenever these are useful. Thus, rather than being puppets, the participants demonstrate that they are able to use discourses that serve their purposes and to ignore those that threaten to marginalise their rural identity and beliefs. Moreover, they balance the contradictions to do what they believe is important work.

In the next chapter, the midwives pick up some of the discourses from the interviews, add a current and future perspective and debate the pros and cons within the focus group. 


\section{CHAPTER SEVEN: A FOCUS ON RURAL MIDWIFERY PRACTICE}

Gossip, anecdote, information, experiences, wisdom, old wounds, new wounds, cross talk, passion, despair, weariness, toughness and humour. The soup, of the focus group. (Journal entry, July, 2001)

\section{Overview}

The meeting for the focus group was like a reunion. Some of us had been out of touch for some time, so there was some catching up to do. We met at a pleasant venue in rural South Otago with lunch ordered to follow the session. I set up the tape recorder and we settled around the fire with coffee. The main themes and ideas that had emerged from the individual interviews, had been collated and sent to the participants previously, plus, on the day there were a few starter topics circulated should we need them. The topic list included the issues and challenges that had been raised in the interviews, plus thoughts on future sustainability. I did not formally establish any ground rules and while there was some cross talk, the discussion was successfully captured on tape.

The most commonly occurring ideas, beliefs and ideological statements that emerged from the interviews had been collated and included in the post interview letter to the participants. These covered individual education and training, the need for business skills, the impact on family and social life, the positive aspects of rural practice, the need for support and access to clinical and educational updates. It was suggested that these were only some of the possible topics that might be discussed. In addition it was suggested that we could also look at future strategies for rural maternity services, as these had also been raised in the interviews. (See Appendices E and F).

How much the direction of the discussion was influenced by my starter questions and how much by the participants' interests was hard to tell. Tierney 
(1990:30), suggests, that when translating stories, we can only capture and reproduce them with a limited insight. Thus "[if] postmodernism has created an ideology of doubt, it stands to reason that our research endeavors also need to reflect that doubt". Which leaves me wondering if we would have covered the same ground had we started without a point of reference.

\title{
The local changes and 'team' discourse
}

The talk began with discussion around what was happening in the local area at the present time. The midwives still in practice locally, had concerns about the Trust's plan to provide an LMC option in addition to their facility role. This, independent midwives said, would be in direct competition with their service. It had the potential to make both options uneconomic, plus divide what was already a small team.

But the way it is being handled now means that we are being put into a very competitive environment...and...um we are going to be...you know... because it is competitive it means there is not a lot of sharing... it means that there is a degree of secrecy as to what is happening and the strategies (FG. 2).

There was also the fear that it would threaten the viability of the maternity unit if both services became uneconomic.

\begin{abstract}
Absolutely, yeah so it has threatened services, whether the women choose to go to [the Trust service], or... if the women stay with us and use our services [then the Trust service] is not viable financially, [and] it threatens the whole thing-it threatens the facility (FG 1).
\end{abstract}

The midwives were unsure as to how well women were being informed of their choices for birth, and opinion was mixed as to whether or not this happened. Clearly the midwives were getting some women referred to them from local GP's who did not act, as LMCs, and for the most part relationships were cordial and collegial. However where a local midwife felt unable to continue to work 
with a local GP, or conversely, a GP refused to work with a local midwife, then for some women this meant that they would not be able to choose to have both practitioners involved in their care. In this circumstance the woman would be referred to the Trust for midwifery services.

\section{Fearing a return to the past}

Also of major concern were the planned changes to DHB s and Primary Healthcare Organizations (PHOs) (The New Zealand Health Strategy, 2000). The midwives were anxious as to how these events would affect their work and income. Should primary maternity funding be devolved they believed that they would be compelled to join a PHO and thereby lose their independent status.

...I picked up my mail from down at the hospital yesterday evening and ...one of the things was [about] a providers group meeting thing-you know? to do with that DHB thing. And one of the things that it said ... was um would the GP's be willing to work for a salary? It has got me very worried because you know if obviously they are looking at putting a package together for our area and if they are looking at putting together a primary providers package in our area that includes us doesn't it? (FG 1).

It just worries me that we will be sucked into that perhaps without any real say-so $(F G, 3)$.

The notion of a 'team' approach was not popular.

"It would be a huge step backwards" (FG 1). And if the change "was the team approach it would be with that strong medical model which we don't need" (FG 2).

Yes because you know where we started... well I know where I started, I know where my history began here, and it does feel like turning the clock right back, and going through all that struggle again... I don't have the energy for that ( $F G 1)$.

Yeah, I have to say it looks a bit gloomy at the moment really. But we have struggled through things before (FG 1). 
I just think we keep on and keep on struggling because I can't see an answer, I really can't ( $F G$ 3.).

\section{A sense of missing the boat}

It was thought that they had to some extent missed the best opportunity for developing the maternity services. For instance, had the team of midwives as a group, gone independent, and put in a bid to manage the service and staff the unit, the current situation might not have happened.

[managing the service is what] we should have done (FG 1).

I know, I know, we should have then it would have been acceptable (FG 3).

While the decision not to team up initially was regretted there was also an acknowledgement that some of the midwives felt unprepared at that time for the challenge- particularly at such a time of uncertainty and change.

But it was too hard to do [then] because you needed everybody (FG 3).

We lacked the experience, we lacked the energy, the business knowledge, to be able to go ahead and do that. We had sort of airy-fairy ideals that would work but we didn't have the knowledge (FG 3).

\section{Advertising and promotion: Borrowing from the discourse of competition}

To help secure the service, women needed to know about it and feel confident to use it. There was the sense of the need to boldly advertise the service. The signage from the first independent midwifery service had worked well to evoke interest and comment from locals and those passing through Balclutha.

And we know that we need [to put up a hoarding] do something like that (FG 1). 
Being nice doesn't work. It doesn't work you have to be strong You have to be nice and strong (FG 3).

You do, you can't namby pamby...we have done that and wangled around things that didn't work. You just have to get straight to the point (FG 1).

When asked about advertising in the local newspaper;

I do a little and I am going to be increasing.... and I am thinking about maybe doing once a month or something, you know regular and I am going to put something on the local radio station which is very cheap advertising...And I have got a hoarding which I have been given permission by the council to put up down at the bottom of my lane... and we are hoping to get a visible presence down in town there (FG 1).

This included looking at the possibility of using an empty shop front.

But I mean we are looking at that now because we are in this competitive environment at the moment so we need to get competitive (FG 1).

But promotion requires time and energy and some knowledge of effective marketing.

I think it is something that we need to put some energy into as well.

And that is the difficulty often we don't have the skills for marketing (FG 2).

I think that there is a business womens' magazine full of those things and a Dunedin contact for short business courses (FG 5).

You could always work with a marketing student to do a project (FG).

Yes my son is doing marketing (FG 2).

I think marketing is a big thing (FG 5).

Ask the council if you could have a sign put on the post, [at the entrance to town]. Like some towns have doctor you could have midwife (FG 3). 
However the midwives didn't have a clear idea of what numbers they had, or how this related to the total number of potential clients in the area. This meant that planning was a guessing game.

But you know if the local women decided to have a local midwife as a care provider, I'm sure there would be plenty of work for three or four midwives. But the existing pool of women that we have there is really not enough for one and a half or two really. Is there? For thinking about income. Yes for fulltime (FG 1).

And there was a belief that local women were unaware of what was available.

Because they haven't heard it all before, It's all word of mouth its parents you have to talk to. The rural women's network and...talk about this and the opportunity and who is involved...(FG 4).

\section{Introducing new graduates to the rural midwifery discourse}

There was unanimous agreement that for the future of rural midwifery you needed keen new graduates.

Well I think for a new graduate, a team of midwives probably works best because then you have got different people that you can call on... And I think there are things you know you need to learn (FG 4).

There was the hope that the midwives could attract a new graduate to their team who could help with some call relief and in return they could provide mentorship. However, uncertainty about the future makes this difficult.

Yeah ...[what] I have been hoping would happen is that we would have a new grad come to the area and set up practice and we would mentor and support her and we would all be cooperative and work in together. ... There is not enough work for people to work in a [competitive] way in this area and it puts our service under threat really (FG 1).

Oh you have to get keen young new grads. We had that here with '*' and '*' that was good. But there haven't been any keen new grads since (FG 3). 
No but I know it will happen I was confident in time that we would get someone. But there is too much talk about the facility going. If you could say if it was only '*' and I [there]... there is definitely room for another grad. But because we have this threat of a whole new set up, it has been too uncertain of what the workloads would be [which would make it difficult] to attract a new grad (FG 1).

\section{Suggestions for managing workload}

It was acknowledged that rural practice put different demands on a new graduate. Thus, how they were prepared and supported was critical. It was suggested, that, "you marry them off to locals" (FG 3). Such a strategy would keep them in the community. However, there was the issue of young families to be taken into account when younger midwives worked in rural areas. Some strategies for managing caseload finances and family were debated and these issues became entangled with philosophical ideas within the discussion.

[One] way around that would be to set up a business and everyone take a salary from that business and so that all the money from the work you are doing goes into that and... (FG 1).

[If you have] individual caseloads, So what '*' is saying if you miss the bus (birth) you miss the money (FG 4).

The only way to avoid that would be set up a structure [where] you have got a business and you are paid a salary from that and therefore if you miss a birth you don't necessarily miss the money (FG 3).

If you did do that [you need good leadership] in the area that could guide a team into a proper business management. I could see it would work (FG 5).

I think you have to get on really well to do that, and I think you have to be on a very equal partnership... without any notion of, I am the senior partner and you are the junior partner. I think you really have to have a great deal of trust in one another. Some people could do it and some people couldn't (FG 1).

I think you have to learn to be able to do it. I don't think I did it very well at all. I think you have actually got to be able to learn to let go and 
have confidence in your partners. I think it is a learning process ( FG, 3).

The midwives reflected on the pressure following the Section 51 legislation to compete for clients (Notice Pursuant to Section 51 of The Health and Disability Services Act 1993 Concerning the Provision of Maternity Services, 1996).

We all wanted to be there, it is part of the job working in partnership and continuity [and] that places you in competition (FG 4).

I know but we have to relearn that bit (FG 3).

There was also the sense that something special might be lost if a midwifery team approach was adopted.

We have got these ideals and its such a strong part of your philosophy for autonomy of practice. I guess it is you know the added extra bits that they get the midwifery. [And] the midwife gains a lot really (FG 5).

\section{Educational preparation for rural practice}

The degree of confidence a new graduate has about working in rural areas may depend on what exposure she is offered in her midwifery education programme to this area of practice.

... my feeling is that if you want to train a rural person especially a rural woman to do that job then you have to [offer her the opportunity to train] in her rural area as much as possible (FG 1).

Financial support from the community was thought to be one way of making this a possibility.

There was however much discussion on the current length of the rural placement for student midwives. This was thought to be too short and there was even the radical suggestion made, that the length the rural placement be 
increased and the urban placement decreased. In Otago the rural placement occurs in the third year of the Direct Entry Midwifery course and is of four weeks duration, whereas other clinical placements are considerably longer.

Well I can't see any reason why she can't spend her whole time in rural apart from her classes attached to a midwife. It might be one day a week, or, something that she actually spends in Dunedin and her travel and some of her fees get sponsored. And she does a city experience. And she can go to somewhere like National Women's [Auckland] for a fortnight (FG 3).

With the third year students that I have had, a lot of them seem to be really rapt in rural practice while they are here, and they say that is great to be able to do that whole package... knowing that you have the skills to deal with given situations. But when it comes to the point actually setting up practice what seems to terrify them is not having the specialist backup readily available. And you know that a lot of them seem to feel as new grads that they don't have the skills to be able to work in a rural area without having it right there (FG 1).

And from someone who had come as a new graduate.

That could be just another more experienced practitioner [available] right at the time. Making it fourteen weeks continuity within an independent midwife working in a base hospital but only four weeks rural...there is no competition really. The reason I stayed was because I had fourteen weeks here (FG 4).

There was a discussion on the number of births the student might experience.

Its silly really, I said to '*' when I came here and did the rural placement I probably had about 14 or 15 babies that I actually caught and I learnt so much more than when I went to Invercargill for a month and caught forty babies. You know. You need to know what happens at what stages. Otherwise what if you are in a rural area and this happens (FG 4).

However, even with support and confidence in their rural area, new graduates feel that they are under greater scrutiny when they transfer to the base hospital. 
A woman being cared for by a new graduate experienced a post partum haemorrhage.

They could have one, (more experienced practitioners) but it didn't do for a new grad to have one the whole house fell down. You were under much more scrutiny (FG 4).

\section{Rural meets urban: The discourse of difference}

As in the individual interviews, the comparison between rural and urban working patterns was aired. While there was a perception that things were improving, areas of conflict and anxiety remain.

I think the attitude to country midwives has changed when I first went there [to Queen Mary] the fact that I was friendly and welcoming I think that gave the cue to the other midwives to be more helpful (FG 5).

While this was conceded there was report that the memory for rural problem births was longer than for town ones.

They have a long memory for anything a rural midwife has been involved in but a very short memory for their own There was one up there that you just wanted to get back into the lift if she was there (FG 3).

And for another the problem was not feeling comfortable to practise in her usual way.

I often find trying to maintain a midwifery model in that setting intimidating...you feel that the protocols...impose on what you are doing. Yes well what you are doing with the woman... and the beds in the middle and I don't sort of work here... and you need to take control and shift things around and they like the CTG on admission which might be totally unnecessary. And you feel that you must do this (FG 2). 
There was, the acknowledgement that it was also difficult for the hospital core staff, who felt that they would be held responsible if something went wrong. Thus they insisted that they needed to be fully informed of everything that was happening. This however meant that the lines of responsibility became blurred, as each was unsure where their individual responsibility lay.

One of the midwife participants, now working in the hospital setting explains the dilemma for core staff:

But if you are an experienced practitioner [in the secondary service] after a while you get called into a problem and it does make you nervous especially if the person seems to be making the wrong decisions. It is a worry (FG 5).

Clearly some of the problems are around communication. Not just about the clinical aspects but also around the level of logistical support required by the rural midwife when she is working with a woman in the base hospital.

I think, from a rural practice coming through it's not possible to be totally familiar with all the equipment. And to me that's the skill that the base hospital have, and you know I am certainly feeling a lot more confident coming in there now, [but] it sometimes makes you feel ...when you ask somebody how ...oh she is a midwife she should know. If you don't know what you are doing when you come in here you shouldn't be coming in here (FG 1).

The rural midwives also expressed uncertainty as to what the skill level was of their urban colleagues.

I notice a big difference coming to town, as there is no individual responsibility about being able to cope with problems. You can trace someone to help with it. We didn't have that luxury [in Balclutha] (FG $5)$. 
One day I had a flat baby and the [core midwife] said, "you know what you are doing". And she was surprised. I mean it was just what do you do isn't it? Not hang around waiting for some expert to come (FG 5).

It used to quite frighten me at times working in the secondary hospital because when I was in Clutha the other midwives on duty... they knew what to do in a baby emergency. She had to run for the bloody machine (FG 3).

Talk then returned briefly to the local unit.

\section{The legacy of the past}

There was the feeling that the management had been supportive in the past and that everyone was involved if there were meetings. Now the local midwives are not involved in decisions about the maternity unit services. There was also the observation that:

These community trusts are medically run and midwifery is struggling to keep a profile (FG 5).

There is a community feeling because it is a community orientated Trust that it's not a real hospital. And that is why some of the women choose to go to Dunedin. It's a small birthing centre thing - Although we didn't have much different up the hill. It hasn't got the hospital thing-it's a perception thing (FG 2).

A lot of that was around the rhetoric...they kept on threatening you know [during the arguments over surgical services]...that how ghastly it was going to be here, and we wouldn't be able to do caesarian sections. That was the big thing. So it wasn't going to be safe for women to have their baby here. It could have been said differently without pulling the shroud out. They struggle to put it away now (FG 1).

It was time for wine and lunch.

\section{Summary}

The focus group session was a ramble rather than a session with focused objectives. The discussion traversed the past, present and future issues and events of their midwifery practice. The talk at times was of despondency and 
frustration and a reluctance to yet again expend the energy to continue the struggle. But these sentiments were countered by expressions of toughness, optimism and resilience.

As in the individual interviews (Chapter Six) the discourse positions of the midwife participants were simultaneously cohesive and contradictory. At other times they described strategies of resistance. The rural midwives articulated as a group the elements of a rural midwifery discourse that emerged in the individual interviews; the tenets of which underlay their determination to find solutions for the current problems.

There was strong support from the midwife participants for the maintenance of a viable local maternity unit; but strong opposition to a shared care team approach as a way of achieving this goal. The 'team' discourse was seen as a threat to their autonomy, and if they were to resist this, they needed to look for options that were consistent with their midwifery discourse. Thus the resistance discourse is recast as alternative strategies. The midwife participants were planning to use marketing and commercial ideas. Ironically, these same market orientated practices had been used against the maternity services during the 1990, decade, ostensibly, in the pursuit, of efficiency and public equity (See Chapter Four). In this instance, the midwives were using these strategies as a counter move, to management strategies proposed by the local doctors and Trust management.

Attracting midwives into the area was the other main strategy. For new midwives to be able to work in the rural area it was considered that they would need a degree of mentoring and exposure to rural practice. Thus, they would understand how rural practice differed from urban practice-that is understand the difference and hence articulate a rural midwifery discourse. For all its' 
challenges, the participants were in agreement that midwifery in rural areas, was worth the fight.

In the next chapter the topics and discourses from the data are further explored and expanded with the ideas suggested for future possibility. 


\section{CHAPTER 8: A GAME PLAN FOR THE FUTURE}

\section{Overview}

The rural midwives agreed that rural maternity services continue to be in the news, and that this is set to continue as practitioners, work through the implications of the recent changes in both funding and healthcare organization. In this study, they demonstrate that, philosophically, they have aligned themselves with women rather than with other health professionals. And as both the women and the midwives in the rural area generally occupy marginal places within the community, this would seem to compound their lack of influence with regard to the allocation of health resources. However, such positioning, may prove to be a strength, if strategies are employed that harness the energy and passion that such an alliance can generate. The rural midwives have indicated how critical it was to work with the local community particularly in regard to the maintenance of current maternity facilities. They also acknowledged that a safe rural maternity service needed comprehensive and functional links for referral and transfer. Whatever mix of future strategies are employed, the midwives recognized that sound financial planning was needed, which took into account the fluctuations in their rural birth numbers.

The focus group showed that, if midwives were to live and thrive in rural areas, issues of sustainability would need to be addressed. These include logistical support and relief for family and recreational pursuits, educational and professional development opportunities, and the introduction and support of new graduates into rural areas. But whatever strategies are in place, the ability to articulate with confidence the essence, or difference, of their service, knowledge, and skill, will be vital. So, too, will a habit of alertness to changes in the political and technological winds, which may require challenge or accommodation in the future. 


\section{Positioning in the new environment: Rumblings and promises}

Pressure, for changes to maternity services continued to feature in the media, following the data analysis. In the wake of the announcement that doctors in Queenstown were quitting maternity care, the local newspapers ran alarmist stories of unsafe and under-serviced maternity care in rural areas (Williamson, "Mayoral alert over birthing risk", 2001). The local mayor initiated a petition for presentation to the Minister of Health, which asked for a return to the way services, had been delivered in the past ("Petition fallen on deaf ears", 2001). The petitioner's request was rejected but not before considerable damage was done to public confidence in the safety of rural maternity services.

This publicity highlights the anxiety already felt by midwives about the change to District Health Boards (DHBs) and the plan for Primary Health Organizations (PHO). The midwife participants in this study felt that, as the maternity budget would likely be devolved to these organizations that they would have to join or be left out in the cold. The biggest fear was the potential for a return to the past with a doctor led team- such an arrangement possibly meaning a return to the shift system, and the demise of the LMC midwife option. Thus, there was despondency that their hard won gains for choice and continuity of care options for women could be lost as they competed with other more dominant models of care.

The Primary Health Care Strategy document (King 2001: 5), offers the vision for "a system where services are organized around the needs of a defined group of people." Such 'systems of services' are to be funded by the DHBs, and while health care practitioners can choose not to join, they are encouraged to do so. There are assurances that the control and decision making around the service provision is intended to be collaborative and agreed between the practitioners and the community. Thus "Primary Health Organizations must be able to 
demonstrate that all their providers and practitioners can influence the organization's decision-making, rather than one group being dominant" (King 2001:5).

There is also the promise that the payments to LMC practitioners under the new arrangements will be the same for all, thus removing the inequity, which has existed since 1996 (Health Funding Authority, 2000). Once these changes are in place the savings made from the re-organization of maternity services will contribute to improved payments for LMC's (Ministry of Health, 3 September 2001).

Access to local maternity services is according to Nesbitt (1996: 164), both ethically sound and cost effective. In the past, "[r]ural units often suffered, from economies of scale"- the low numbers and one to one labour care being seen as wasteful. In the United States of America, managed care organizations are moving into rural areas and there is concern that units offering one to one care will be seen as wasteful of resources. Thus low volume units might be closed. However it was also possible that the outcome statistics for these units are better than urban-based services, and it may cause these organizations to review their policies (Nesbitt, 1996). After all, it affirms the efficiency discourse.

Taking into account the findings of this study, if the DHB document is enacted as proposed it would seem that there is a viable opportunity for midwives to continue to offer a full primary LMC service to the local community. The success of this will depend on how fairly rural midwives are treated at the local level. Even more critical for the survival of a rural midwifery service, is the continuance of equitable payments that are not exposed to local whim. For instance a local organization should they hold the budget for maternity care, 
could elect to pay midwifery services less money, or expect more services for the same funding. Midwives do not have access to other funding streams to augment their income, as their work demands a full time commitment. Thus, any change to the funding model threatens their job security and the viability of their continued rural work.

If these foundational requirements are met the midwives will be free to focus their energies on promoting and developing their service. For this they require the support and confidence of their colleagues in the rural area but even more critically that of the women with whom they work. The rural midwife participants intimated that, their relationship with their community, and the women in particular, was a part of their construction.

\section{Working from the margins: A place of struggle and strength}

Within the wider local community, it is women in their childbearing years that access the maternity services. Historically, such women are unlikely to participate in any major way on national or local bodies where policies and resource allocations are made. As could be seen with the preoccupations of the community spokespeople in the 'Local News', for this aging and sparsely populated community in the South, the main health and social concerns lie elsewhere. Similarly, within the wider health environment, midwifery is a marginal discourse, with rural midwives being further marginalised within the midwifery population.

Acknowledgement of the social positioning of both midwives and women is useful for an understanding as to why their voices are frequently missing from debates around local politics, health, and maternity services in particular. So it is perhaps surprising and heartening to note that despite the pressures from changes in health services, funding restraints and at times vociferous opposition 
to midwives practicing autonomously, that the LMC midwifery service in the south has survived and consolidated.

According to Tully and Mortlock (1999), for a group to aspire to professional status they need first to stake out a body of knowledge and a specified clientele. For medicine, registration is controlled to prevent potential competitors from being able to legitimately practice. Exclusionary strategies are also employed which include the subordination of other occupations by delegating the extent of their roles and the areas in which they may practice. For midwives, the alignment with women in a working relationship, with a sharing of information, and the development of a reflective and negotiated partnership, is described as a "new professionalism discourse." This, being a feminist process, that steps away from the trappings of the high status expert who held all the knowledge and skill. Within the partnership the midwife and the woman share the responsibility of the birth process, thus, there is a moral element for both (Tully \& Mortlock, 1999: 167).

This study supports hooks (1990: 147-8), contention that when a marginalised group moves there is the opportunity to choose their location. Such positioning could be "on the side of the colonizing mentality", or standing "in political resistance with the oppressed"..."visible and noisy." Standing within such a marginal place can "nourish one's capacity to resist" as others try to silence, co-opt or undermine their position (hooks, 1990:148-150). The distinction is made between marginality imposed by oppressive structures and that chosen as a "location of radical openness and possibility" (hooks, 1990:153). So not the luxury of carping from a familiar location which is easily ignored, but standing in another to challenge confront and discomfort. Thus in offering a service to women, rural midwives can make some choices about how and with whom they 
align, acknowledging not just their marginal position, but also the strengths and variety, within their group.

\section{Thoughts for the future from the research}

\section{The local maternity unit}

One topic of discussion in the focus group was the significance of the local maternity unit. It is possible for the midwives to band together to offer a complete maternity service, which includes the management of the unit. This could provide a visible and credible service consistent with the co-ordinated structures advocated by the government. While this is an attractive option it presents a challenge with regard to the practical and fiscal management of the facility.

The maternity annexes, homes and hospitals of rural New Zealand have historically been the pride of many isolated areas in New Zealand, and are the concrete evidence that a local maternity service is available (Patterson, 2000). Where such units remain, there are problems maintaining and staffing them. Their survival depends firstly on women choosing to birth locally and secondly, on the preparedness of the midwives to continue to provide 24-hour midwifery cover.

For the local midwives to take on the responsibility of the facility would add substantially to their commitments. The unit would need to be staffed when women were admitted and maintain a call service during 'down' time. Similarly, responsibility for maintenance, cleaning, checking equipment and ordering stores, would all need to be assumed by the midwife group. This could however be offset to some extent by the facility fees, which would allow the midwives to employ staff to manage, the day, to day work. 
In 1998, population based funding was described by Annette King, the then Opposition spokesperson on health, as a "blunt instrument and a dangerous weapon for provincial New Zealand." She further commented, that, " A rural health premium must be linked to a minimum level of access to ensure that appropriate health services at adequate levels can be provided in provincial areas" (Clutha Leader, 19th January, 1998:8).

For units such as Balclutha, with small and erratic numbers, some financial incentive, at least at the start, is required to encourage the midwives to stay and work in the area and build up their caseloads. Another option suggested by one of the participants, was, a 'remote' payment, centred on the distance from a midwifery service base, rather than from base hospitals. This would allow coverage that made sense geographically- at least for postnatal care. Such a solution would entail persuading midwives in the area to join the group and share the workload. Local midwives are best placed to relieve the full time LMC midwife for recreational and family breaks, as accessing locum cover from out of the area is problematic. How you pay your locum and whether you offer accommodation and transport are sticky issues in areas with low numbers and long hours of call. An added challenge for a stranger is having, to come to grips with the culture and geography of the local area. Moreover, locum cover can be tricky to organize at short notice in times of crisis.

\section{Entrepreneurial zeal}

Alongside any strategies to assume responsibility for the service, the midwife participants agreed that a campaign to attract women to birth, locally, was an important first step. The feeling was that some women were fearful and chose to go out of the area. A midwife, comments on some of the areas that she feels contribute to this. 
...[T]here is a problem with women's perception of safety I think. And I think there has been so much hype around the loss of services in rural areas. The loss of surgical services and women were told it wasn't going to be safe for them to have their babies in the rural area. And there aren't so many doctors available. They feel well, they can't get a doctor here so we'll go town where we can get a doctor. I think that is because there are still a lot of women who don't really know what midwives do...(Trans. 1: 16).

The best publicity and promotion for midwifery care is the one by one relationship with the women for whom they care. In fact, many of the strategies that built up the vision of midwifery care in the early 1990's can be revisited. This would include the confident presentation of a care package, with the emphasis on continuity and support to help women have the birth experience they desire. Articles in the local newspapers, radio, and advertising signs would all add to a public profile. This visibility would need to go hand in hand with involvement in local women's groups, particularly support groups geared towards the needs of young women and families. Hobbs (1993), suggests, that clear communication of your service, quality production of flyers and business cards, plus a diary of contacts for future opportunities and networking is important.

Such contact needs to be extended to include other health professionals both locally and regionally with whom you need cordial and effective relationships. For instance in a bid to try and bridge the rural / urban divide, contact or even a shift worked in the base hospital, could be invaluable as an orientation, and networking exercise.

Critical to any business venture, and recognized by the rural midwife participants should the management of the facility be considered, was the need for a sound business plan with attention to cash flow management. This would include accountancy and legal advice; particularly if there were agreements 
between partners with regard to practice responsibilities and income disbursements. Baseline information is needed regarding the current situation with regard to the number of women who have accessed the local service compared to those who have chosen, for whatever reason, to seek care elsewhere. This need not be the basis for future planning, as the aim would be to increase the uptake of local services. To discover if any strategy is successful, such a basic exercise needs to be done.

A set of broad characteristics to underpin a flexible and safe rural maternity service could resemble those that were agreed to in Canada. These included a qualified, competent and committed professional staff with sufficient financial and technical resources to meet national standards of care. To facilitate ease of transfer, written protocols were recommended, plus open lines of communication and collaboration with regional referral centers (Canadian Medical Association's Joint Positions Paper on Rural Maternity Care, 1998). In addition, the rural midwives group would need to attend to issues of quality assurance. These would include not just an audit of their outcomes but also a survey of their consumers with regard to the acceptability of their service and for ideas as to how it could be improved.

\section{Working together and a personal safety net}

As well as business and financial plans the research participants agreed that they needed a personal support plan. While this can sometimes be found within the camaraderie of the group, opportunities for critical reflection from outside this circle might be more appropriate.

Of particular importance according to Flint (1994), is for midwives to plan in advance for their leave and recreational and family breaks. Such planning should be regarded as equal in importance to other aspects of the business. Individual midwives need to be open and honest with their colleagues about 
their needs for relief and time out to avoid misunderstandings, as no team benefits from members who are burnt out or resentful. To establish and maintain such a midwifery group, it was felt that members needed to;

... trust in one another... I think you have got to be able to learn to let go and have confidence in your partners (Trans. 2: FG).

Taylor (2000: 112), suggests, that personal and professional reflection, “...is a valuable source of stability in an otherwise changing and unpredictable world of work." Further, the adoption of a critical friend is invaluable. This is a trusted person who can assist an individual to make sense of their dilemmas in a way that is both supportive, non judgmental, but also challenging (Taylor, 2000). Reflection, is also recommended, by Carr (1996:289), as a tool to critically explore practice experiences; " ...in order to lead to new understanding and appreciations." And while there would be a desire for harmony, denial of differences could threaten and strain group solidarity. Young (1990: 305) suggests that, "a politics of difference", which accepts the many facets of the individuals in the group, may help to increase tolerance and therefore avoid the splintering that could occur. If internal disputes were not openly dealt with, the group would struggle to provide a cohesive and functional entity.

\section{Keeping up to date}

"There isn't a lot of communication between urban and rural so I came to that depression thing at the college the other night. I knew nothing about mother and baby networks...you are just isolated and especially when you are not attached to a HHS (Trans.4: 15).

As indicated above, services and the accessibility to education and support are perceived by the rural midwives to be more available in the town areas. And while some updating can be done electronically and by accessing library sources, attendance at courses and seminars represents an important opportunity to meet with colleagues and exchange ideas. It is reassuring to talk with 
someone who is wrestling with the same dilemmas and frustrations that you are also experiencing. Such networking with colleagues can also alert the midwife to local and national political moves that may impact on their service and practice. Membership and contact with the midwifery professional body is also a way of linking into areas where policies are made, and can prove a source of support for addressing issues that frustrate and impede the provision of the local midwifery service.

While the rural midwives felt cut off from some of the opportunities open to their urban colleagues, more relevant perhaps for them is the development of strategies and technology to aid with emergencies in rural areas. These initiatives were not referred to by the midwife participants, which may indicate either that they have not been involved in their development, or, that their current emergency linkages meet their needs when consultation or transfer is required.

Nesbitt (1996), talks about tele-ultrasound, which can transmit images directly to specialists so that timely and appropriate referral can be made. Similarly, other technologies such as telemedicine enable practitioners to access specialist opinion or advice electronically. The ready availability of these techniques is suggested to increase the confidence of the practitioner and of the woman. The downside of course is the possibility that such technology would be used routinely rather than selectively. Over-reliance could lead to a lack of practitioner confidence and the degradation of their skills. Therefore, it would seem that for the rural midwives, the challenge, will be to select wisely from the technology available, whilst keeping a normal focus in their midwifery practice supported by the best evidence available- a tall order. 


\section{An eye to the future}

The survival of midwifery in rural New Zealand is dependent on a percentage of new midwifery graduates, choosing to live and work in these areas. The midwives in this study signaled that this was an issue that required not just a local effort but also the help of educational institutions and the professional body. One suggestion was that financial support and local practice options be provided for women in the community wanting to gain a midwifery qualification. Another idea was that the rural placement could be longer. It was thought that the current rural placement was too short for students to become confident about working in a rural area. An additional advantage would be that students who have had some time in a rural area, would, even if they chose to work elsewhere, have a deeper understanding of the way birth happens in rural areas, and the day to day issues for their rural colleagues.

\section{The difference}

I think the highlights were actually having some autonomy at this time... and I think the climate... that relationship with women was one of the best times ever - to actually have that type of partnership relationship. And how good when it went really well (Trans 5:7).

The quote expresses some nostalgia for the early 1990's when there was a surge of passion from midwives and women and a ready response to the dominant medical model of birth. Choices for women and midwives have since become, mainstream and are woven into the fabric of health legislation. Such a position is ripe for complacency. However the concerns about the planned local health changes and the move to Primary Health Care Organizations funded by the District Health Boards, has given the midwives a sense of disquiet. But what but what exactly feels so threatening about it is difficult to articulate.

It is probable that this sense of difference, is a mix of personal experience, philosophical and social positioning, with layers of historical relating patterns 
resistant to change. Lyotard (1988), names this sense le differend, seeing it as a case of conflict that is not able to be resolved because there is no rule of judgement that is equitable to both parties. Thus, when a consensus approach is required for functioning of the organization, then, whatever rule is applied will favour one position or genre over others. Partly, why this occurs is because of the great difficulty of putting into language, exactly what feels different. This happening or le differend may occur unexpectedly and the moment passes. There is no time to reflect and respond in appropriate language.

If, however, things are to change or at least be challenged with some success, there needs to be some common rule that can bridge incommensurable fields of experience (Williams, 2000). In some instances, consensus might be possible but where this cannot happen, justly, then an equal opportunity for expression may at least lead to a better understanding.

It is possible that those promulgating the changes will adopt some of the dominant narratives that prevailed during the 1990's. Thus pragmatics, efficiency and moral equity notions could well be re-constructed and represented in a different hue. This would make it difficult for individual midwives to stand aside and risk isolation in a rural area. Cochrane (1993) acknowledges this situation in relation to both midwives and nurses. In confrontation, they may incur disapproval and if such incidents are frequent, confidence is eroded, which can result in a subordinate attitude. However, it is a rare situation in which all the issues are clear and simple, and there may be doubts as to what is the best response. Such doubt can immobilize or drive underground the sense of difference and result in at least the appearance of compliance (Cochrane, 1993). 
Such a wearing down process may result in capitulation, which does not serve the interests of women or midwives. More ironically, it does not serve the interests of the dominant culture, as there is no counter discourse to stimulate social and scientific progress. Thus, it is critical that there is a local and strong response that is both respectful and clear. This may require reflection and preparation for a variety of circumstances in advance of any challenge.

Lyotard (1988: 181) writes that, "[t]he only insurmountable obstacle that the hegemony of the economic genre comes up against is the heterogeneity of phrase regimens and of genres of discourse. This is because there is not language and 'being', but 'occurrences'." This suggests that a dominant discourse can deal effectively with one less dominant if it is a known opponent and presents in a consistent fashion. What derails the former, are the "occurrences" or unpredicted local and particular challenges from those whose understanding and experience is different.

\section{A feeling for svelteness}

To be truly postmodern is to be suspicious of all authority. Such suspicion rather than being inert can rather be a position of openness and flexibility, that is not bound in rules and regulations. (Sim, 1996: 91)

\section{Language games and irony}

It appears from my study that the midwives who made the changes in the 1990's in South Otago had a feeling for svelteness. According to Sim, (1996:94), Lyotard portrayed this notion as the opportunity to act to change or loosen bonds. It was also the development of a habit of wakefulness, creativity and metamorphic capacity; thus introducing unpredictability and guerilla-like qualities into local action. Such activities could be the harassing of state or capital, using the tactics of entrepreneurs, or, the reverse, if this was more effective. Action therefore need not always be restricted to protesting on the 
margins but using the laws, science, and pragmatic arguments against those that would seek to dominate and control.

However the irony of such potentially disruptive processes is that the large systems benefit. If they were to continue without the renewing energy of novelty and change that such irritant groups imposed on them, they would eventually self-destruct. Thus, the challenger does them a favour by alerting them to new prospects, ideas, or activities, thereby stimulating regeneration and increasing performativity (Lyotard, 1997). For example, others have appropriated some of the service particulars midwives strove to introduce, such as active birth, and more flexible and individualized care. Thus, the differences between midwifery led care and a shared, or, team care approach, may not be immediately apparent. Even the words integral to the midwifery discourse; such as, 'choice' and 'continuity' have been adopted and appear in documents and arguments in other guises. For example, there have been suggestions that continuity of care could also include care provided by a multidisciplinary team in addition to that provided by a named practitioner. Women campaigned for the choice to have more say in how and with whom they gave birth but this notion of choice is being used by GPs as an argument for more funding in primary maternity care (Cook, "Maternity care changes wanted by rural women," 2000).

It is possible for there to be a usurpation of the midwifery discourse in rural areas by competing discourses or language games able to convince or persuade decision makers that a change is desirable. Political favour is fickle and the language games that worked in the last decade may not succeed in the next.

Midwives traditionally do not enter politics but the policies affecting them are generated from the health politics of the ruling party in government (Jenkins, 
1995). For midwives to seek election to political parties may be one way to influence such legislation. However, what could be seen as positive change for midwives, such as registration and the statutory right to a defined practice area, exposes them to further control and practice restrictions; dependent on who has the ear of government (Jenkins, 1995).

There is also the desire to stay united. However at some points in time, striving for unity may create a strain if midwives are both trying to bridge the gap between participating at an institutional level, and acting as a provocateur for change. A split in the ranks according to Jenkins (1995), may even be useful, allowing a more radical group to stand outside and challenge the establishment. But, I don't believe it needs to be an either/or situation. If a notion of svelteness is used, movement between these and other positions could reasonably be made, if only in argument, debate, or refusal to comply. Tully and Mortlock (1999:166), suggest, that, “...control over medical/ health work are not secured once and for all but is the focus of ongoing negotiation and contestations between various occupational groups."

Thus, it would seem that for rural midwives to offer women, a midwifery LMC option, in this and possibly many other rural areas, is a daily struggle. Not just to do the work and offer the service, but also to resist being directed by others who would seek to control and determine how they may practise. It would be anathema for the midwives who have experienced the joys and challenges of autonomy to contemplate returning to the fragmented service of the past. But equally there is no certainty that even the most carefully crafted plan will secure the service.

The genie however is out of the bottle. Women have tasted the freedom to make some choices around how and with whom they give birth, and midwives have 
been liberated to exercise their full range of skills and compete on equal terms for payment of this primary service. There is also good evidence to support rural birth and evidence based practice guidelines that support many of the practice activities of midwives. Therefore it is difficult to imagine a return to the past. However, I am mindful that never in my wildest dreams did I imagine the events and revolutionary change that I experienced in the 1990's. It would I believe be naive to assume that equally dramatic change could not happen again. Therefore, it will be important to take advantage of any window of opportunity, to employ the pragmatics of activism, not necessarily expecting to win lasting victory, but sufficient to cause oppressors pause for thought (Sim, 1996). It is just possible however that a sense of our history and the exploration of our reality can help rural midwives explicate the 'differend' that has been felt silently and hitherto was difficult to phrase. And if the aspects of practice that provide the most satisfaction are denied them in the new environment, then a realistic choice for women in rural areas would also be lost.

But its neat working and it is nice being part of that community and [rural midwifery] has got the autonomy that you can kind of enjoy... as long as... yeah... you can actually do the practice you want. Its cool (Trans. 5:22-3). 


\section{CHAPTER NINE: FINAL REFLECTIONS}

There remains for me the sense of a tension between passion for the cause and the need to avoid the pitfalls of partiality. There is the risk of slippage to either domination or submission. Victory, by minority or marginal groups, seems not to be a possibility; a short day in the sun may be possible, whereas long-term entrenchment is not. But maybe I can scratch the paint a little (Journal entry, October, 2001).

\section{Why rural midwifery?}

An abiding interest in the issues for rural health services and maternity care in particular was my reason for choosing this area to study. It also appears that little research has been done worldwide in the area of rural midwifery, so there is the potential for this study to make a contribution to the discipline of midwifery internationally. The choice of such a defined area was in part personal indulgence and sentimentality, but primarily because the rural area under study experienced the full range of changes in both the health services generally, and midwifery, in particular. It was a microcosm, which was representative of the 1990 to 2000 decade, and therefore a desirable area for research.

As pointed out previously, in 1990, South Otago offered a wide range of health care with the Balclutha hospital regarded as its jewel in the crown. The erosion of these services occurred despite a vigorous and committed local campaign. Toward the end of the decade the range of health services had dwindled, and the hospital on the hill was gone. The hospital with its' acute medical, surgical, anaesthetic and frail elderly service areas was lost, being replaced by a community Trust covered largely by the local GPs.

Primary maternity services remain. These had traditionally been managed in a medical model with midwives and other maternity staff working eight hours shifts. In 1990, following the Amendment to the Nurses Act, rural midwives 
along with their urban colleagues took the opportunity to assume the care for women throughout normal pregnancy and birth. This included the development of an LMC midwifery service that offered local women a full range of care options, including home birth. As a model they adopted and adapted the midwifery discourse extant at that time, articulated by Guilliland and Pairman (1995). This model included discourses around partnership, continuity, and midwifery knowledge of normal birth.

The change in the Act was in part due to an alignment of some propitious political stars. It was also in the interest of the State to contain costs, and try to rein in the fee for service structure, while continuing to address the consumer desire for more say in their care. But while the changes were about some very pragmatic things like efficiency, they were also about justice and equity.

\section{Reflections on the study design and findings}

I was also working as a midwife over this decade and the rapidity of these changes took me very much by surprise. In an attempt to make some sense of these events, I looked at some of the ideas of the postmodernists and feminists and what a combination of these theoretical positions might reveal. My desire was not just to find some explanatory idea but also to discover some strategies for action.

Postmodern thought propounds the idea that we construct and reconstruct what we see and believe about the world, and that discourses, or language games, inherent in our representational and textual communications, are the vessels that create ourselves, and our institutions (Lyotard, 1992; Foucault, 1972; Derrida; 1995; Baudrillard, 1997). Such ideas gave me permission to play with multiple notions of reality. And while this was a freedom it was also an unmapped terrain in which I might lose any sense of worth or purpose. To find some place 
to stand, the addition of a feminist sense of purpose with a postmodern twist of reflexivity, added a centering dimension (Lather, 1991: Butler, 1994) Patriarchy.and gender politics, it seems, are alive and well, and have not gone away, rather they are represented in different guises.

In addition, ideas around marginalisation that were not bound by structural notions of economic relations, afforded another perspective to view the position of the rural midwives. I liked the idea of moving within a margin, (hooks, 1990), and speaking from a different place, depending on what position best serves the purpose.

The mix of research methods, with interview and focus group felt comfortable for me in this project. Helpful too, was the reading of the local newspapers as a way of putting a chronological framework alongside the memories of the participants. The matrix of perspectives from the different data sources, provided a rich mix for finding the patterns that I have named as discourses and language games.

However the task of looking for the influence of underlying discourses in the analysis process was challenging. It was difficult to decide which to concentrate on and how to go about naming them. Categorizing of themes would have been easier, but I don't believe this would have elicited the underlying motivational imperatives that discourse analysis affords.

The five midwives who participated in this project gave the study a local richness and raw human element, which would not have been achievable with a survey or a purely theoretical format. However, it remains a small study of a particular group within a defined geographical area. Nevertheless, aspects of the 
data may resonate with others who identify in some way, either because of their rural work, or their positioning within the community.

Analysis of the transcripts from the rural midwives revealed some common discourse positions. My interpretation of the data suggests that the rural midwives are firstly constructed by extant midwifery discourse and further by particulars in their environment. These were their sense of being deeply embedded within their community, and a strong sense of rurality. The latter was tensioned not just by their physical distance from urban areas, but also by a felt 'difference' related to their particular practice challenges. However, underpinning these was a firmly held belief in the possibility of birth for healthy women in their local area. This belief persists despite having to transfer women and babies to secondary services, under emergency conditions. These defining discourses I have named a rural midwifery discourse.

From the focus group session, which followed the interviews, there were reminisces from the past and ideas for the future. The health service is continuing to evolve and there were concerns that gains may be lost if there is significant change in political or fiscal support. And even with the current system, sustainability depends on both local and national acknowledgement of the important contribution of rural midwives. Strategies for survival were suggested and included the utilization of their community and professional links, plus a sound business plan. There were expressed needs for personal support, adequate leave and professional development opportunities. Critical also was the need to support new graduates to consider rural practice.

For the marginal discourse of rural midwives, there is continued competition from medical discourse with its increasing use of technology. Widespread and expensive use of such technology continues, despite a lack of evidence that it 
contributes, to improved outcomes. But the history of maternity services in New Zealand and elsewhere, suggests that arguments for safety and cost effectiveness do not always win the day, however legitimate their claim.

\section{Work to do: Other research possibilities}

To explore the variety and complexity of rural maternity care and to better address issues of sustainability, more research projects are needed. Further studies using interview and focus group methods could be used. The notion of the rural midwifery discourse could be mapped in more detail, and the inevitable progression to action might produce more detailed and workable strategies for sustainable work arrangements.

This study focused on the rural LMC midwife. However the staffing of many rural maternity units is dependent on non-LMC midwives and others. As their contribution can be vital to the maintenance of a local maternity service, they should be a part of any extended study. For some areas there are insufficient numbers of midwives willing to commit to LMC services on a full time basis, so a way of providing relief and support locally is critical.

For a national perspective a mix of both quantitative and qualitative studies could provide rich data, which would be useful for planners and providers of maternity care. Information about how other rural areas manage could also provide a source of ideas for rural midwives keen to adapt local arrangements.

The midwives in this study identified a rural/ urban difference that they believed at times hindered smooth transfer in times of crisis. Anecdotally, such interface issues also occur when urban LMC midwives transfer to secondary services. Of particular interest would be how the hospital based (core midwives), perceive their urban and rural colleagues. This also was not 
explored. Therefore, a similar study with both urban LMC midwives and core midwives, could expose, other discourse positions. While this may not bridge the 'differend' it may afford a better understanding of the others' perceptions and ultimately foster a more supportive practice environment.

Clearly, no amount of elaborate planning would succeed without the confidence and support of the women who are the centre and reason for the service to exist. Studies, which look at women's perception of their local maternity service and how or when they would choose to use it, are an area ripe for exploration.

Foundational to any wider study will be accurate and detailed perinatal data. This is promised for the future and would enable evaluation of rural outcomes. Such a benchmarking exercise is needed if quality improvement strategies are to be successful. If rural services confirm the good outcomes that past studies have shown, then, funding arrangements should reflect this, thereby making it financially attractive to provide a viable service for women.

\section{Looking back - looking forward}

Whatever else this work achieves it has left me at this juncture with a deeper understanding (or misunderstanding) of midwifery history and a richer appreciation of the changes in rural areas. Along with this goes the knowledge that whoever writes the history constructs it from his or her perspective and agendas. Thus, I have a new appreciation of how ideas are sold and handed on and the role of the 'hander on' in this process; more importantly, how they might be rejected, resisted, subverted or mutated in this process.

Most enlightening for me was the critical notion of timing. How successful a change event is, depends it seems on a moment in time. This cannot always be anticipated, as while a time might appear opportune for some reasons there is 
no knowing the totality of the influences that haven't been calculated and taken into the mix. There is also no certainty, or accurate method, of predicting where a change will go, how long it will last; or whether the change will take an evolutionary, incremental, or even revolutionary form.

If this study does no more than highlight the complex position of midwives in smaller comminutes where caseloads are small and the midwives are challenged by the need to try and make a living from their practice, then it will have succeeded. Perhaps it also flags the vulnerability of the rural midwife and her reliance on the support of her peers for survival. I prefer not to entertain the idea that these midwives are a remnant of the past that will eventually disappear like so many of the rural maternity homes. Rather, I choose to see childbirth in rural areas as an opportunity for birth to occur with technology kept at arms' length, to be accessed only when needed. But if this dream is worth pursuing and preserving it cannot be left to rural midwives alone.

Lyotard (1997), suggests that the performativity of an organization needs the irritation of local action groups and ideas to renew and transform it. Thus, the actions that seek to disrupt and disquiet dominant discourses are perversely the assurance of their continued growth and strength. This mechanism was demonstrated in the analysis of the language games of efficiency and moral good that punctuated the debates over health services during the decade under study. So for rural midwives, complacency is not an option and action needs to continue afresh.

There is the opportunity for the rural midwives to move and to speak what they know with confidence. hooks (1990), suggests, that those who inhabit the margins can move and find a place from which to speak that can surprise and unsettle those who would seek to control and contain them. While never 
belonging in the centre, there is the chance to visit and move on before being colonized. While it may be difficult to see how some complex situations might be changed at least they can be given a good shake.

\section{Future dreaming}

Even as this work was being written the participant midwives were exploring new initiatives. A successful rural midwives' networking day had been organized in Central Otago and the issues that were raised were those that emerged with the midwifery participants in this study. I had the sense of a 'coming of age' and ownership of the future direction for rural midwifery. Strategies are being discussed for safe practice and for making the lifestyle sustainable and rewarding. Most encouraging were the alliances being forged between hitherto separate groups aimed at co-operation and collaboration with regard to call, emergency cover, and colleague support. Particularly the acknowledgement of how critical it was to be able to discuss with a colleague practice decisions and outcomes, without fear of censure. Email addresses have been exchanged and there is a determination to make this a regular event.

A new chapter has opened in the way health services are to be delivered in New Zealand. The competitive model of the past has been set aside, for now, and the midwives see new challenges to their role as the DHBs are bedded in and PHOs are set to evolve and take responsibility for primary care. Positive news for midwives was the announcement by the Ministry of Health regarding an increase to LMC funding in respect of postnatal care and the service for remote rural women (Increase in maternity funding, Radio New Zealand, April 19, 2002). The challenge for rural midwives will be how to negotiate, and position themselves within this new environment without losing the confidence of women, or their passion for their work. 
The end of this journey is the beginning of the next and the middle of another- an arbitrary convenient and nonsensical interruption (Journal entry March 2002). 


\section{REFERENCES}

Abel, S., \& Kearns, A. S. (1991). Birth places: A geographical perspective on planned home birth in New Zealand. Social Science and Medicine, 33, (7), $825-834$.

Albrecht, T. L., Johnson, G. M., \& Walther, J. B. (1993). Understanding communication processes in focus groups. In D.L. Morgan (Ed.). Successful focus groups: Advancing the state of the art. Newbury Park, London: Sage Pub.

Aldridge, J. (1993). The textual disembodiment of knowledge in research account writing. Sociology, 27 (1), $53-66$.

Alice, L. (1999). Power, experience, and process in feminist research. In C. Davidson \& M.Tolich (Eds.). Social science research in New Zealand: Many paths to understanding. Auckland New Zealand: Longman.

Anderson, L. (1998, January, 12). Health. Clutha Leader. p.10.

Appignanesi, R., \& Garrett, C. (1989). Postmodernism for beginners. Cambridge, United Kingdom: Icon Books Ltd.

Bakker, R. H. C., Groenewegen, P. P., Jabaaij, L., Wouter, M., Sixma, H., \& de Veer, A. (1996). 'Burnout' among Dutch midwives. Midwifery 12. 174-181.

Balclutha hospital bound by policy. (1991, August 26). Clutha Leader. p. 3. 
Balclutha hospital under review. (1996, February 22). Clutha Leader, p. 12.

Barnes, P. M., \& Dossey, M. S. (1999). Triage issues in an out -ofhospital birth center. Journal of Nurse-Midwifery, .44 (5), 458-470.

Baudrillard, J. (1997). Simulacra and simulation. Michigan: The University of Michigan Press.

Belgrave, M. (1991). Medicine and the rise of the health professions in New Zealand 1860 - 1939. In L. Bryder, A healthy country: Essays in the social history of medicine in New Zealand. Wellington New Zealand: Bridget Williams Books.

bell hooks. (1990). Yearning: Race and gender and cultural politics. Boston MA: South End Press.

Benhabib. S. (1990). Epistemologies of postmodernism: A rejoinder to Jean-Francois Lyotard. In L. J. Nicholson (Ed.). Feminism / Postmodernism. New York: Routledge.

Best, S., \& Kellner, D. (1991). Postmodern theory: Critical interrogations. New York: The Guilford Press.

Birth notices. (1990, May 30). Clutha Leader, p.5

Birth notices. (1991, September 4). Clutha Leader, p.15. 
Bolitho, D. (1991, July 13) Balclutha bound by policy. Clutha Leader.

Bryder, L. (Ed.). A healthy country: Essays in the social history of medicine in New Zealand. Wellington New Zealand: Bridget Williams Books.

Butler, J. (1994). Contingent foundations: Feminism and the question of 'postmodernism'. In S. Seidman (Ed.). The postmodern turn: New perspectives on social theory. Cambridge: Cambridge University Press.

Call for rural surgical cuts. (1991, March 15). Clutha Leader, p.5.

Campbell, R., \& MacFarlane, A. (1994). Where to be born: The debate and the evidence. ( $2^{\text {nd }}$ ed.). National Perinatal Epidemiological Unit, Radcliffe Infirmary Oxford.

Canadian Medical Association's joint position paper on rural maternity care. (1998). http://www.cma.ca/cjrm/vol-3/issue-2/0075htm. 19/03/01.

Carew, E. (1987). New Zealand's money revolution: A comprehensive, up to the minute guide to New Zealand's rapidly changing financial system. Wellington: Allen \& Unwin/ Port Nicholas Press.

Carpenter, H. (1971). An improved system of nursing education for New Zealand. Report to the Department of Health: Wellington.

Carr, E. C. J. (1996). Reflecting on clinical practice: Hectoring talk or reality? Journal of Clinical Nursing. 5, 289-295.

Changes explained. (1997, May 8). Clutha Leader, p.9. 
Cochrane, S. (1993). Midwives nurses and doctors: Interprofessional relationships. In T. Murphy - Black (Ed.). Issues in midwifery. New York: Churchill Livingstone.

Cook, M. (2000, December, 22). Maternity changes wanted by rural women. Otago Daily Times, p.3.

Cooper, M. (1998). Towards the professionalism of New Zealand midwifery 1840 - 1921. Unpublished master's thesis, Massey University, Palmerston North, New Zealand.

Cox Dzurec, L. (1989). The necessity for and evolution of, multiple paradigms for nursing research: A poststructuralist perspective. Advances in Nursing Science. 11 (4), 69-77.

Creasy, J. M. (1997). Women's experience of transfer from community-based to consultant-based maternity care. Midwifery 13, 32-39.

Creech, W. (1999). Roadside to Bedside: Developing a 24 - hour clinically integrated acute management system for New Zealand. Ministry of Health: Wellington.

Creech, W. (1999). Rural health policy: Meeting the needs of rural communities. Ministry of Health: Wellington.

Crombie, D._(1998). Revised Maternity Notice. Transitional Health Authority: Wellington. 
Daellenbach, R. (2000). The paradox of success and the challenge of change: Home birth associations of Aotearoa / New Zealand. Paper presented at the New Zealand College of Midwives Conference, St. Peter's School, Cambridge.

Davidson, C., \& Tolich, M. (Eds.). (1999). Social science research in New Zealand: Many paths to understanding. Auckland New Zealand: Longman.

Davis, E. (1987). A midwife's guide to pregnancy and birth. $\left(2^{\text {nd }}\right.$ ed. $)$. Berkely California: Celestial Arts.

Davis, P. (1981). Health and healthcare in New Zealand. Auckland: Longman Paul.

Davis, P. (1999). Professions and practices. In P. Davis \& K. Dew (Eds.). Health and society in Aotearoa New Zealand. Auckland New Zealand: Oxford University Press.

Denzin, N. K. (1991). Images of Postmodern Society. London: Sage Pub. Ltd.

Derrida, J. (1995). Writing and difference. London: Routledge.

Dickson, G. (1990). A feminist poststructuralist analysis of the knowledge of menopause. Advances in Nursing Science. 12 (3), 15-31.

Donley, J. (1998). Birthrites: Natural versus unnatural birth in New Zealand. Auckland, New Zealand: The Full Court Press. 
Durand, A. M. (1992). The safety of home birth: The Farm study. American Journal of Public Health. 82 (3), 450 - 453.

Eagleton, T. (1996). The illusions of postmodernism. Oxford UK: Blackwell Pub. Ltd.

English, W. (1998). Hospital Services Plan. Ministry of Health: Wellington.

Fahey, K. (1997). Postmodern feminist emancipatory research: Is it an oxymoron? Nursing Inquiry, 4, $27-33$.

Ferguson, W. (1999). The decline of general practitioner involvement in maternity care and its possible consequences for maternal and infant health. New Zealand Medical Journal. 112, 410 - 411.

Flax, J. (1990). Postmodernism and gender relations in feminist theory. Nicholson, L. J. (Ed.). Feminism/ Postmodernism. New York: Routledge.

Flint, C. (1994). Midwifery caseloads. Oxford UK: Butterworth Heinemann.

Ford-Gilboe, M., Campbell, J., \& Berman, H. (1995). Stories and numbers: Coexistence without compromise. Advances in Nursing Science. 18 (1), 14-26. 
Foucault, M. (1972), The archaeology of knowledge and the discourse on language. New York: Pantheon books.

Fougere, G. (1995). What is the core business of vote health? Paper presented at the Symposium on the delivery of health services to smaller communities. Hamilton New Zealand.

Fullerton, J. T., Jackson, D., Snell, B. J., Besser, M., Dickinson, C., \& Garite, T. (1997). Transfer rates from free standing birth centres - A comparison with the national birth centre study. Journal of Nurse- Midwifery. $\underline{24}(1), 9-16$.

Garcia, J., Kilpatrick, R., \& Richards, M. (Eds.), (1990). The politics of maternity care: Services for childbearing women in $20^{\text {th }}$ century Britain. Oxford: Clarendon Press.

Gavey, N. (1989). Feminist poststructuralism and discourse analysis. Psychology of Women Quarterly. 13, 459-475.

Gordon, R. J. (1990). The effects of malpractice insurance on certified nurse-midwives: The case of rural Arizona. Journal of Nurse-Midwifery. 35 (2), 99-105.

Griffith, P. (1996). The culture of midwifery practice: Does it have a relationship to birth environment? And what are the implications for midwifery? Physiological aspects of childbirth. 357-368.

Guilliland, K. (1998). Current issues for New Zealand midwifery and maternity services. NZCOM National Newsletter, Issue 10, 2 - 6 . 
Guilliland, K. (1999). Shared care in maternity services: With whom and how? Health Manager, 6 (2), 4-8.

Guilliland, K., \& Pairman, S. (1995). The midwifery partnership: A model for practice. Monograph Series, 95/1. Victoria University of Wellington.

Gulbransen, G., Hilton, J., McKay, L., \& Cox, A. (1997). Home birth in New Zealand 1973-93: Incidence and mortality. New Zealand Medical Journal, 110, 87-89.

Harstock, N. (1990). Foucault on power: A theory for women? In L. J. Nicholson (Ed.). Feminism/ Postmodernism. New York: Routledge.

Harvey, D. (1989). The condition of Postmodernism. Oxford: Basil Blackwell Ltd.

Health Board policy outlined to staff. (1990, May 30). The Clutha Leader. p.1.

Health services changes explained. (1991, September, 30). Clutha Leader, p.1.

Heisenberg. W. (1991). The Copenhagen interpretation of quantum theory. In T. Ferris (Ed.). The world treasury of physics, astronomy, and mathematics. New York: Back Bay Books, Little, Brown \& Co. 
Hewison, A. (1993). The language of labour: An examination of the discourses of childbirth. Midwifery. 9, 225-234.

Heydon, S. J. (1990). South Otago Hospital Board: The provision of hospital services. Unpublished Master's thesis, Otago University. Hocken Library, Dunedin.

Hobbs, L. (1993). The independent midwife: A guide to midwifery practice. London: Books for midwives Press.

Holloway, I., \& Wheeler, S. (1996). Qualitative research for nurses. London: Blackwell Science.

Horder, M. (1994, August, 31). No capitulation. Clutha Leader. p. 1.

Hospital result of long, hard fight. (1991, February 20). The Clutha Leader, p. 10.

Jameson, F. (1991). Postmodernism or, the cultural logic of late capitalism. London: VERSO.

Janes, R. (1999). Rural hospitals in New Zealand. New Zealand Medical Journal, 112 (1093), 297 - 299.

Jenkins, R. (1995). Midwifery - a matter of politics. In T. Murphy Black (Ed.). Issues in midwifery. New York: Churchill Livingstone.

Joint Regional Health Authorities. (June, 1984). Report to the Maori Women's working group of the Review of maternity benefits: Cultural safety 
specifications for provider competencies and qualifications in maternity services. Author.

Jones, O. (1997). Setting up a midwife managed birth centre. MIDIRS, Midwifery Digest. 7 (4), $514-516$.

King, A. (1998, January, 19). Health's blunt instrument dangerous weapon. Clutha Leader. P. 8.

King, A. (2000). Improving our health: Health Funding Authority: Wellington.

King, A. (2000). The New Zealand health strategy. Ministry of Health: Wellington.

King, A. (2001). The primary health care strategy. Ministry of Health: Wellington.

Kitzinger, J. (1995). Introducing focus groups. British Medical Journal, .311, $99-311$.

Kloosterman, G. J. (1978). The Dutch system of home births. In S. Kitzinger \& J. A. Davis (Eds.). The place of birth. London: Oxford University Press.

Krueger, R. A. (1994). Focus groups: A practical guide for applied research. ( $2^{\text {nd }}$ ed.). Thousand Oaks, California: Sage Pub. Inc. 
Labes, N. (1999, October, 14). Review recognises rural opinion. Clutha Leader, p.9.

Langley, C. (2001). Rural midwifery. MIDIRS, Midwifery Digest. 11 (3) $317-8$.

Lather, P. (1991). Getting smart, Feminist research and pedagogy with/in the post modern. New York: Routledge, Chapman \& Hall Inc.

Lather, P. (1997). Creating a multilayered text: Women, AIDS, and angels. In W. G.Tierney \& Y. S. Lincoln (Eds.). Representation and the text: Reframing the narrative voice. New York: State University of New York Press.

Less choice in maternity services. (1999, October 14). Clutha Leader.

Lincoln, Y. S. (1997). Self, Subject, Audience, Text: Living at the edge, writing in the margins. In W. G. Tierney \& Y. S. Lincoln (Eds.). Representation and the text: Reframing the narrative voice. New York: State University of New York Press.

Lode, J. (1991). Midwifery by tractor: Running a rural service. Midwife Health Visitor \& Community Nurse. 27 (6), 190 -191.

London, M., \& Ross, J. (1995). Professional responsibilities. Paper presented at the Symposium on the delivery of health services to smaller communities: Hamilton New Zealand, 104-107. 
Lupton, D. (1992). Discourse analysis: A new methodology for understanding the ideologies of health and illness. Australian Journal of Public Health. 16 (2), 145-149.

Lyotard, J. F. (1988). The 'differend': Phrases in dispute. Minneapolis: University of Minnesota Press.

Lyotard, J. F. (1992). The Postmodern explained to children, London: Turnaround.

Lyotard, J. F. (1997). The Postmodern condition; A report on knowledge. Manchester United Kingdom: Manchester University Press.

McCarthy, A., Hegney, D., \& Pearson, A. (2000). The perception of rural nurses towards role change within the context of organisational change. Australian Journal of Advanced Nursing. 17 (4), 21 - 28.

McCormick, R. (1995). How should the purchaser/provider split work in a rural area? Paper presented at the Symposium on the delivery of health services to smaller communities. Hamilton New Zealand. 148-155.

Mc Dougall, P. (1999). Focus groups: An overview of their use as a research method. MIDIRS Midwifery Digest. 9 (3).292 - 294.

Mc Lean, G., Landey, D., \& Ward, J. P. (Eds.), (1999). The country and city revisited. Cambridge: Cambridge University Press. 
Mc Nulty, D, \& Mc Lellan, F. (1990). Nursing and the new technology. In P. Abbott \& C.Wallace (Eds.). The sociology of the caring professions. London: The Falmer Press.

Mc Robbie, A. (1994). Postmodernism and popular culture. London: Routledge.

Maternity petition has fallen 'on deaf ears'. ( $8^{\text {th }}$ October, 2001). Otago Daily Times. P.3.

Maternity services changed. (1991, May 17). Clutha Leader. p. 6.

Mayes, F. (1999). Bella Tuscany: The secret life in Italy. Milson's Point NSW Australia: Anchor Transworld Pub.

Mein Smith, (1986). Maternity in dispute: New Zealand 1920 - 1939. Wellington New Zealand: V. R. Ward, Government Printer.

Midwives on the net. (1998, May 7). Clutha Leader. p.3.

Mills, A. (1995). Commentary on 'The quest for fairness in local services'. Symposium on the delivery of health services to smaller communities. Hamilton New Zealand. 51 - 56.

Morgan, D. L. (1997). Focus groups as qualitative research. $\left(2^{\text {nd }} e d.\right)$. London: Sage Pub.

Morse, J. M., \& Field. P.A. (1996). Nursing Research: The application of qualitative approaches. ( $\left.2^{\text {nd }} e d.\right)$. California: Chapman \& Hall. 
Nesbitt, T. S. (1996). Rural maternity care: New models of access. Birth. 23. (3). $161-166$.

Nesbitt, T. S., Larson, E. H., Rosenblatt, R. A., \& Hart, L. G. (1997). Access to maternity care in rural Washington: Its effect on neonatal outcomes and resource use. American Journal of Public Health. 87 (1), 85 - 90.

New Zealand College of Midwives, (Inc), (1993). Midwives Handbook for Practice. Author.

New Zealand First. The coalition agreement: Coalition government progress October, 1996 to October 1997. http://www.nzfirst.org.nz/coalition/96-97.htm. $25^{\text {th }}$ January, 2002.

No capitulation. (1994, August 22). Clutha Leader, p.1.

Nurses Act. (1977). No. 53. Reprint as at 1/1/95. (RS - Vol. 33, p353). Annotations to $17^{\text {th }}$ November, 1999. Wellington New Zealand.

O'Leary, P. (1990). Social influences on the health of the rural population in New Zealand, Nursing Praxis in New Zealand. 6 (1), 15 - 21.

Papps, E., \& Olssen, M. (1997). Doctoring childbirth and regulating midwifery in New Zealand: A Foucauldian perspective. Palmerston North New Zealand: Dunmore Press Ltd.

Parkes, C. M. (1991). The impact of the medicalisation of New Zealand's maternity services on women's experiences of childbirth, 1904 - 
1937. In L. Bryder (Ed.). A Healthy Country: Essays on the social history of medicine in New Zealand. Wellington: Bridget Williams Books.

Patterson, J. A. (2000). Rural midwifery: Challenges of the last decade, and where to from here? Paper presented at the New Zealand College of Midwives Inc. Sixth Biennial National Conference. Cambridge, New Zealand.

Polaschek, N. R. (1998). Cultural safety: A new concept in nursing people of different ethnicities. Journal of Advanced Nursing. 1998, 27, 452 457.

Polkinghorne, D. E. (1997). Reporting qualitative research as practice. In W. G. Tierney \& Y. S. Lincoln (Eds.). Representation and the text: Reframing the narrative voice. New York: State University of New York Press.

Powers, P. (1996). Discourse analysis as a methodology for nursing inquiry. Nursing Inquiry.3. 207-217.

Probyn, E. (1990). Travels in the postmodern: Making sense of the local. In L. J. Nicholson (Ed). Feminism/ Postmodernism. New York: Routledge.

Protesters do Balclutha proud. (1992, February 17). Clutha Leader, p.1.

Public excluded from health discussions. (1994, September, 28). Clutha Leader. p. 5. 
Rachels, J. (1986). The elements of moral philosophy. ( $2^{\text {nd }}$ ed.). New York: McGraw Hill Inc.

Rawling, P. (2000). Midwifery exchange - The bush to the city. Birth Issues 8 (4), $145-146$.

Regional Health Authority. (1996). Maternity Services: Notice pursuant to section 51 of the Health and Disability Services Act 1993 concerning the provision of maternity services. Author.

Roberts, K., \& Taylor, B. (1998). Nursing research processes: An Australian perspective. Melbourne: Nelson ITP.

Rosenblatt, R. A., Reinken, J., \& Shoemack, P. (1985). Is obstetrics safe in small hospitals? The Lancet, 24th 1985. 429- 432.

Rural health groups on the right track. (1995, July 3). Clutha Leader, p.3.

Rural hospitals facing knife. (1993, December 3). Clutha Leader, p.1.

Sandall, J. (1997). Midwives' burnout and continuity of care. British Journal of Midwifery. 2. 106-111.

Sarup, M. (1993). An introductory guide to post-structuralism and postmodernism. ( $2^{\text {nd }}$ ed.). New York: Harvester Wheatsheaf. 
Savage, W. (1990). How obstetrics might change: Wendy Savage talks to Robert kilpatrick. In J. Garcia., R. Kilpatrick, \& M. Richards (Eds.). The politics of maternity care. Oxford: Clarendon Press.

Schwandt, T. A. ( 1997). Textual gymnastics, ethics, and angst. In W. G. Tierney \& Y. S. Lincoln (Eds.). Representation and the text: Reframing the narrative voice. New York: State University of New York Press.

Shaw Morrison, R., \& Peoples, L. (1999). Using focus group methodology in nursing. The journal of continuing education in nursing. 30 (2), 62-65.

Shorter, E. (1982). A history of women's bodies. New York: Basic Books Inc.

Sim, S. (1996). Jean-Francois Lyotard. London: Prentice Hall Harvester Wheatsheaf.

Sim, S. (Ed.). (1999). The ICON critical dictionary of postmodern thought. Cambridge, U.K: ICON Books Ltd.

Sinja, B. (1991, November 22). Sacrifices to save medical school. Clutha Leader, p. 5.

Smallbane, E. (1998). Launceston birth centre. Australian Nursing Journal. 5 (11), $34-35$. 
Smulders, B. (2002). Midwifery in Holland and New Zealand. Paper presented at the New Zealand College of Midwives $7^{\text {th }}$ National Biennial Conference. Dunedin, NZ.

Spencer, L. (1999). Postmodernism, modernity and the tradition of dissent. In S. Sim (Ed.). The ICON critical dictionary of postmodern thought. Cambridge UK: ICON Books Ltd.

Statistics New Zealand. (1996). Regional Summary, 1996 census. population and sex. Statistics New Zealand. Author.

Statistics New Zealand.(2000). New Zealand Census of population and dwelling statistics. (1985; 1991; 1996). Supermap.

Stone, S. E., Brown, M. P., \& Westcott, J. P. (1996). Nurse midwifery service in a rural setting. Journal of Nurse-Midwifery. 41 (5), 377 - 382.

Taylor, B. J. (2000). Reflective practice: A guide for nurses and midwives. St. Leonards, NSW Australia: Allen and Unwin.

Tew, M. (1995). Safer childbirth? A critical history of maternity care. London: Chapman \& Hall.

Thornham, S. (1999). Postmodernism and feminism. In S. Sim (Ed.). The ICON critical dictionary of postmodern thought. Cambridge UK: ICON books Ltd.

Three options possible. (1993, December 10). Clutha Leader, p.1. 
Tierney, W. W. (1990). Lost in translation: Time and voice in qualitative research. In W. G. Tierney \& Y. S. Lincoln (Eds.). Representation and the text: Reframing the narrative voice. New York: State University of New York Press.

Tilyard, M. W., Williams, S., Seddon, R. J., Oakley, M. E., \& Murdoch, C. J. (1988). Is outcome for general practitioner obstetricians influenced by workload and locality? New Zealand Medical Journal, April $\underline{1988}, 207-209$.

Timeline of maternity benefits negotiations. (1997). New Zealand College of Midwives Journal. 16, 8 -9.

Tomlin, J. (1999). What is postmodernism? Paper presented at the Otago Polytechnic public seminar series. School of Art. Dunedin.

Trantor, D. (1993, June 21). Health reforms, [letter to the editor]. Clutha Leader, p. 10.

Travis, S. (1999). Birth centres in Berlin. Birth Issues, 8 (3), 96 - 97.

Traynor, M. (1997). Postmodern research: No grounding or privilege, just free-floating trouble making. Nursing Inquiry. 4, 99- 107.

Tully, E., \& Mortlock. B. (1999). Professionals and practices. In P. Davis \& K. Dew (Eds.). Health and society in Aotearoa New Zealand. Auckland New Zealand: Oxford University Press. 
Turner, B. (1992). Regulating bodies: Essays in medical sociology. London: Routledge.

Unshackling the Hospitals, Report of the Hospitals and Related Services Taskforce, (1988). Wellington, NZ.

Upton, S. (1991). Your health and the public health. Ministry of Health: Wellington.

Van Daalen, R. (1988). Dutch obstetric care: Home or hospital, midwife or gynaecologist? Health Promotion. 2 (3), 247 - 255.

Vann, M. K. (1998). Professional autonomy for midwives: An essential component of collaborative practice. Journal of Nurse-Midwifery. 43 (1). $41-45$.

Van Teijlingen, E., \& McCaffery, P. (1987). The profession of midwife in the Netherlands. Midwifery, 3, 178-186.

Vedam, S., \& Kolodji, Y. (1995). Guidelines for client selection in the home birth midwifery practice. Journal of Nurse-Midwifery. 40 (6). $508-521$.

Walmsley, K. (1999). The Wessex maternity centre: A midwifery service outside the NHS. The Practicing Midwife. 2, 12-13.

Watson, L., Potter, A., \& Donohue, L. (1999). Midwives in Victoria, Australia: A survey of current issues and job satisfaction. Midwifery (1999), $\underline{15}, 216-231$. 
Wetherall, M. (1999). Discourse analysis. In C. Davidson \& M. Tolich (Eds.). Social science research in New Zealand: Many paths to understanding. Auckland New Zealand: Longman.

Williams, J. (2000). Lyotard and the political. New York: Routledge.

Williams, R. (1975). The country and the city. Oxford: Oxford University Press.

Williamson, K. (2001, March, 6). Mayoral alert over birthing 'risk'. Otago Daily Times. P.1.

Woodcock, H. (1994). Midwife-led care at an isolated GP maternity unit. Modern Midwife. 4 (11). 30 - 31.

Young, I. M. (1990). The ideal of community and the politics of difference. In L.J. Nicholson (Ed.). Feminism/ Postmodernism. New York: Routledge. 


\section{APPENDICES}

\section{Appendix A}

\section{Research proposal to Ethics Committee}

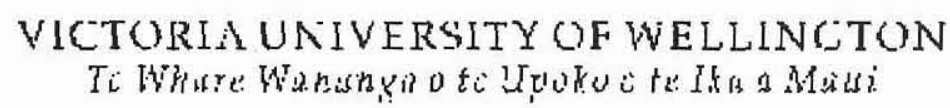

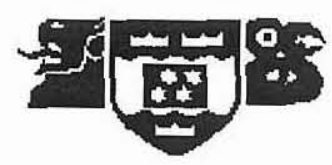

HUMAN ETHICS COMMITTEE

Application for Approval of Research Projects *

Nature of Proposed Research:

Staff Research No

Student Research yes Course code NURS 591

\section{Project Title:}

What are the issues for midwives who provide Lead Maternity Care (LMC) services in rural South Otago? A discourse analysis

\section{Investigators:}

(a) Principal Investigator - Name ....Jean Patterson

School/Dept/Group Student of Victoria University of Wellington, Nursing and Midwifery Department

Any Professional Code of Ethics to be followed

(Name) The New Zealand College of Midwives Code of Ethics

(b) Other researchers. No.

(c) Supervisor (in the case of student research projects)

Joy Bickley Senior Lecturer Department of Nursing and Midwifery, Victoria University of Wellington 
Proposed Starting Date

Proposed Date of Completion

Proposed Source of Funding
August 2002

July 2002

Victoria University Graduate Research fund

Please write legibly or type if possible. A copy of this document can be printed from the WWW at http:Ilwww.niw.ac.nzladministrative/hec

\section{Briefly Outline:}

(a) The Objectives of the Project

- To explore the issues for Lead Maternity Carer (LMC) midwives in rural South Otago over the past ten years.

- To surface the key issues and experiences of the midwives.

- To look at how these reflections fit within a local, national and international rural midwifery context.

- To potentially highlight issues of concern or value for funders and managers of health services, and maternity services in particular.

Midwives have over this last decade experienced significant change both within their profession and within the health system (Guilliland, 1999). At the same time the demographic profile of the South Island has continued to reflect both a rural to urban drift, and an aging of the population (Statistics, New Zealand, 1996). For rural midwives working in these areas the pace of the changes has left little time or energy for reflection or considered innovation to meet these combined challenges. Rural birth in New Zealand as in other Westernised countries has been shown to be a safe and valued option for women (Gulbransen, Hilton, McKay \& Cox, 1997: Rosenblatt, Reinken, \& Shoemack, 1985). Thus I see this project as an opportunity to explore the issues with some of the Lead Maternity Care midwives and potentially to unearth some ideas, complexities or strategies for the future.

\section{(b) Method of Data Collection}

I propose to interview the participants individually. I then plan to hold a focus group with the same group of interviewees to discuss the findings and explore possible discursive positions.

Following the data collection I propose to explore the data sets for particular themes and discourses.

In gathering the data I plan to take advantage of both individual interviews and a focus group process. Thus I would hope to capture the personal experience of the 
midwives. For these I plan to use a semi-structured interview plan. That is, an opening question for all participants and several seeding questions if necessary during the interview. The focus group process is planned to occur once all the transcripts have been returned to the participants and any changes made.

Within the group process I am hoping that the group dynamic will stimulate further exploration of the memories, experiences and ideas which surface in the interviews. And it is the discursive positions, themes and constructions that emerge as the midwives explore and try to make sense of their respective and common experiences that I hope to capture.

For each interview I anticipate allowing at time of approximately one to two hours. For the focus group I am planning to suggest to the participants that we meet for around two hours. At the start I plan to ask the group to set some simple ground rules. I anticipate that these would cover issues such as confidentiality, and respect for each other's opinions and recollections. I would also ask that the participants try to keep to one speaker at a time in order to firstly avoid talking over their contribution and secondly to facilitate accurate transcription of the discussion.

As a theoretical framework I plan to use postmodern / feminism. Thus I will be reading within both these areas for inspiration. Currently several authors inform my position namely: Lyotard, (1997) with regard to exploring systems and 'language games'; Lather, (1991) and Butler, (1994) with regard to praxis and notions of both postmodernism and feminism, and in particular their critique of the combination of these two potentially paradoxical positions. Hewison, (1993), and Gavey, (1989) in relation to strategies around discourse analysis; Krueger, (1994) and Morgan, (1993), for guidance in the conduct and issues surrounding the focus group process; and, McLaughlin, (1997), in which the author explores current discourses in childbirth within the postmodern feminist framework.

(C) The Benefits and Scientific Value of the Project

- To give rural midwives an opportunity to explore their key experiences over the last ten years,

- To look at the types of issues and discourses that emerge in the data.

- To contribute to the research and scholarship within the discipline of midwifery.

- To provide potentially useful information that is relevant for the midwives and also for health service providers and funders.

As far as I can ascertain this area of inquiry has not been documented or explored to any extent in New Zealand, particularly over these last ten eventful years. Thus this research will be a small glimpse of what rural midwifery practice is about and may 
open up other areas for further inquiry that may have direct benefits for rural women, and the practitioners who care for them.

\section{(d) Characteristics of the Participants}

The participants will be between four and six midwives who have provided Lead Maternity Care services for women in rural South Otago over the last ten years.

\section{(e) Method of Recruitment}

Participants, who meet the criteria for inclusion in the research project, will be initially, contacted by letter. However as the midwives have known me both as a colleague and friend I have elected to have the first contact via an intermediary person. In this instance I have approached Deborah Davis who is familiar with my research interests and conversant with my current research proposal. Deborah teaches within the Midwifery school at the Otago Polytechnic and is currently pursuing her Professional doctorate in midwifery. She has indicated her willingness to be available to respond to replies and queries from the potential participants. And despite our common workplace and interests I feel confident that Deborah would be scrupulously conscientious with regard to giving the participants fulsome information without causing them to feel pressured to participate.

(f) Payments that are to be made/expenses to be reimbursed to participants

Reimbursements will be offered where the participants incur costs related to freeing themselves up for interviews or in attending the focus group session. I would envisage that this might include travel or petrol costs, and possibly childcare.

(g) Other assistance (e.g. meals, transport) that is to be given to participants.

I plan to follow the focus group session with light refreshments.

(h) Special hazards and/or inconvenience (including deception) that participants will encounter

I do not anticipate that the participants will be subject to any special hazard or inconvenience, and the research method and purpose is planned to be transparent. However for some the exploration of their past experiences could be upsetting and evoke painful memories. Should this occur I would anticipate that the group and or myself as the researcher could help the affected participant to work through the issue at the time. If however the person is very distressed this may not be the most appropriate response and further help or counselling may be needed. In anticipation of such a problem occurring I would in advance have available names of skilled 
counsellors that could be offered for consideration.

An important concern is that I know the potential participants personally and I have worked with them in the past. Therefore there is the possibility that they would feel obligated to participate.

In an effort to avoid this situation I have enlisted the help of my colleague who will act as an intermediary in the first instance, and her role is detailed in the next section.

(i) How informed consent is to be obtained (Include a copy of the consent form and information sheet that is to be used.) (See paragraphs 4.3.1(g), 5.2, 5 5 and 5.6.1 of the guidelines). If written consent is not to be obtained, please explain why

- Firstly, the midwives eligible for inclusion, will be contacted by letter. This contact will detail the proposed research project, the data collection methods, and the anticipated use and dissemination of the findings. A consent form will be included with this letter. (Please refer to Appendices one and two)

- Secondly a midwife-teaching colleague from the School of Midwifery, Otago Polytechnic in Dunedin, has agreed to act as an intermediary and be the contact person for the prospective midwife participants. This person has no personal investment in the research project but will be appraised of the research aims objectives and methods. She will therefore be able to answer any queries about the project and record the details of those who express an interest in participating.

- Third should the midwife wish to participate she would return the signed consent form to my colleague in the enclosed reply paid envelope. Only on receipt of the consent form would I then contact the midwife.

(j) State whether the consent is for the collection of data, attribution of opinions or information, release of data to others, or use for particular purposes

- The signing of the consent form and its return will assume consent for involvement in both the interview and subsequent focus group process, unless of course the participant elects to withdraw at any time.

- It will also cover the release or publication of extracts from the study that have been arrived at by the group or as a result of data analysis.

- The raw data, will be seen only by the researcher and supervisor, and transcribed by a professional transcriber who will sign a confidentiality agreement.

- Any quotations to be cited in the text will first have the agreement of the participant who contributed the comments and these will be reviewed for accuracy by that participant.

(k) Whether the research will be conducted on an anonymous basis. If not, state 
how issues of confidentiality of participants are to be ensured if this is intended. (See paragraph 4.3.1(e) of the guidelines) (e.g. who will listen to tapes, see questionnaires or have access to data)

The professional transcriber in addition to the researcher and possibly the research supervisor will listen to the tapes from both the interviews and focus group. The participating midwives will be asked to keep confidential to the group, the details of discussions and comments made in the pursuit of the research. In addition any comments or excerpts from the raw data that is inserted into the text of the thesis will not be attributed to any particular group member or contain any other identifying information such as the names of other colleagues.

(1) Procedure for the storage of, access to and disposal of data, both during and at the conclusion of the research. (See section 7 of the guidelines)

Throughout the data collection phase, subsequent analysis and the writing of the thesis document, I propose to keep the tapes and transcriptions locked securely in a metal filing cabinet at my home. At the conclusion of the research project I intend to dispose of the raw data by destroying the tapes and paper transcriptions. I may however elect to retain the data stored on disks for a period up to five years following the completion of the project. Such files will be protected with a password.

\section{(m) Feedback Procedures (See section 8 of the guidelines)}

The participants will be given the opportunity to read the verbatim transcripts of their tapes and to make any deletions that they are reluctant to sanction in the subsequent analysis. If all the participants agree there would be the opportunity to share the summarised transcripts before meeting as a group. Following the group session there would also be the opportunity to delete any comments from the transcripts that any of the group participants regretted making. Following the completion of the thesis the participants would be offered a summary or a flail copy of the thesis.

(n) Reporting and Publication of Results

A copy of the completed thesis will be lodged in the Victoria University of Wellington library and also in the Nursing and Midwifery Department of that University.

Extracts or chapters from the thesis will be offered for publication in both national and international scholarly midwifery journals.

\section{$\underline{\text { References }}$}

Butler, 1. (1994). Contingent foundations: Feminism and the question of 
postmodernism'. In Seidman, S. (Ed.) The Postmodern Turn: new perspectives on social theory, Cambridge: Cambridge University Press.

Gavey, N. (1989). Feminist Poststructuralism and discourse analysis. Psychology of Women Quarterly, 1989,13, pp 459-475.

Guilliland, K. (1999). Shared care in maternity services: with whom and how? Health Manager, 6 (2), 4-8.

Gulbransen, 0., Hilton, J., McKay, L. \& Cox, A. (1997). Home birth in New Zealand 1973-93: Incidence and mortality, New Zealand Medical Journal, 110: 8789.

Hewison, A. (1993). The language of labour: an examination of the discourses of childbirth. Midwifery, (1993) 9, 225-234.

Krueger, R. A. (1994). Focus 2roups: A practical guide for applied research. (2nd ed.) Thousand Oaks, California: Sage Pub. Inc.

Lather, P. (1991). Getting smart, Feminist research and pedagogy within the post modern. New York: Routledge, Chapman \& Hall Inc.

Lyotard, J. F. (1997). The Postmodern condition: a report on knowledge. Manchester United Kingdom: Manchester University Press.

Mc Laughlin, (1997). A woman's place: An exploration of current discourses of childbirth. MA Thesis, Victoria University of Wellington.

Morgan, D. L. (1993). Successful Focus Groups: Advancing the state of the art. Newbury Park, London: Sage Pub.

New Zealand Official Yearbook (1998), pp, 88-90.

Regional Summary, 1996 Census. Population and Sex. P.23.

Rosenblatt, R. A., Reinken, I \& Shoemack, P. (1985). Is obstetrics safe in small hospitals? The Lancet, August, 24, 1985.

\section{Signature of Investigators as listed on page 1 (including Supervisors) Date:}

Please send this completed application form to the Secretary, Human Ethics Committee, Hunter Building or, in the case of applications from Schools or Departments with an approved ethics sub-committee, to the Convener of that sub-committee. 


\section{Appendix B}

\section{Ethics approval letter}

VICTORIA UNIVERSITY OF WELLINOTON

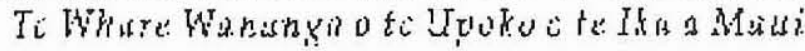

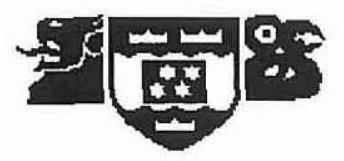

\section{MEMORANDUM}

TO: Jean Patterson Nursing \& Midwifery

FROM: Graeme Kennedy Convener, Human Ethics Committee

DATE: 17 October 2000

\section{SUBJECT: APPLICATION FOR ETHICAL APPROVAL: WHAT ARE THE ISSUES FOR MIDWIVES WHO PROVIDE LEAD MATERNITY CARE SERVICES}

Thank you for your application for ethical approval, which has been considered by the Standing Committee of the Human Ethics Committee. Your application is approved and you can proceed with your research, subject to the following minor amendments:

In the information letter:

(i) What does "surfacing" mean? This needs to be clarified or rewritten, as does "lived these changes" on the next line.

(ii) Page 2, line 5, delete $\underline{\text { school. }}$

(iii) Page 3 , there is no mention of the transcriber also hearing the tapes nor that any identifying information will be removed from quotes as per section (k) of your application form, bullet point 3 .

(iv) There needs to be something in the information letter about the right of applicants to withdraw as per the consent form. Withdrawal should be before the completion of data analysis.

Please send the amended information sheet to the secretary of the HEC before beginning data collection.

Approval is given for the period 17 October 2000 to 31 July 2002.

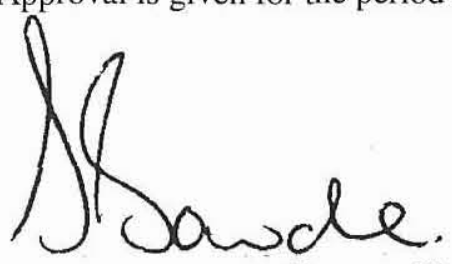

pp Graeme Kennedy

Convener, Human Ethics Committee 


\title{
Appendix C
}

\author{
Letter to participants \\ VICTORIA UNIVERSITYOF WELLINGTON

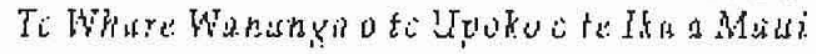

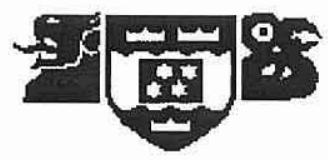

6th January, 2001

\section{Dear Colleague}

I am a student undertaking my Master of Arts (Midwifery) with the Department of Nursing and Midwifery, Victoria University of Wellington, and I currently teach midwifery at the Otago Polytechnic.

I have previously worked extensively as a midwife in rural areas of New Zealand and I am writing to invite you to participate in a research project that proposes to explore some of the key experiences and issues for rural midwives.

As you will know the change in the Nurse's Act (1977) in 1990 restoring midwife autonomy, plus significant changes to health services in rural areas, particularly in the South, have changed traditional ways of providing maternity care.

For my Master's thesis I would like to explore what these changes have meant for midwives who have offered Lead Maternity Care (LMC) services to women in the South Otago area over the last ten years. To date I have been unable to uncover any research that has specifically looked at what has happened in rural midwifery services over this time period. Therefore by looking at some of the key experiences of a group of midwives who lived these changes, I would hope that a richer understanding of the nature of rural midwifery practice would emerge. The findings may also prove useful to other rural practitioners, and those who fund or manage rural maternity services.

I am aware that you may on receipt of this letter, feel obligated to take part as we have worked together in the past. Therefore to try and minimise this response I have asked my colleague Deborah Davis to act as an intermediary. Deborah completed her Masters in Midwifery in Australia and is currently enrolled in the 
Professional Doctorate. Her midwifery background includes five years experience as a home birth midwife in Australia. She is currently teaching in the midwifery school at Otago Polytechnic, largely in the postgraduate area. Deborah has agreed to be available to answer any questions you may have about this research project, and will be the person to whom you would return the consent form should you choose to participate. (See below for her contact details)

\section{The Research}

My plan for this research project is firstly to record an individual interview with each participant. These would be recorded at a venue and time convenient to you.

Some of the questions I propose to ask are:

What have been some of your key experiences over the last ten years?

What were the special moments for you?

Did you experience any particular crises over this time period?

Were there any key moments when you felt that change had occurred?

When change occurred, what influence if any did it have on your midwifery practice?

A transcript of your tape will be returned to you so that you can make any deletions or additions that you think are appropriate.

Once the interviews have been completed and the transcripts adjusted, I plan for us to meet as a group This focus group meeting will also be taped and used as an opportunity to discuss the main issues and key experiences that have been shared previously in the individual interviews. Within the group setting it is anticipated that more insights and memories will emerge, triggered by the recollections and comments of the other group members. Refreshments will be available after this session.

Following the transcription of the focus group tapes, a summary of the comments and ideas will be returned to the participants for any last minute thoughts or additions.

Throughout the duration of this research project the discussion in both the interview transcripts and the focus group will remain confidential to the participant group, a professional transcriber, my supervisor Joy Bickley, and myself.

The tapes and transcripts will be kept secure in a locked filing cabinet and destroyed at the completion of the project.

Should any excerpts from the conversations be used in the thesis or in subsequent publications, they will not be attributable to any particular individual, and wherever possible identifying information will be removed from such quotations. 
Participants have the right to withdraw at any time. Such withdrawal however should be before the completion of the data analysis.

It is my belief that any of your insights or expertise that you can share will be invaluable in exploring this subject.

If you would like to be involved or require more information about any aspect of this project please contact-

Should you wish to contact me or my supervisor Joy Bickley about any aspect of the research the contact numbers are as follows:

Sincerely

Jean Patterson 


\section{Appendix D}

\section{Consent form}

I have read and understand the purpose and proposed method of this study.

I understand that:

The objective is to explore and record the issues for rural midwives who currently or have in the past ten years, assumed the lead maternity carer role for women, in the rural area of South Otago.

My contribution will remain confidential to the group and that tape recordings will be kept secure until the research project is complete.

I am free to withdraw at any time.

By signing this form I have indicated that I am willing to take part in the interview and the focus group exercise.

Signed

Date

(Contact details attached) 


\section{Appendix E}

\section{Letter to participants following interviews}

16th May 2001

\section{Dear Colleague}

Thank you for your contribution to the research with your interview. It has been a great learning experience for me.

The focus group is an opportunity to pick up on some of the themes that emerged in the taped interviews, and it is my hope that the discussion will develop the ideas and contribute to a deeper understanding of the issues for midwives working as LMCs in rural areas.

From my reading of the transcripts there were some common patterns and themes. These seemed to touch on the following:

- Our education and or training and how this affected our readiness for autonomous practice.

- The desirability of working in a continuity midwifery model.

- The constraints on this by other demands such as the need to be business-like, and the limits of the systems, both organisational and financial.

- The impact of the job demands on your family and social life.

- The positive aspects of rural practice such as a sense of autonomy, and your place in the community.

- The need for a range of support including, colleagues, family, and mentoring for both clinical and personal issues.

- Ready and timely access to information and advice plus, regular opportunities for ongoing education and clinical updates.

The discussion will by no means be limited to these ideas rather they will serve as points to start the discussion. 
To facilitate taping it might be more practical to have the session in a polytechnic tutorial room. This would take care of the heating and technological stuff, and I could either arrange to have lunch brought in or take you to the University staff club - or a cafe of your choice. This of course would be my shout. There will also be petrol vouchers to cover your travel costs and if any creche costs are incurred they will also be reimbursed.

At this stage I am looking to start the session following a cup of coffee (the real stuff) at around lOam midwife time till around 12ish. Lunch will follow between 12 and $1 \mathrm{pm}$., which should leave the afternoon free for you to shop or indulge in the caf6 culture of Dunedin.

However, I realise that for some it might be inconvenient to be out of your area so if that is the case I can look at something close to our in Balclutha and adapt all of the above.

At this stage I would like to give you some date options for the focus group. These are for July and if they are all unsuitable I will look at August.

I would appreciate your returning the section below so that I can plan the focus group and make the necessary bookings.

Warm wishes

Jean

Please detach and return in the reply paid envelope

$\underline{\text { Venue (please circle your preference) }}$

DUNEDIN BALCLUTHA OTHER

Date (Please tick all or any of the dates when you could be available)

\begin{tabular}{|l|l|l|l|l|l|}
\hline Month & Day & Date & Yes & No & Comments \\
\hline July & Thurs & $5^{\text {th }}$ & & & \\
\hline July & Friday & $6^{\text {th }}$ & & & \\
\hline July & Mon & $9^{\text {th }}$ & & & \\
\hline July & Tues & $10^{\text {th }}$ & & & \\
\hline July & Wed & 11 th & & & \\
\hline
\end{tabular}


Thank you

\section{Appendix F}

\section{Letter confirming focus group venue}

18th June, 2001

Dear

Just to confirm the date, time and venue for the focus group and to give you a menu to peruse.

To accommodate the majority time and venue wise, I have booked at Garvan Homestead for Tuesday the lOth July.

It has a room for us so it will be private enough to tape.

We can order lunch from the a la carte menu, (see attached) on arrival so that we can eat promptly around 12 ish. This will free you up for the afternoon if you have other pressing commitments.

My expectation is that this session will be very informal and aimed more at working with the predominant themes and ideas raised in the interviews with a view to brainstorming some possible strategies for the future. However if more issues arise we can explore them as well. I am not expecting to come up with pat solutions but rather to add some of your thinking and experience to the subject of rural midwifery and how it might nurtured in sparse or isolated areas.

Looking forward to catching up with everyone. Please phone (03) 4728449 if you have any questions.

Warm wishes

Jean 
Appendix G

Map of local area 
